No. 32.]

\title{
TRANSACTIONS
}

\author{
OF THE
}

\section{FACULTY OF ACTUARIES}

Paid-up Policies and Surrender Values. By ALFRED ERNeST SpraGUe, M.A., D.Sc., F.F.A., F.I.A., Assistant Seeretary to the Edinburgh Life Assurance Company.

[Read before the Faculty, 14 January 1907.]

$\mathrm{T}$ 1 HE principles upon which surrender values should be calculated are discussed at length in papers by Mr. Macfadyen (J. I. A., xvii, 381) ; Mr. Crisford (J.I. A., xxi, 301); and Mr. Fulford (J.I. A., xxxv, 199), but none of the methods proposed appear entirely satisfactory in practice, and $I$ have therefore attempted to devise a scheme which shall not only give results in reasonable accordance with strict theory, but also prove simple and easily worked in its practical application.

Mr. Macfadyen held the view that the surrender of a policy should be regarded as the purehase of a reversion, and that the price should be the net value of the policy by the Carlisle table, with interest at the rate of 5 per cent or 6 per cent per annum. In an earlier paper ( $J . I . A ., \mathrm{xv}, 297)$ he showed that under ordinary circumstances the paid-up policy to be allowed for a

(Notation : Throughout this paper $\mathbf{P}, \mathrm{P}^{\prime}$, and $\mathbf{P}^{\prime \prime}$ respectively denote Office annual premiums for assurances "without profits," "with profits," and "with discounted bonuses"; and $\pi$ and $\pi^{\prime}$ respectively denote net annual premiums for uniform assurances and for assurances increasing at a fixed rate per annum.)

VoL. III. 
limited-payment or endowment assurance policy might safely be arrived at by reducing the original sum assured in the ratio of the number of premiums actually paid, to the full number originally payable. This is now generally known as a "proportionate" paid-up policy, and will hereafter be referred to under that name. He did not, however, suggest any method of caloulating the amount of the paid-up policy in the case of ordinary whole-life assurances, and no scheme can be considered complete which omits so important a matter.

Mr. Crisford based his surrender values on the reserve held by the Office, making deductions therefrom to allow for the possibility of loss to the Office through withdrawal of healthy lives, and for the loss of future contributions to expenses. These deductions were: (1) 5 per cent of the reserve to allow for possible adverse selection: (2) $2 \frac{1}{2}$ per cent of the value of the future Office premiums, to provide for future expenses: so that his formula was (for a whole-life policy for 21 )

$$
\text { Surrender Value }=.95 \times{ }_{n} \mathrm{~V}_{x}-.025 \mathrm{P}_{x^{\mathrm{a}}} \mathrm{a}_{x+n^{*}}
$$

He arrived at the paid-up policy by reducing the sum assured in the ratio of the reserve to the value of the future premiums plus the reserve, the formula being (leaving bonuses out of account)

$$
\text { Paid-up Policy }=\frac{{ }_{n} \mathrm{~V}_{x}}{{ }_{n} \mathrm{~V}_{x}+\mathrm{P}_{x^{2} x+n}}
$$

Mr. Fulford also held that the surrender value should be equal to the reserve less deductions for (1) expenses, and (2) adverse selection; but he arrived at the amount of his deductions in a different manner from Mr. Crisford. Owing to the fact that "select" mortality tables have come into general use, we are now able to calculate the reserve that should be made for a life that is still "select"; and Mr. Fulford naturally adopted this value in place of making an arbitrary deduction of five per cent from the Office reserve. He also modified the allowance for 'expenses' in view of the changed conditions under which the business is now carried on, arriving finally at the formula (for a whole-life policy for $£ 1$ ),

$$
\text { Surrender Value }=_{n}(h V)_{x}-\left\{\frac{.021}{\mathrm{a}_{[x]}}+.025 \mathrm{P}_{x}\right\} \mathrm{a}_{[x+n]}
$$

from which the paid-up policy was deduced by dividing it by a loaded single premium.

Both Mr. Crisford's and Mr. Fulford's methods are complicated, and therefore involve considerable trouble in their practical application; and both lead to the inconsistency that the surrender value is altered by the mere conversion of the policy into a paidup policy. 
Mr. Chatham has given a method (applicable to endowment assurances and limited-payment policies) which avoids this inconsistency, and has the great advantages of simplicity and ease of application : namely, to take the $\mathrm{O}^{\mathrm{M}} 4 \frac{1}{2}$ per cent net value of the "proportionate" paid-up policy and of the existing bonuses. (See pp. 12, 13, and 39 of the current volume of the Transactions.)

It has been suggested that, after making proper allowances for expenses and selection, deductions should also be made from the reserve, as compensation for (1) loss of interest said to be caused by the fact that surrender values are practically payable on demand, and that this necessitates the investment of a portion of the funds in readily convertible securities; (2) alleged breach of contract caused by surrender-the policyholder being the only party thereto who has power to terminate the policy at will; and (3) - in a proprietary Office-loss of future profits which might be earned on the policy if it were continued.

Now an examination of the published accounts of the Offices shows that surrenders form only a small fraction (about 6 per cent) of their total outgo, and that their total funds are increasing. This increase seems likely to continue for many years, and it follows that in ordinary circumstances a well-managed Office may safely invest the bulk of its funds in securities which need not necessarily be readily convertible, inasmuch as its income is more than sufficient to meet all its outgoings, and there is, therefore, no need to realise any portion of its investments. Of course it is prudent to keep a portion of the funds invested in readily convertible securities, as a provision against any sudden and unforeseen demand; but the probability of such a demand arising seems to be small, and to depend more upon possible fluctuations in mortality than upon the amount of surrenders. Again, it should be borne in mind that the policyholder has entered into no contract to continue payment of the premiums, and that, in most cases, the Office has expressly bound itself to pay a surrender value in the event of discontinuance. It is therefore clear that a surrender is not in any sense a breach of contract, and that no claim for compensation can be founded on that ground. The third point is of very small moment, as the shareholders are, as a rule, entitled to only a small proportion of the profits, and in practice the distinction between the mutual and proprietary systems is very fine. I therefore do not think that any of these three considerations should affect the amount of the surrender value or paid-up policy.

There is great difference of opinion as to the effect of sur- 


\section{Paid-up Policies and Surrender Values}

renders upon the rate of mortality; and I doubt whether it is possible to produce conclusive evidence on the point. On the one hand we have the figures deduced by Mr. Chatham (J.I. A., xxix, 81) from the Institute experience, which proved that the rate of withdrawal in the Scottish portion of the experience was less than in the total, but the rate of mortality was higher. This seems to show that withdrawals have a favourable, rather than an unfavourable effect on the rate of mortality; but, on the other hand, Mr. G. F. Hardy has proved (J. I. A., xxiii, 1) that those policyholders of the "British Empire" Office who surrendered their bonuses for cash were better lives than those who did not. With such contradictory evidence on the point it seems to me only prudent to assume that on the average the option of withdrawing is exercised in the same direction as most other options, namely, adversely to the Office; and to calculate surrender values of life assurance policies on the assumption that the lives withdrawing are still "select." It will be seen later that this does not apply to the surrender of annuities. In this connection I take the opportunity of pointing out a fact which students are apt to overlook, namely, that the great majority of assured lives are "select"; and that the difference between the "select" and the "ultimate" rates of mortality arises from the inclusion among the latter, of a comparatively few lives who have fallen into bad health. An examination of the $O^{[\mathrm{x}]}$ table shows that out of 94,974 "ultimate" lives aged 20 , only 1278 or 1.35 per cent are "damaged"; and 93,696 or 98.65 per cent are still "select." The proportion of "damaged" lives is 2.11 per cent at age 40 , and 6.58 per cent at age 60 , and it gradually increases with age; but even at age 75 the "damaged" lives are still in a small minority, as nearly 80 per cent remain "select." Taking all the "ultimate" lives from ages 20 to 75 inclusive, it will be found that 96 per cent are still "select" and only 4 per cent are "damaged." It is therefore clear that the majority of policyholders are "select" lives, and remain so for the greater part of their lifetime; and that the increase in the rate of mortality as "selection" wears off, is not due to a general or widespread deterioration in the lives, but to the breakdown in health of a small minority. That is to say, lives as a rule are "select," the "damaged" lives being exceptions; and the effect of withdrawals upon the rate of mortality will depend upon whether the withdrawing lives contain a greater or smaller proportion of these exceptions than the lives who remain. Now an examination of the mortality of these exceptions, i.e. of the "damaged" lives, 
shows that it is very high-about 25 to 30 per cent of them dying within a year-and it is therefore evident that they must on the whole be in very bad health, and that a substantial proportion of them must be practically on their deathbeds. Now, if a man is suffering from an illness almost certain to prove fatal within a few months, it is extremely unlikely that he will surrender his policy ; and it is an almost unknown thing for a policy to be surrendered when the assured is on his deathbed. We may therefore say that as a rule cases of extreme bad health will be eliminated from the withdrawals, and this is quite sufficient to cause a marked "selection" adverse to the Office, unless it be counterbalanced by other causes.

If inconsistencies are to be avoided, it is essential to have a direct relation between the amount of the paid-up policy and the surrender value, so that one of them can be derived from the other, instead of being calculated quite independently; and I propose accordingly, first to find the amount of the paid-up policy that should be allowed, and then to deduce the surrender value from this.

\section{PAID-UP POLICIES.}

WHOLE-LIFE ASSURANCES WITHOUT PROFITS.

The full theoretical amount for each unit of the original assurance is $1-\frac{\pi_{x}}{\pi_{x+n}}$ calculated on the same basis as the reserves ; but it will generally be admitted that some deduction should be made from this. In such-calculations it is not uncommon to deduct a uniform percentage from the reserve; but this has the effect of penalising the older lives unduly, as the deduction becomes largest at the limiting age of the table, when it ought to be least. This appears at once from the consideration that at extreme old age the paid-up policy and the surrender value should be approaching the sum assured, as they must both coincide therewith at the moment the sum assured becomes payable; and it is therefore clear that a uniform percentage deduction is wrong in principle. This is probably the cause of the fact, proved by the above-mentioned gentlemen, that the values then allowed by Offices were, generally speaking, too low when the policy had been a long time in force. 
If the assured be still in good health at age $x+n$, he can effect a new policy for $\frac{\mathrm{P}_{x}}{\mathrm{P}_{x+n}}$ per unit of the sum assured, at the premium he is paying, namely $\mathrm{P}_{x}$. Therefore the past premiums ought to secure a paid-up policy for $1-\frac{\mathrm{P}_{x}}{\mathrm{P}_{x+n}}$. If, on the other hand, he is in bad health, he will have to pay a higher premium than $P_{x+n}$ for each unit of the new assurance, and therefore the past premiums ought to secure a larger paid-up policy than $1-\frac{\mathbf{P}_{x}}{\mathbf{P}_{x+n}}$. This is also evident from the consideration that if he is at the point of death it would pay the Office to get any reduction in the sum assured, so that under such circumstances they could offer with safety a paid-up policy for nearly the full sum assured.

A closer examination of the formula shows that it automatically makes allowances for the elements of (1) adverse selection, and (2) expenses, provided the Office premiums are calculated from a "select" mortality table and loaded in the usual way with a percentage and a constant.

$$
\text { For } \mathrm{P}_{x}=\pi_{[x]}(1+k)+c,
$$

$$
\text { hence } 1-\frac{\mathrm{P}_{x}}{\mathrm{P}_{x+n}}=1-\frac{\pi_{[x]}(1+k)+c}{\pi_{[x+n]}(1+k)+c}=1-\frac{\pi_{[x]}+h}{\pi_{[x+n]}+h} \text { where } h=\frac{c}{1+k} \text {. }
$$

Now, if a constant quantity $h$ be added both to the numerator and denominator of a proper fraction, the value of that fraction is increased. Therefore $\frac{\pi_{[x]}+h}{\pi_{[x+n]}+h}$ is greater than $\frac{\pi_{[x]}}{\pi_{[x+n]}}$, and $1-\frac{\mathrm{P}_{x}}{\mathrm{P}_{x+n}}$ is less than $1-\frac{\pi_{[x]}}{\pi_{[x+n]}}$, so that a deduction is made on account of expenses; and the use of the "select" value $\pi_{[x+n]}$ implies that the life is still "select" at age $x+n$. These considerations seem to show that in all cases an Office might allow a paid-up policy of $1-\frac{\mathrm{P}_{x}}{\mathrm{P}_{x+n}}$; but they are perhaps not altogether conclusive, and it might be well to make some deduction from this value. This deduction should tend to decrease as the duration of the policy increases; and in view of the heavy expense of obtaining new business it might reasonably take the form of neglecting the first year's premium and thus using the formula $1-\frac{\mathbf{P}_{x+1}}{\mathbf{P}_{x+n}}$. This has the advantage of being a ready and convenient method 
of complying with the general rule not to allow any surrender value during the first year of assurance.

In order to illustrate the proposed method, it is necessary to fix upon a scale of Office premiums; and the average rates charged by the British Offices naturally suggest themselves as appropriate to this purpose. There are, however, two objections to this course : (1) The average rates are not calculated upon any fixed law, and therefore do not proceed from age to age with sufficient regularity to secure a smooth progression in the values of the corresponding paid-up policies; and, more important, (2) the published tables of rates do not extend to sufficiently advanced ages. I have therefore calculated a table of rates based on the $\mathrm{O}^{[\mathrm{NM}]}$ table with $3 \frac{1}{2}$ per cent interest, loaded in such a manner as to correspond as closely as possible with the average Office rates, the formula being $P_{x}=1 \cdot 1 \pi_{[x]}+001$. This formula was arrived at after a series of trials; and, as will be seen from the following table, it gives results fairly close to the average Office rates. The use of the $\mathrm{O}^{[\mathrm{NM}]}$ table is attended with these great advantages: (1) that the values proceed with regularity throughout the table; and (2) that although the "select" values are not published at ages above 75 , they can be calculated from the formulas by which the table is constructed, and a smooth table of premiums calculated for every age up to the extreme limit of life. This is a matter of some importance in practice, as a great deal of future trouble is saved by constructing complete tables at the time a scheme of surrender values is adopted. Most of us have no doubt experienced the difficulty caused by exceptional cases falling beyond the limits of the Office tables; and, in order to avoid this, I recommend that any scale which may be adopted should be constructed so as to include provision for the exceptional cases of extreme age which, though few in number, will otherwise cause a great deal of trouble. Accordingly I have carried the tables up to age 100, though few (if any) of us are likely to meet with such a case in practice.

It may be as well to point out here, that I express no opinion as to the suitability, for Office use, of these or any of the other Office premiums given in this paper. They are used simply to illustrate the proposed methods of calculating paid-up policies and surrender values, on the grounds that they represent fairly well the average Office rates up to age 70 , and that they give a smooth progression of values up to the extreme limit of life. 


\section{Paid-up Policies and Surrender Values}

TABLE A.-Office Premiums for " non-participating" Whole-life Assurances of 100.

\begin{tabular}{|c|c|c|c|}
\hline$\underset{x}{\text { Age. }}$ & $\begin{array}{l}\text { Average of pub- } \\
\text { hshed office rates. } \\
\text { (1) }\end{array}$ & $\begin{array}{c}100 P_{x} \\
(2)\end{array}$ & $\begin{array}{l}\text { Difference. } \\
\text { (2)-(1) }\end{array}$ \\
\hline \multirow[t]{2}{*}{$\begin{array}{r}10 \\
15 \\
20 \\
25 \\
30 \\
35 \\
40 \\
45 \\
50 \\
55 \\
60 \\
65 \\
70 \\
75 \\
80 \\
85 \\
90 \\
95 \\
100\end{array}$} & $\begin{array}{r}1 \cdot 450 \\
1 \cdot 621 \\
1 \cdot 808 \\
2 \cdot 046 \\
2 \cdot 358 \\
2 \cdot 767 \\
3 \cdot 379 \\
4 \cdot 008 \\
4 \cdot 979 \\
6 \cdot 217 \\
8 \cdot 088 \\
10 \cdot 842\end{array}$ & $\begin{array}{r}1 \cdot 309 \\
1 \cdot 438 \\
1 \cdot 600 \\
1 \cdot 806 \\
2 \cdot 067 \\
2 \cdot 402 \\
2 \cdot 835 \\
5 \cdot 397 \\
4 \cdot 136 \\
5 \cdot 113 \\
6 \cdot 417 \\
8 \cdot 173 \\
10 \cdot 548 \\
13 \cdot 769 \\
18 \cdot 124 \\
23 \cdot 956 \\
31 \cdot 694 \\
41 \cdot 723 \\
\mathbf{5 4} \cdot 459\end{array}$ & $\begin{array}{l}-\cdot 012 \\
-\cdot 021 \\
-\cdot 002 \\
+\cdot 021 \\
+\cdot 044 \\
+\cdot 068 \\
+\cdot 018 \\
+\cdot 128 \\
+\cdot 134 \\
+\cdot 200 \\
+\cdot 085 \\
-\cdot 094\end{array}$ \\
\hline & & Total, & +369 \\
\hline
\end{tabular}

The following table shows the paid-up policies deduced from these rates by the formula $1000\left(1-\frac{\mathrm{P}_{x+1}}{\mathrm{P}_{x+n}}\right)$; compared with: (1) the full theoretical amounts by the formula $1000\left(1-\frac{\pi_{x}}{\pi_{x+n}}\right)$ on an $\mathrm{O}^{\mathrm{M}} 3$ per cent basis; and (2) the total premiums paid. 
TAsLe B.-Paid-up Policies. Single and Joint Lives.

Original Policy for 1000 without Profits.

\begin{tabular}{|c|c|c|c|c|c|c|c|}
\hline \multirow{3}{*}{ Duration. } & \multicolumn{7}{|c|}{ Ages at entry, to. } \\
\hline & \multicolumn{3}{|c|}{ Single Lives. } & \multicolumn{2}{|c|}{$\begin{array}{l}\text { Two Joint Lives, } \\
\text { Equal Ages. }\end{array}$} & \multicolumn{2}{|c|}{$\begin{array}{l}\text { Three Joint Lives, } \\
\text { Equal Ages. }\end{array}$} \\
\hline & OM $3 \%$ net. & Office. & \begin{tabular}{|c|} 
Total \\
Premiums \\
paid.
\end{tabular} & ON $3 \%$ net. & office. & om $3 \%$ net. & Office. \\
\hline $\begin{array}{r}5 \\
10 \\
15 \\
20 \\
30 \\
40 \\
50 \\
60 \\
70 \\
80 \\
90\end{array}$ & $\begin{array}{l}129 \\
247 \\
355 \\
451 \\
611 \\
736 \\
833 \\
901 \\
945 \\
970 \\
984\end{array}$ & $\begin{array}{r}74 \\
167 \\
262 \\
356 \\
530 \\
678 \\
802 \\
874 \\
927 \\
958 \\
976\end{array}$ & $\begin{array}{r}65 \\
131 \\
196 \\
262 \\
393 \\
524 \\
655 \\
785 \\
916 \\
1047 \\
1178\end{array}$ & $\begin{array}{l}123 \\
240 \\
349 \\
446 \\
608 \\
738 \\
838 \\
907 \\
949 \\
972 \\
982\end{array}$ & $\begin{array}{r}61 \\
\mathbf{1 4 1} \\
228 \\
317 \\
\mathbf{4 9 4} \\
\mathbf{6 5 2} \\
\mathbf{7 7 7} \\
\mathbf{8 6 6} \\
\mathbf{9 2 2} \\
\mathbf{9 5 5} \\
\mathbf{9 7 2}\end{array}$ & $\begin{array}{l}120 \\
236 \\
345 \\
443 \\
606 \\
739 \\
840 \\
909 \\
950 \\
971 \\
979\end{array}$ & $\begin{array}{r}54 \\
129 \\
211 \\
299 \\
477 \\
641 \\
772 \\
863 \\
920 \\
952 \\
968\end{array}$ \\
\hline & \multicolumn{7}{|c|}{ Ages at entry, 20.} \\
\hline $\begin{array}{r}5 \\
10 \\
15 \\
20 \\
30 \\
40 \\
50 \\
60 \\
70 \\
80\end{array}$ & $\begin{array}{l}143 \\
270 \\
383 \\
483 \\
650 \\
778 \\
868 \\
926 \\
960 \\
979\end{array}$ & $\begin{array}{r}94 \\
208 \\
318 \\
423 \\
604 \\
745 \\
845 \\
910 \\
948 \\
970\end{array}$ & $\begin{array}{r}80 \\
160 \\
240 \\
320 \\
\mathbf{4 8 0} \\
640 \\
800 \\
960 \\
1120 \\
1280\end{array}$ & $\begin{array}{l}143 \\
270 \\
383 \\
484 \\
655 \\
786 \\
877 \\
933 \\
963 \\
976\end{array}$ & $\begin{array}{r}82 \\
188 \\
294 \\
398 \\
586 \\
735 \\
841 \\
908 \\
946 \\
966\end{array}$ & $\begin{array}{l}142 \\
270 \\
383 \\
484 \\
658 \\
791 \\
881 \\
935 \\
961 \\
972\end{array}$ & $\begin{array}{r}78 \\
180 \\
284 \\
389 \\
580 \\
733 \\
840 \\
907 \\
944 \\
962\end{array}$ \\
\hline & \multicolumn{7}{|c|}{ Ages at entry, 30 . } \\
\hline $\begin{array}{r}5 \\
10 \\
15 \\
20 \\
30 \\
40 \\
50 \\
60 \\
70\end{array}$ & $\begin{array}{l}154 \\
291 \\
412 \\
520 \\
695 \\
819 \\
899 \\
946 \\
971\end{array}$ & $\begin{array}{l}114 \\
250 \\
374 \\
486 \\
669 \\
798 \\
883 \\
933 \\
961\end{array}$ & $\begin{array}{r}103 \\
207 \\
310 \\
413 \\
620 \\
827 \\
1034 \\
1240 \\
1447\end{array}$ & $\begin{array}{l}155 \\
292 \\
417 \\
527 \\
707 \\
\mathbf{8 3 2} \\
908 \\
949 \\
\mathbf{9 6 7}\end{array}$ & $\begin{array}{l}107 \\
239 \\
362 \\
476 \\
665 \\
799 \\
883 \\
932 \\
957\end{array}$ & $\begin{array}{l}155 \\
294 \\
419 \\
531 \\
714 \\
837 \\
911 \\
948 \\
962\end{array}$ & $\begin{array}{l}105 \\
235 \\
360 \\
475 \\
666 \\
800 \\
883 \\
930 \\
953\end{array}$ \\
\hline
\end{tabular}


2 IO Paid-up Policies and Surrender Values

\begin{tabular}{|c|c|c|c|c|c|c|c|}
\hline \multirow{3}{*}{ Duration. } & \multicolumn{7}{|c|}{ Ages at entry, 40.} \\
\hline & \multicolumn{3}{|c|}{ Single Lives. } & \multicolumn{2}{|c|}{$\begin{array}{l}\text { Two Joint Lives, } \\
\text { Equal Ages. }\end{array}$} & \multicolumn{2}{|c|}{$\begin{array}{l}\text { Three Joint Lives, } \\
\text { Equal Ages. }\end{array}$} \\
\hline & OM 3\% net. & Office. & $\begin{array}{c}\text { Total } \\
\text { Premiums } \\
\text { paid. }\end{array}$ & OM $\mathbf{3} \%$ net. & Office. & OM 3\% net. & Office. \\
\hline \multirow[t]{2}{*}{$\begin{array}{l}5 \\
10 \\
15 \\
20 \\
30 \\
40 \\
50 \\
60\end{array}$} & $\begin{array}{l}171 \\
323 \\
456 \\
\mathbf{5 7 0} \\
\mathbf{7 4 5} \\
\mathbf{8 5 8} \\
\mathbf{9 2 3} \\
\mathbf{9 5 9}\end{array}$ & $\begin{array}{l}136 \\
290 \\
426 \\
542 \\
722 \\
838 \\
907 \\
946\end{array}$ & $\begin{array}{r}142 \\
284 \\
425 \\
567 \\
851 \\
1134 \\
1418 \\
1701\end{array}$ & $\begin{array}{l}175 \\
332 \\
469 \\
586 \\
762 \\
870 \\
937 \\
\mathbf{9 5 3}\end{array}$ & $\begin{array}{l}134 \\
289 \\
427 \\
546 \\
727 \\
842 \\
908 \\
942\end{array}$ & $\begin{array}{l}177 \\
336 \\
476 \\
594 \\
770 \\
873 \\
926 \\
943\end{array}$ & $\begin{array}{l}134 \\
290 \\
429 \\
549 \\
730 \\
842 \\
906 \\
936\end{array}$ \\
\hline & \multicolumn{7}{|c|}{ Ages at entry, 50.} \\
\hline \multirow[t]{2}{*}{$\begin{array}{l}5 \\
10 \\
15 \\
20 \\
30 \\
40 \\
50\end{array}$} & $\begin{array}{l}196 \\
365 \\
506 \\
623 \\
790 \\
\mathbf{8 8 7} \\
\mathbf{9 3 9}\end{array}$ & $\begin{array}{l}157 \\
328 \\
473 \\
591 \\
762 \\
864 \\
921\end{array}$ & $\begin{array}{r}207 \\
414 \\
620 \\
\mathbf{8 2 7} \\
\mathbf{1 2 4 1} \\
\mathbf{1 6 5 4} \\
\mathbf{2 0 6 8}\end{array}$ & $\begin{array}{l}205 \\
381 \\
527 \\
644 \\
805 \\
891 \\
930\end{array}$ & $\begin{array}{l}159 \\
334 \\
480 \\
599 \\
767 \\
864 \\
915\end{array}$ & $\begin{array}{l}210 \\
389 \\
536 \\
653 \\
809 \\
888 \\
919\end{array}$ & $\begin{array}{l}161 \\
337 \\
484 \\
603 \\
768 \\
861 \\
906\end{array}$ \\
\hline & \multicolumn{7}{|c|}{ Ages at entry, 60.} \\
\hline $\begin{array}{l}5 \\
10 \\
15 \\
20 \\
30 \\
40\end{array}$ & $\begin{array}{l}223 \\
406 \\
554 \\
669 \\
821 \\
905\end{array}$ & $\begin{array}{l}177 \\
362 \\
511 \\
623 \\
788 \\
876\end{array}$ & $\begin{array}{r}321 \\
642 \\
963 \\
1283 \\
1925 \\
2567\end{array}$ & $\begin{array}{l}235 \\
425 \\
573 \\
685 \\
825 \\
887\end{array}$ & $\begin{array}{l}181 \\
369 \\
518 \\
633 \\
786 \\
866\end{array}$ & $\begin{array}{l}241 \\
433 \\
579 \\
68 ! \\
817 \\
867\end{array}$ & $\begin{array}{l}182 \\
371 \\
518 \\
632 \\
780 \\
852\end{array}$ \\
\hline & \multicolumn{7}{|c|}{ Ages at entry, 70.} \\
\hline $\begin{array}{r}5 \\
10 \\
15 \\
20 \\
30\end{array}$ & $\begin{array}{l}248 \\
442 \\
590 \\
699 \\
839\end{array}$ & $\begin{array}{l}193 \\
387 \\
536 \\
649 \\
796\end{array}$ & $\begin{array}{r}527 \\
1055 \\
1582 \\
2110 \\
3164\end{array}$ & $\begin{array}{l}258 \\
453 \\
595 \\
695 \\
804\end{array}$ & $\begin{array}{l}1.94 \\
387 \\
533 \\
643 \\
776\end{array}$ & $\begin{array}{l}259 \\
\mathbf{4 5 0} \\
\mathbf{5 8 5} \\
\mathbf{6 7 7} \\
\mathbf{7 6 5}\end{array}$ & $\begin{array}{l}193 \\
384 \\
527 \\
632 \\
751\end{array}$ \\
\hline & \multicolumn{7}{|c|}{ Ages at entry, 75 . } \\
\hline $\begin{array}{r}5 \\
10 \\
15 \\
20 \\
25\end{array}$ & $\begin{array}{l}258 \\
455 \\
600 \\
702 \\
776\end{array}$ & $\begin{array}{l}198 \\
393 \\
541 \\
652 \\
733\end{array}$ & $\begin{array}{r}688 \\
1377 \\
2065 \\
\mathbf{2 7 5 4} \\
\mathbf{3 4 4 2}\end{array}$ & $\begin{array}{l}263 \\
454 \\
589 \\
679 \\
735\end{array}$ & $\begin{array}{l}197 \\
389 \\
532 \\
635 \\
707\end{array}$ & $\begin{array}{l}258 \\
441 \\
565 \\
641 \\
683\end{array}$ & $\begin{array}{l}194 \\
381 \\
518 \\
613 \\
675\end{array}$ \\
\hline
\end{tabular}




\section{JOINT-LIFE ASSURANCES WITHOUT PROFITS.}

Following the same lines as above, the formula for the paid-up policy is $1-\frac{\mathbf{P}_{x+1} \cdot x+1}{\mathbf{P}_{x+n . x+n}}$; and the formula deduced, after a series of trials, for the Office premiums necessary to illustrate it, is $P_{x: x}=1 \cdot 1 \pi_{[x]:[x]}+\cdot 002$, which gives a close approximation to the average Office premium.

TABLe C._-Office Premiums for " non-participating" Joint-life Assurances of 100.

\begin{tabular}{|c|c|c|c|}
\hline$\underset{x}{\Delta g e .}$ & $\begin{array}{l}\text { Average of } \\
\text { published office } \\
\text { rates. } \\
\text { (1) }\end{array}$ & $\begin{array}{c}100 P_{x: x} \\
\quad(2)\end{array}$ & $\begin{array}{c}\text { Difference. } \\
\text { (2)-(1) }\end{array}$ \\
\hline \multirow[t]{2}{*}{$\begin{array}{l}20 \\
25 \\
30 \\
35 \\
40 \\
45 \\
50 \\
55 \\
60\end{array}$} & \multirow[t]{2}{*}{$\begin{array}{r}2 \cdot 613 \\
2 \cdot 822 \\
3 \cdot 275 \\
3 \cdot 733 \\
4 \cdot 346 \\
5 \cdot 133 \\
6 \cdot 229 \\
7 \cdot 817 \\
10 \cdot 050\end{array}$} & $\begin{array}{l}2 \cdot 567 \\
2 \cdot 854 \\
3 \cdot 227 \\
3 \cdot 712 \\
4 \cdot 353 \\
5 \cdot 187 \\
6 \cdot 329 \\
7 \cdot 848 \\
9 \cdot 901\end{array}$ & $\begin{array}{l}-\cdot 046 \\
+\cdot 032 \\
-\cdot 048 \\
-\cdot 021 \\
+\cdot 007 \\
+\cdot 054 \\
+\cdot 100 \\
+\cdot 031 \\
-\cdot 149\end{array}$ \\
\hline & & Total, & -040 \\
\hline
\end{tabular}

There are no published tables of Office premiums for three joint lives, and I have therefore assumed that a similar loading to the above would be fairly representative, and have calculated premiums and paid-up policies on that basis.

Table $\mathrm{B}$ shows these paid-up policies and the corresponding $\mathrm{O}^{\mathrm{M}}$ 3 per cent net amounts.

Owing to the property of "Uniform Seniority" possessed by the $\mathrm{O}^{\mathrm{MM}}$ and $\mathrm{O}^{[\mathrm{NM}]}$ tables, it is possible to substitute for any number ( $n$, say) of joint lives of different ages (who have been insured for the same number of years less than 10 , or who have all been insured more than 10 years) the same number of lives whose ages are equal, by means of the equation

$$
\begin{gathered}
c^{x}+c^{y}+c^{z}+\ldots(n \text { terms in all })=n c^{w} \\
\text { or } \mu_{x}+\mu_{y}+\mu_{z}+\ldots(n \text { terms in all })=n \mu_{w},
\end{gathered}
$$

and it is therefore only necessary to consider the case where the ages are equal. It should be noticed that the value of $c$ is the same in both these tables, so that the substituted lives are of the same age in both cases.

An examination of the table shows that the "single-life" and the "joint-life" paid-up policies correspond very closely, and that for most of the ordinary ages at entry and durations the 


\section{Paid-up Policies and Surrender Values}

"Office" amounts are nearly identical. There is, at the younger ages, a tendency in the amounts to decrease as the number of lives is increased; but, on the other hand, it may be said that the formula does not quite do justice to the joint-life policyholders. The premium is larger than in single-life cases, and therefore the deduction of the whole of the first year's premium presses the more heavily upon them. In view of this, and more especially of the immense practical advantage gained by reducing the number of tables to a minimum and thus simplifying the work, I propose to use the same table of paid-up policies for single and for joint lives, irrespective of the number of lives involved. In each joint-life case the equivalent age $w$ can be determined at the outset, and used throughout the existence of the policy as the age with which to enter the table of paid-up policies.

\section{LAST-SURVIVOR ASSURANCES WITHOUT PROFITS.}

The principle of uniform seniority does not, in the case of a last-survivor assurance, enable us to make such a substitution as that mentioned above; and it is therefore necessary to consider the case where the ages differ, as well as where they are equal.

The formula which I found gave the closest approximation to the average office premiums is :-

$$
\mathbf{P}_{\overline{x: y}}=1 \cdot 075 \pi_{\overline{[x]:[y]}}+\cdot 00175 \text {. }
$$

TABLE D.-Office Premiums for "non-participating" Last-Survivor Assurances of 100.

\begin{tabular}{|c|c|c|c|c|c|}
\hline & \multicolumn{2}{|c|}{ Ages. } & $\begin{array}{l}\text { Average of } \\
\text { published office } \\
\text { rates. } \\
\text { (1) }\end{array}$ & $\begin{array}{c}100 P_{\overline{x: y}} \\
(2)\end{array}$ & $\begin{array}{c}\text { Difference. } \\
\text { (2)-(1) }\end{array}$ \\
\hline $\begin{array}{c}\text { Difference } \\
\text { of Age } 30 \\
\text { Years. }\end{array}$ & $\begin{array}{l}20 \\
25 \\
30 \\
35 \\
40 \\
45 \\
50 \\
55 \\
60 \\
20 \\
25 \\
30\end{array}$ & $\begin{array}{l}20 \\
25 \\
30 \\
35 \\
40 \\
45 \\
50 \\
55 \\
60 \\
50 \\
55 \\
60\end{array}$ & $\begin{array}{l}1 \cdot 038 \\
1 \cdot 153 \\
1 \cdot 336 \\
1 \cdot 566 \\
1 \cdot 869 \\
2 \cdot 266 \\
2 \cdot 782 \\
3 \cdot 459 \\
4 \cdot 376 \\
1 \cdot 451 \\
1 \cdot 642 \\
1 \cdot 915\end{array}$ & $\begin{array}{l}1 \cdot 004 \\
1 \cdot 155 \\
1 \cdot 343 \\
1 \cdot 582 \\
1 \cdot 886 \\
2 \cdot 278 \\
2 \cdot 790 \\
3 \cdot 468 \\
4 \cdot 374 \\
1 \cdot 407 \\
1 \cdot 632 \\
1 \cdot 907\end{array}$ & $\begin{array}{l}-\cdot 034 \\
+\cdot 002 \\
+\cdot 007 \\
+\cdot 016 \\
+\cdot 017 \\
+\cdot 012 \\
+\cdot 008 \\
+\cdot 009 \\
-.002 \\
-.044 \\
-.010 \\
-.008\end{array}$ \\
\hline & & & & Total, & $-\cdot 027$ \\
\hline
\end{tabular}

I have assumed that a similar loading to the above would give fairly representative premiums for assurances on the last survivor of three lives, and have calculated premiums and paid-up policies 


\section{Paid-up Policies and Surrender Values}

on that basis. The following table shows these paid-up policies and the corresponding $\mathrm{O}^{\mathrm{M}} 3$ per cent net amounts :-

TABLE E.-Paid-up Policies.-Last Survivor.-While all the

lives survive. Original Policy for 1000 uithout Profits.

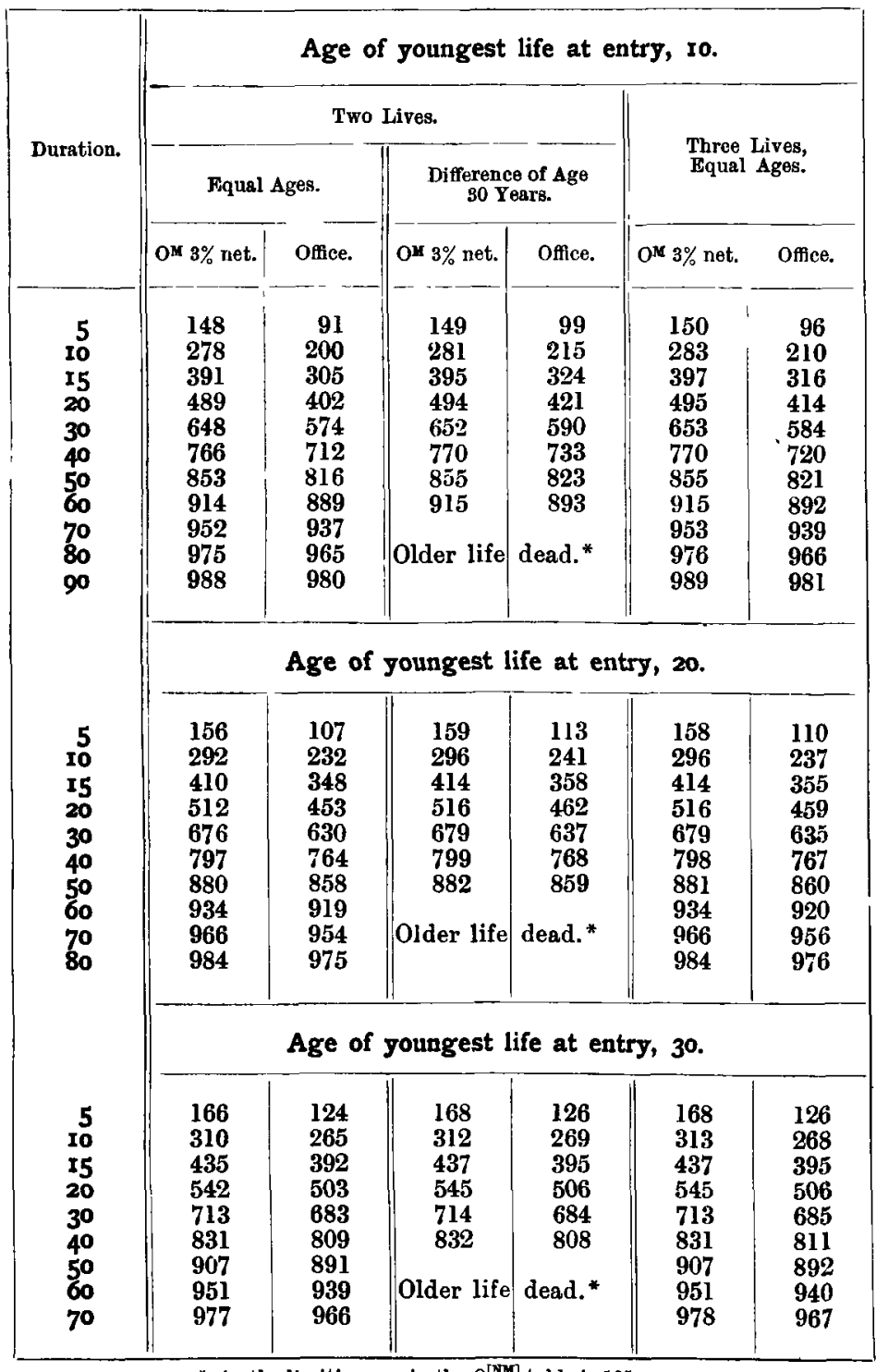

* As the limiting age in the $0^{[\mathrm{NM}]}$ table is 105 years. 
214 Paid-up Policies and Surrender Values

\begin{tabular}{|c|c|c|c|c|c|c|}
\hline \multirow{4}{*}{ Duration. } & \multicolumn{6}{|c|}{ Age of youngest life at entry, 40.} \\
\hline & \multicolumn{4}{|c|}{ Two Lives. } & \multirow{2}{*}{\multicolumn{2}{|c|}{$\begin{array}{l}\text { Three Lives, } \\
\text { Equal Ages. }\end{array}$}} \\
\hline & \multicolumn{2}{|c|}{ Equal Ages. } & \multicolumn{2}{|c|}{$\begin{array}{l}\text { Differences of Age } \\
30 \text { Years. }\end{array}$} & & \\
\hline & ON $3 \%$ net. & Office. & OM $3 \%$ net. & Office. & ox $^{\mathrm{x}}$ 3\% net. & Offlee. \\
\hline \multirow[t]{2}{*}{$\begin{array}{r}5 \\
10 \\
15 \\
20 \\
30 \\
40 \\
50 \\
60\end{array}$} & $\begin{array}{l}181 \\
336 \\
470 \\
583 \\
755 \\
865 \\
929 \\
966\end{array}$ & $\begin{array}{l}141 \\
299 \\
436 \\
553 \\
731 \\
846 \\
914 \\
952\end{array}$ & \begin{tabular}{|c}
181 \\
338 \\
472 \\
585 \\
756 \\
\\
Older life
\end{tabular} & $\begin{array}{r}141 \\
299 \\
435 \\
551 \\
728 \\
\text { dead }\end{array}$ & $\begin{array}{l}181 \\
337 \\
470 \\
583 \\
754 \\
864 \\
930 \\
968\end{array}$ & $\begin{array}{l}142 \\
300 \\
437 \\
554 \\
732 \\
847 \\
915 \\
953\end{array}$ \\
\hline & \multicolumn{6}{|c|}{ Age of youngest life at entry, 50.} \\
\hline \multirow[t]{2}{*}{$\begin{array}{r}5 \\
10 \\
15 \\
20 \\
30 \\
40 \\
50\end{array}$} & $\begin{array}{l}201 \\
372 \\
514 \\
630 \\
796 \\
893 \\
949\end{array}$ & $\begin{array}{l}\mathbf{1 6 1} \\
\mathbf{3 3 5} \\
\mathbf{4 8 0} \\
\mathbf{5 9 9} \\
\mathbf{7 7 0} \\
\mathbf{8 7 1} \\
\mathbf{9 2 8}\end{array}$ & & & $\begin{array}{l}201 \\
371 \\
512 \\
628 \\
795 \\
893 \\
952\end{array}$ & $\begin{array}{l}160 \\
335 \\
480 \\
600 \\
772 \\
873 \\
930\end{array}$ \\
\hline & \multicolumn{6}{|c|}{ Age of youngest life at entry, 60 . } \\
\hline $\begin{array}{l}5 \\
10 \\
15 \\
20 \\
30 \\
40\end{array}$ & $\begin{array}{l}226 \\
411 \\
559 \\
676 \\
830 \\
919\end{array}$ & $\begin{array}{l}\mathbf{1 8 2} \\
\mathbf{3 7 0} \\
\mathbf{5 2 1} \\
\mathbf{6 3 9} \\
798 \\
\mathbf{8 8 7}\end{array}$ & & & $\begin{array}{l}225 \\
409 \\
558 \\
674 \\
831 \\
923\end{array}$ & $\begin{array}{l}180 \\
369 \\
521 \\
640 \\
800 \\
890\end{array}$ \\
\hline \multirow{3}{*}{$\begin{array}{l}5 \\
10 \\
15 \\
20 \\
30\end{array}$} & \multicolumn{6}{|c|}{ Age of youngest life at entry, 70 . } \\
\hline & $\begin{array}{l}252 \\
449 \\
600 \\
712 \\
863\end{array}$ & $\begin{array}{l}197 \\
395 \\
547 \\
661 \\
811\end{array}$ & & & $\begin{array}{l}251 \\
449 \\
600 \\
713 \\
870\end{array}$ & $\begin{array}{l}198 \\
\mathbf{3 9 8} \\
\mathbf{5 5 0} \\
\mathbf{6 6 5} \\
\mathbf{8 1 6}\end{array}$ \\
\hline & \multicolumn{6}{|c|}{ Age of youngest life at entry, 75 . } \\
\hline $\begin{array}{r}5 \\
10 \\
15 \\
20 \\
25\end{array}$ & $\begin{array}{l}264 \\
466 \\
615 \\
722 \\
816\end{array}$ & $\begin{array}{l}203 \\
403 \\
554 \\
667 \\
751\end{array}$ & & & $\begin{array}{l}264 \\
467 \\
617 \\
726 \\
826\end{array}$ & $\begin{array}{l}205 \\
406 \\
558 \\
671 \\
757\end{array}$ \\
\hline
\end{tabular}


It will be noticed that the amounts depend almost entirely upon the age of the youngest life, a difference of even 30 years in the ages, or the introduction of a third life, making no important difference in the amounts. Further, a comparison with the table of single-life paid-up policies shows that although the last are always the smaller, yet the difference is comparatively small except at the younger ages at entry when the duration is short. It may, however, be said that as the last-survivor premiums are less than those for single lives, the formula for the paid-up policy, perhaps, tends to give rather too large amounts as compared with single-life policies. Partly for this reason, but chiefly for the sake of simplicity, I propose to use the same table of paid-up policies for single-life and last-survivor policies, irrespective of the number of lives involved, and of the difference (if any) in their ages; taking, in last survivor cases, the age at entry of the youngest life, as the age with which to enter the table of paid-up policies.

The above amounts are calculated on the assumption that the lives are all still surviving at the time the paid-up policy is quoted; and if one or more of them be dead, a slightly different procedure must be followed.

First take the case of a policy on two lives, $x$ and $y$; one of whom, say $x$, is dead. Since the assurance then depends solely on the survivor, $y$, the premium (per unit of the sum assured) for a new policy of the same amount would be $\mathrm{P}_{y+n}$, and the formula for the paid-up policy would become $1-\frac{\mathrm{P}_{\overline{x+1}: y+1}}{\mathrm{P}_{y+n}}$. Now by an inspection of the Office tables of premiums we can at a glance find a number $r$ such that $\mathrm{P}_{y-r}=\mathrm{P}_{\overline{x: y}}$ (unless $x$ and $y$ are both very young), and by entering the table of single-life paid-up policies with age $y-r$ and duration $n+r$ we get a very close approximation indeed to the exact amount by the formula; the amounts being, in fact, practically identical. For $P_{\overline{x+1: y+1}}$ will be practically equal to $\mathrm{P}_{y-r+1}$, therefore, approximately, $1-\frac{\mathrm{P}_{\overline{x+1: y+1}}}{\mathrm{P}_{y+n}}=1-\frac{\mathrm{P}_{y-r+1}}{\mathrm{P}_{y-r+n+r}}$, which is the paid-up policy given by the single-life table where the age at entry is $y-r$, and the duration is $n+r$. The number $r$ remains unaltered during the remainder of the policy's existence, and therefore only requires to be determined once, when it can be recorded for future reference.

Secondly, take the case of a policy on three lives, $x, y$, and $z$, one of whom, say $x$, is dead. In these circumstances the premium (per unit of the sum assured) for a new policy of the same amount 


\section{I 6 Paid-up Policies and Surrender Values}

is $P_{\overline{y+n: \varepsilon+n}}$ and the paid-up policy is therefore $1-\frac{P_{\overline{x+1: y+1: z+1}}}{\mathbf{P}_{\overline{y+n: 2+n}}}$

Now, an inspection of the Office tables of premiums enables us to find a number $s$ such that $\mathrm{P}_{\overline{y-8: z-8}}=\mathrm{P}_{\overline{x: y: z}}$ (unless the lives are very young), and if the table of single-life paid-up policies be entered with age at entry $y-s$ (where $y$ is less than $z$ ), and duration $n+s$, the result will be the paid-up policy.

For $\mathrm{P}_{\overline{x+1: y+1: s+1}}$ will be practically equal to $\mathrm{P}_{\overline{y-8+1: 8-s+1}}$, so that (approximately) $1-\frac{\mathrm{P}_{\bar{x}+1: y+1: \varepsilon+1}}{\mathbf{P}_{\overline{y+n: 8+n}}}=1-\frac{\mathbf{P}_{\overline{y-8+1: z-8+1}}}{\mathrm{P}_{\overline{y-8+n+8: z-8+n+8}}}$, which is the paid-up policy allowed for a policy effected on the last survivor of two lives, $y-s$ and $z-s$, which has been $n+s$ years in force; and as has been shown above, this is very nearly the same as the paidup policy allowed for a single-life policy effected at age $y-s$, and of duration $n+s$. The number $s$ will remain unaltered so long as both $y$ and $z$ survive.

Thirdly, take the case of a policy on the last survivor of three lives, $x, y$, and $z$, two of whom, say $x$ and $y$, are dead, in which case the formula for the paid-up policy becomes $1-\frac{\mathrm{P}_{\overline{x+1: y+1: z+1}}}{\mathrm{P}_{z+n}}$. By inspection of the Office tables of premiums we can find a number $t$ such that $P_{z-t}=P_{\overline{x: y: 2}}$ (unless the lives are very young), and if the table of single-life paid-up policies be entered with age at entry $z-t$, and duration $n+t$, the result will be the paid-up policy. For (approximately) $1-\frac{P_{x+1: y+1: z+1}}{P_{s+n}}=1-\frac{P_{s-t+1}}{P_{z-t+n+t}}$, which is the paid-up policy allowed for a single-life policy effected at age $z-t$, which has been $n+t$ years in force. The number $t$ remains unaltered during the remainder of the policy's existence.

It is therefore possible to construct from the Office premiums for whole-life assurances without profits, a single table of paid-up policies, which can be used safely and conveniently in practice for every whole-life policy by uniform annual premiums, irrespective of the number of lives involved.

If the Office has changed its rates of premium between the issue of the policy and its conversion into a paid-up policy, the question arises: What difference should this make in the value to be allowed? If the rates have been raised in the meantime, the policyholder has all along been paying less than a new entrant at the same age would be charged; and therefore as the Office has received less from him, it would appear reasonable that he should receive a smaller paid-up policy than would be given by the formula according to the present scale of premiums. On the other 
hand, it may be said that as he has secured the same reversion as an entrant of the same age under the new tables, but pays a smaller premium for it, his contract is more valuable; and that this fact should be recognised by granting him a somewhat larger paid-up policy. Similar considerations apply, mutatis mutandis, if the rates of the Office have been lowered. That is to say, purely theoretical reasoning by the retrospective and prospective methods leads to two diametrically opposite conclusions. In these circumstances $I$ think the best course is to construct a table of paid-up policies from the premiums at present in use, and to apply it to all policies whether the premiums payable thereunder are the same as, or different from, those under the present scale.

\section{IIMITED-PAYMENT POI.ICIES AND ENDOWMENT ASSURANCES.}

In dealing with these classes of policies we have to recognise the fact that owing to the pressure of competition and the force of public opinion many Offices have adopted the arbitrary rule of allowing a "proportionate" paid-up policy corresponding to the number of premiums paid, with or without the addition of existing bonuses; and I have therefore examined the prospectuses and other publications of a number of Offices in order to ascertain the general practioe on this point. There are 59 British Offices each of which has funds of over half-a-million pounds sterling, and I confined the investigation to these. Fifty-one of them guarantee a "proportionate" paid-up policy in some form or another as shown in the following table:-

Offices guaranteeing "proportionate" paid-up Policies.

\begin{tabular}{|c|c|c|c|c|c|c|}
\hline $\begin{array}{l}\text { From } \\
\text { Outset. }\end{array}$ & $\begin{array}{c}\text { After 1 } \\
\text { Year's } \\
\text { Premium } \\
\text { paid. }\end{array}$ & $\begin{array}{c}\text { After 2 } \\
\text { Years' } \\
\text { Premiums } \\
\text { paid. }\end{array}$ & $\begin{array}{l}\text { After 3 } \\
\text { Years' } \\
\text { Premiums } \\
\text { paid. }\end{array}$ & $\begin{array}{c}\text { After } 1 \text { th } \\
\text { of total } \\
\text { Premumams } \\
\text { paid. }\end{array}$ & $\begin{array}{c}\text { Bonus added to pro- } \\
\text { portionate paid-up } \\
\text { Policy. }\end{array}$ & Totals. \\
\hline 1 & 0 & 5 & 4 & 0 & None. & 10 \\
\hline 2 & 0 & 0 & 0 & 0 & Future profits. & 2 \\
\hline 0 & 1 & $\mathbf{I}$ & 3 & 0 & Proportion of ex- & 5 \\
\hline 0 & 1 & 2 & 1 & 0 & $\begin{array}{l}\text { Do. and future } \\
\text { profits. }\end{array}$ & 4 \\
\hline 0 & 1 & 13 & 10 & 2 & $\begin{array}{l}\text { Whole of existing } \\
\text { Bonus. }\end{array}$ & 26 \\
\hline 1 & $\mathbf{0}_{3}$ & 0 & 3 & 0 & $\begin{array}{l}\text { Do. and future } \\
\text { profits. }\end{array}$ & 4 \\
\hline 4 & 3 & 21 & 21 & 2 & & 51 \\
\hline
\end{tabular}




\section{I 8 Paid-up Policies and Surrender Values}

The great majority of these guarantees apply both to limited-payment policies and to endowment assurances; but six of the Offices appear to limit the privilege to the former class, and one seems to limit it to the latter. The table cannot be regarded as an absolutely accurate exhibit of the practice of the 51 Offices, for some of them introduce slight modifications which have been disregarded, as otherwise the groups would have been too numerous. For example, one Office guarantees a paid-up policy after two years' premiums have been paid under an endowment assurance; but requires at least three years' premiums in the case of a limited payment policy; and another Office which has the same condition regarding the former class, guarantees a proportionate paid-up policy under a limited-payment policy after only one year. Of the remaining eight Offices, one states that the paid-up policy is "about" the same proportion of the sum assured that the number of premiums paid bears to the full number originally payable; another guarantees a paid-up policy equal to all the premiums paid plus any vested bonuses-while six make no definite statement on the subject.

This shows that the majority of Offices adopt some form or other of a "proportionate" paid-up policy, and I think they are right in doing so. The public can understand the system, and it appeals to them as being in accordance with "common-sense," and therefore reasonable and fair; and it will be seen from Tables $K-S$ that as a rule it gives values which are within those provided by the reserves of the Offices-the reserve for the proportionate paid-up policy being generally less than the net value of the original policy. At ages above 50 the system gives rather too much in the case of limited-payment policies, and also in the case of endowment assurances for a short term of years, though the discrepancy here is less.

If reference be made to Mr. Macfadyen's paper above mentioned (J. I. A., xv, 297) it will be seen that he did not extend his investigation to a sufficiently high age at entry to exhibit fully this defect in the method; and it may be that had he done so, he would have come to a somewhat modified conclusion. Some Offices attempt to remedy the defect by limiting their guarantee of a proportionate paid-up policy to cases where the age at entry does not exceed a fixed age, say 50 or 60 , but they do not state how they deal with cases falling outside this limit. In view of the comparative infrequency of such cases, and of the great advantage of having one rule instead of a number, I am of opinion that an Office may justifiably guarantee a pro- 
portionate paid-up policy in the case of every policy effected by limited payments, provided at least two years' premiums have been paid thereon, and irrespective of the class of assurance. I would therefore extend the rule to double endowments, pure endowments, and deferred annuities, with or without return of premium in the event of death, it being understood that the reduced benefit must be of the same nature as the original. It appears to me that any disadvantage of this course will be more than compensated by the popularity and simplicity with which it is attended.

\section{INCOME POLICIES.}

Many Offices have schemes under which the sum assured is payable in instalments over a period of years, instead of in one sum on the policy becoming a claim. That is to say, the benefit is an annuity-certain instead of a sum of cash. The term of this annuity is usually 20 years, 5 per cent of the nominal sum assured being paid in advance each year, so that each $£ 1$ assured is equivalent to $\cdot 05 \mathrm{a}_{\overline{20}} \cdot$. Assuming the Office to value on a 3 per cent basis, this is equal to 76619 $(\cdot 05 \times 15.3238)$, and such policies are therefore virtually the same as ordinary policies for that fraction of the nominal sum assured, so that the paid-up policies could be calculated by the same rules. It is, however, usually inconvenient to grant paidup policies on this system, as the annual instalment would be very small; and the trouble of keeping so small an annuity on the books would outweigh any advantages afforded thereby. Accordingly the paid-up policy should generally be made payable in one sum on the policy becoming a claim; and its amount got by applying the rules for the conversion of ordinary policies of similar class (whole-life, limited-payment, or endowment assurance as the case may be), and multiplying the result by $\cdot 76619$.

\section{DEBENTURE POLICLES.}

Under this scheme the Office agrees to retain the sum assured in its hands for a specified term of years, usually 20, allowing interest in the meantime at the rate of, say, 4 per cent.

Assuming a 3 per cent valuation basis as before, the policy inoney may be regarded as deposited with the Office at that rate, so that the contract is virtually equivalent to an ordinary assurunce, plus a 20-year annuity-certain of 1 per cent of the sum assured. Accordingly each unit of the sum assured may be 
treated as equivalent to $1+.01 a \overline{20}(3$ per cent $)$; or $1+.01 a \frac{(2)}{20 \mid}$, if the interest be payable half-yearly. This last expression is equal to $1 \cdot 14958$ (say $1 \cdot 15$ ), so that a " 4 per cent Debenture" policy may be treated as if it were an ordinary policy for an amount 15 per cent larger than the nominal sum assured.

\section{CHILDREN'S DEFERRED ASSURANCES.}

Under this scheme the assurance does not commence until the attainment of a specified age, or the expiry of a fixed number of years after entry; and the premiums are consequently much less than those for immediate assurances. If death occurs before the specified age (usually 21), the premiums are generally returned; but policies are occasionally issued at even lower rates with "non-returnable" premiums. The benefit is therefore equivalent to a deferred assurance combined with a pure endowment for a smaller amount. After the assurance has come into force, the paid-up policy may be found by the formula $1-\frac{P}{n \bar{P}}$, where $\mathrm{P}$ is the premium actually payable, and $\mathrm{P}$ is the premium that would be charged in the case of a new entrant at the attained age, for an immediate assurance similar to that secured by the existing policy, namely whole-life, limited-payment, or endowment assurance, as the case may be. Having regard to the profit obtainable by the Office under the endowment portion of the contract, during the period for which the assurance was deferred, I do not think it is necessary to omit the first premium, as in the case of immediate assurances. At any time before the assurance has come into force, the paid-up policy may be found by the "proportionate" method. Thus, if the assurance be deferred for $r$ years; if the paid-up policy that would be given by the above formula at the end of that term be denoted by ${ }_{r}(\mathrm{FP})$; and if $n$ premiums $(n<r)$ have been paid; then the amount of the paid-up policy at the end of $n$ years is $r(\mathrm{FP}) \times \frac{n}{r}$. The nature of the paid-up benefit must of course be the same as that of the original contract, namely, a deferred assurance, with or without return of premiums, as the case may be.

\section{REVERSIONARY BONUSES.}

In the case of a whole-life policy with participation in profits the paid-up policy might be found by the formula $1-\frac{\mathbf{P}_{x+1}^{\prime}}{\mathbf{P}_{x+n}^{\prime}}$, with 
suitable modifications for joint-life and last-survivor policies. This will give a greater or less paid-up policy than the formula $1-\frac{\mathbf{P}_{x+1}}{\overline{\mathbf{P}}_{x+n}}$ according as

$$
\begin{aligned}
& \mathrm{P}_{x+1}^{\prime} \text { is }<\text { or }>\frac{\mathrm{P}_{x+1}}{\mathrm{P}_{x+n}}, \\
& \mathrm{P}_{x+n}^{\prime} \\
& \mathrm{P}_{x+1}^{\prime} \text { is }<\text { or }>\frac{\mathrm{P}_{x+n}^{\prime}}{\mathrm{P}_{x+n}^{\prime}},
\end{aligned}
$$

or as

that is to say, according as the ratio of the "participating" to the "non-participating" premium increases or diminishes with the age at entry.

The following table shows the averages of the published rates of premium for assurances with profits, and their ratio to the corresponding rates without profits; and it will be seen that, on the whole, this ratio tends to diminish as the age at entry increases, though there are several irregularities caused by the somewhat irregular progression of the average office premiums.

TABLe F.-Average Office Premiums for Whole-life Assurances of 100, with and without Profits.

\begin{tabular}{|c|c|c|c|}
\hline & \multicolumn{2}{|c|}{ Average Premiums } & \\
\cline { 2 - 4 } & $\begin{array}{c}\text { With Profits } \\
\mathrm{P}_{x}^{\prime}\end{array}$ & $\begin{array}{c}\text { Without Profits } \\
\mathbf{P}_{x}\end{array}$ & $\frac{\mathbf{P}_{x}^{\prime}}{\mathrm{P}_{x}}$ \\
\hline & & & \\
\hline 15 & $1 \cdot 721$ & $1 \cdot 450$ & $1 \cdot 187$ \\
20 & $1 \cdot 967$ & $1 \cdot 621$ & $1 \cdot 213$ \\
25 & $2 \cdot 183$ & $1 \cdot 808$ & $1 \cdot 207$ \\
30 & $2 \cdot 467$ & $2 \cdot 046$ & $1 \cdot 206$ \\
35 & $2 \cdot 817$ & $2 \cdot 358$ & $1 \cdot 195$ \\
40 & $3 \cdot 258$ & $2 \cdot 767$ & $1 \cdot 177$ \\
45 & $3 \cdot 817$ & $3 \cdot 379$ & $1 \cdot 130$ \\
50 & $4 \cdot 567$ & $4 \cdot 008$ & $1 \cdot 139$ \\
55 & $5 \cdot 621$ & $4 \cdot 979$ & $1 \cdot 129$ \\
60 & $7 \cdot 042$ & $6 \cdot 217$ & $1 \cdot 133$ \\
65 & $8 \cdot 996$ & $8 \cdot 088$ & $1 \cdot 112$ \\
70 & $11 \cdot 321$ & $10 \cdot 842$ & $1 \cdot 044$ \\
\hline
\end{tabular}

As is explained hereafter (p. 238), the cost of a compound bonus of 1 per cent per annum is approximately represented by a difference of 1 per cent in the rate of interest used in valuing the initial benefit. Accordingly the net annual premium $\pi^{\prime}{ }_{[x]}$ for an assurance with the right to such a bonus is approximately equal to

$$
\frac{\mathrm{A}_{[x]}(\text { at rate } i-01)}{\mathrm{a}_{[x]}(\text { at rate } i)} \text {. }
$$

Using the same basis as before ( $\mathrm{O}^{[\mathrm{NM}]} 3 \frac{1}{2}$ per cent) I have constructed by this formula the following table:- 


\section{Paid-up Policies and Surrender Values}

TABLe G.-Net "Select" Premiums for Assurance of 1.

\begin{tabular}{|c|c|c|c|}
\hline $\boldsymbol{x}$ & $\begin{array}{c}\text { With } \\
\text { Compound Bonus } \\
\text { of } 1 \text { per cent } \\
\boldsymbol{\pi}_{[x]}^{\prime}\end{array}$ & $\begin{array}{l}\text { Withont Profits } \\
\qquad \pi_{[x]}\end{array}$ & $\frac{\pi_{[x]}^{\prime}}{\pi_{[x]}}$ \\
\hline $\begin{array}{r}10 \\
15 \\
20 \\
25 \\
30 \\
35 \\
40 \\
45 \\
50 \\
55 \\
60 \\
65 \\
70 \\
75 \\
80 \\
85 \\
90 \\
95 \\
100\end{array}$ & $\begin{array}{l}\cdot 01542 \\
\cdot 01685 \\
\cdot 01864 \\
\cdot 02077 \\
\cdot 02345 \\
\cdot 02682 \\
\cdot 03108 \\
\cdot 03652 \\
\cdot 04359 \\
\cdot 05282 \\
\cdot 06497 \\
\cdot 08123 \\
\cdot 10312 \\
\cdot 13274 \\
\cdot 17244 \\
\cdot 22566 \\
\cdot 29622 \\
\cdot 38754 \\
\cdot 50374\end{array}$ & $\begin{array}{l}\cdot 01099 \\
\cdot 01216 \\
\cdot 01364 \\
\cdot 01551 \\
\cdot 01788 \\
\cdot 02093 \\
\cdot 02486 \\
\cdot 02997 \\
\cdot 03669 \\
\cdot 04557 \\
\cdot 05743 \\
\cdot 07339 \\
\cdot 09498 \\
\cdot 12426 \\
\cdot 16385 \\
\cdot 21687 \\
\cdot 28722 \\
\cdot 37839 \\
\cdot 49417\end{array}$ & $\begin{array}{l}1 \cdot 403 \\
1 \cdot 397 \\
1 \cdot 367 \\
1 \cdot 339 \\
1 \cdot 312 \\
1 \cdot 281 \\
1 \cdot 250 \\
1 \cdot 219 \\
1 \cdot 188 \\
1 \cdot 159 \\
1 \cdot 131 \\
1 \cdot 107 \\
1 \cdot 086 \\
1 \cdot 068 \\
1 \cdot 052 \\
1 \cdot 041 \\
1 \cdot 031 \\
1 \cdot 024 \\
1 \cdot 019\end{array}$ \\
\hline
\end{tabular}

I have also constructed (on an $\mathrm{O}^{\mathrm{M}} 3 \frac{1}{2}$ per cent basis) the following table, which gives the premiums for an assurance with right to a simple bonus of 1 per cent per annum, and their ratio to the corresponding non-profit premiums :-

TABLE H.-Net "Aggregate" Premiums for Assurance of 1 .

\begin{tabular}{|c|c|c|c|}
\hline $\boldsymbol{x}$ & $\begin{array}{c}\text { With } \\
\text { Simple Bonus } \\
\text { of } 1 \text { per cent } \\
\pi^{\prime}\end{array}$ & $\begin{array}{l}\text { Without Profits } \\
\qquad \pi_{x}\end{array}$ & $\frac{\pi_{x}^{\prime}}{\pi_{x}}$ \\
\hline $\begin{array}{l}10 \\
15 \\
20 \\
25 \\
30 \\
35 \\
40 \\
45 \\
50 \\
55 \\
60 \\
65 \\
70 \\
75 \\
80 \\
85 \\
90 \\
95 \\
100\end{array}$ & $\begin{array}{l}\cdot 01231 \\
\cdot 01400 \\
\cdot 01604 \\
\cdot 01849 \\
\cdot 02146 \\
\cdot 02503 \\
\cdot 02945 \\
\cdot 03503 \\
\cdot 04225 \\
\cdot 05174 \\
\cdot 06445 \\
\cdot 08169 \\
\cdot 10541 \\
\cdot 13836 \\
\cdot 18441 \\
\cdot 24853 \\
\cdot 33596 \\
\cdot 44905 \\
\cdot 62214\end{array}$ & $\begin{array}{l}\cdot 00893 \\
\cdot 01032 \\
\cdot 01204 \\
\cdot 01416 \\
\cdot 01677 \\
\cdot 01997 \\
.02400 \\
.02917 \\
\cdot 03597 \\
\cdot 04504 \\
\cdot 05733 \\
\cdot 07416 \\
\cdot 09749 \\
\cdot 13007 \\
\cdot 17580 \\
\cdot-23963 \\
\cdot 32682 \\
\cdot 43973 \\
.61262\end{array}$ & $\begin{array}{l}1 \cdot 378 \\
1 \cdot 357 \\
1 \cdot 332 \\
1 \cdot 306 \\
1 \cdot 280 \\
1 \cdot 253 \\
1 \cdot 227 \\
1 \cdot 201 \\
1 \cdot 175 \\
1 \cdot 149 \\
1 \cdot 124 \\
1 \cdot 102 \\
1 \cdot 081 \\
1 \cdot 064 \\
1 \cdot 049 \\
1 \cdot 037 \\
1 \cdot 028 \\
1 \cdot 021 \\
1 \cdot 016\end{array}$ \\
\hline
\end{tabular}




\section{Paid-up Policies and Surrender Values}

These tables show that both for a simple and a compound bonus the ratio $\frac{\pi_{[x]}^{\prime}}{\pi_{[x]}}$ steadily diminishes as $x$ increases (when the mortality table is well graduated), and the same thing holds for the Office premiums if they are loaded with the same constant and percentage in each case. For, on this hypothesis,

$$
\mathbf{P}^{\prime}=\frac{\pi^{\prime}(1+k)+c}{\pi(1+k)+c}=\frac{\pi^{\prime}+h}{\pi+h} \text { where } h=\frac{c}{1+k},
$$

and the form of this expression shows that since $\frac{\pi^{\prime}}{\pi}$ diminishes with the age but is always $>1, \frac{\mathrm{P}^{\prime}}{\mathrm{P}}$ will be slightly $<\frac{\pi^{\prime}}{\pi}$ but $>1$, and will diminish in a similar manner though not quite so rapidly. Accordingly it appears that if an Office charges premiums based on a well-graduated table, and properly loaded, the paid-up policy given by the formula $1-\frac{\mathrm{P}_{x+1}^{\prime}}{\mathbf{P}_{x+n}^{\prime}}$ will in all cases be less than that given by the formula $1-\frac{\mathbf{P}_{x+1}}{\mathbf{P}_{x_{+} n}}$. If the rates are based on the $\mathrm{H}^{\left[{ }^{[m]}\right]}$ table, irregularities will appear at the early ages at entry, owing to the irregular mortality shown by that table between ages 20 and 30 ; but for the greater part of the table the same relation holds. As a general rule, therefore, it will be found that the proposed method gives smaller results when applied to "participating" than when applied to "non-participating" policies; which was perhaps only to be expected, as it implies that in the former case the paid-up policy will share in future profits and therefore be increased by the addition of bonuses from time to time. There are, however, several objections to allowing a paid-up policy to share in the future profits; among which may be mentioned the facts that the assured ceases to contribute towards the "bonus-loading," that the allocation of periodical bonuses to a large number of small paid-up policies causes a great deal of labour-possibly out of proportion to the benefits of such a course, and that when a policyholder cannot continue to pay his premiums it is generally to the advantage of his family that the paid-up policy should be for as large an amount as possible from the outset. I therefore propose that in all cases (unless a request to the contrary be made), the paid-up policy should not share in future profits; and that its amount should, for "participating" as well as "non-participating" policies, be ascertained by the formula $1-\frac{\mathbf{P}_{x+1}}{\mathbf{P}_{x+n}}$, with the addition, in "participating" cases, of any vested bonus addi- 


\section{Paid-up Policies and Surrender Values}

tions; and I would follow a similar course in all cases where a "proportionate" paid-up policy is granted. The only difference in the amounts of paid-up policy allowed for "participating" and "non-participating" assurances would therefore be that in the former case the amount of any existing bonus would be added.

In the case of an Office dividing its profits on the compound reversionary bonus plan, some modification is required if inconsistencies are to be avoided ; since the proposed paid-up policy is without profits, and a compound bonus is virtually a paid-up assurance with profits. If they were simply added together and the total were not to share in future profits, it will be seen from what follows (p. 256) that the policyholder would get a smaller surrender value if he surrendered the whole benefit outright, than if he first surrendered the bonus for its cash value, and immediately thereafter surrendered the policy. To meet this difficulty I propose that in such a case the amount of the bonus should be increased in the ratio of the surrender value of a "participating" policy to the surrender value of a similar "non-participating" policy, and that this increased amount be added to the paid-up policy given by the formula $1-\frac{\mathrm{P}_{x+1}}{\mathrm{P}_{x+n}}$. The difficulty conld be also met, in whole-life cases, by making the paid-up policy $=\left(1-\frac{\mathrm{P}^{\prime}{ }_{x+1}}{\mathrm{P}_{x+n}^{\prime}}\right) \times$ sum assured +existing bonus, and allowing it to share in future profits ; but this would not apply to limited payment and endowment assurance policies where a "proportionate" paid-up policy is guaranteed; and it seems to me better to adopt a rule which can be applied to all classes of assurance. It will be seen that this proposed rule assumes that the existing bonuses are in each case the equivalent of the difference between the "participating" premiums actually paid and those that would have been paid for a "non-participating" policy; and though this will not always be scientifically accurate, it is probably sufficiently near the truth to form a good practical rule.

\section{DISCOUNTED BONUS SYSTEM.}

Under this plan the Office anticipates a certain bonus, and applies its present value in reduction of the premium. If the bonus actually realised should exceed the amount anticipated, the excess is applied either in increasing the sum assured, or in further reduction of the premium; but if it falls short thereof 
the policyholder has to make good the deficiency, either by suffering a reduction of the sum assured or paying an increased premium. Now an examination of the figures given by Mr. G. F. Hardy (J. I. A., xxxi, 265, 268) shows that though the reduction of premium $\mathrm{P}^{\prime}-\mathrm{P}^{\prime \prime}$ increases with the age at entry, it does not increase nearly so rapidly as the premium $\mathrm{P}^{\prime}$.

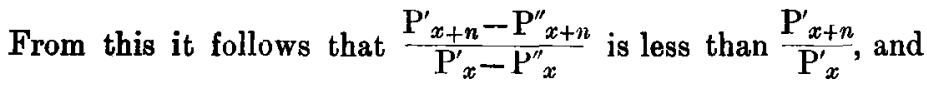
therefore $\frac{\mathbf{P}_{x+n}^{\prime \prime}}{\mathbf{P}_{x}^{\prime \prime}}$ is greater than $\frac{\mathbf{P}_{x+n}^{\prime}}{\mathbf{P}_{x}^{\prime}}$ and $1-\frac{\mathrm{P}_{x}^{\prime \prime}}{\mathbf{P}_{x+n}^{\prime \prime}}$ is greater than $1-\frac{\mathrm{P}_{x}^{\prime}}{\mathrm{P}_{x+n}^{\prime}}$. That is to say, the paid-up policy on this system is larger than that on the ordinary "participating" plan.

I examined a set of Office tables of premiums based on the $\mathrm{H}^{[\mathrm{M}]}$ (select) tables, and consistently loaded, and found that the ratio $\frac{\mathrm{P}^{\prime \prime}}{\mathrm{P}}$ increased with the age at entry (though there were a few irregularities at the younger ages due to the irregular mortality above mentioned), but that this increase was very slow.

It follows that, according to those tables, $1-\frac{\mathrm{P}_{x}^{\prime \prime}}{\overline{\mathrm{P}}_{x+n}^{\prime \prime}}$ is generally greater than $1-\frac{\mathbf{P}_{x}}{\mathbf{P}_{x+n}}$, but that the excess is very small. According to a set of tables published by a second Office, the former expression was very slightly less than the latter; and a third set gave slight deviations in both directions. The general conclusion to be drawn from these facts is that $1-\frac{\mathrm{P}_{x}}{\mathrm{P}_{x+n}}$ is a very close approximation to $1-\frac{\mathrm{P}^{\prime \prime}{ }_{x}}{\mathrm{P}^{\prime \prime}{ }_{x+n}}$, and this was perhaps to be expected, since the "discounted bonus" premiums published by an Office are generally very close to its "non-participating" premiums.

I therefore suggest that the amount of a paid-up policy allowed for an assurance under this plan, might be the same as that allowed for a "non-participating" assurance. The reasoning implies, however, that this paid-up policy is to be granted on the "discounted bonus" plan, and is therefore liable to be increased or diminished if the future rate of bonus exceeds or falls short of the anticipated rate. In order to avoid the trouble of numerous small changes in the amounts assured by such contracts, it would probably be better to issue the paid-up policy on the "nonparticipating" plan, and this raises the question: Upon what terms 


\section{Paid-up Policies and Surrender Values}

can a paid-up policy on the discounted bonus system be converted into one without profits? The rate of bonus anticipated under the system is generally a substantial proportion of the rate declared by the Office, e.g. four-fifths, five-sixths, or even moreand having regard to the tendency of the rate of interest to fall, and the rate of expenditure to rise, it may be said that the anticipated rate represents approximately the rate which, on a cautious estimate, the Office is likely to maintain in the future. If this be correct, it follows that, on converting a paid-up policy on this plan into a "non-participating" assurance, its amount should be reduced; as the former benefit depends upon estimates which may not be realised, while the latter is fixed and guaranteed. As will be explained hereafter, under the heading of surrender values, it seems to me that the Office might, in such a calculation, make allowance for one-half to two-thirds of the estimated future bonus. Thus, if the estimated rate is $30 \mathrm{~s}$., the policyholder might be credited with a rate of, say, $20 \mathrm{~s}$., leaving a difference of $10 \mathrm{~s}$. per annum to be deducted from the paid-up policy on its conversion into a fixed benefit. This leads to the conclusion that the amount of the paid-up policy to be granted on the "non-participation" plan might be

$$
\left(1-\frac{\mathbf{P}_{x+1}}{\mathbf{P}_{x+n}}\right) \times \frac{\mathbf{A}_{[x+n]}\left(\mathrm{O}^{[M]} 41 \%\right)}{\mathbf{A}_{[x+n]}\left(\mathrm{O}^{[\mathbb{M}]} 4 \%\right)}
$$

where the difference of one-half per cent in the rate of interest represents the deduction to be made in respect of the $10 \mathrm{~s}$. per annum of bonus. Of course the exact difference in the rates of interest should depend upon the circumstances of the particular Office; the above formula being given merely as an illustration. It will be noticed that this method, though arrived at by a different process, is in principle the same as that suggested by Mr. G. F. Hardy, namely, to reduce the surrender value by increasing the rate of interest used in the calculation thereof.

If, during the currency of the original contract, the profits have exceeded the anticipated rate, the sum assured will have been increased by bonuses, or the premiums will have been further diminished. The amount of such bonuses, or the reversionary equivalent of such further reduction of future premiums, should be added to the paid-up policy given by the above formula. On the other hand, if it should happen that the profits fall short of the anticipated rate, and the sum assured has to be reduced, or the premiums increased, the paid-up policy would have to be diminished to a corresponding extent. 


\section{MINIMUM PAID-UP POLICIES.}

As it would cause a great deal of trouble to have a large number of paid-up policies for trifling amounts placed on the books of an Office, I think it is a good rule to fix upon a minimum sum below which no paid-up policy will be granted. Some Offices fix this limit at $£ 50$, but I am inclined to think this is rather too high, and would suggest $£ 25$ or even $£ 20$. If it were smaller than this, it is very doubtful whether the results would repay the extra trouble involved. There would be a likelihood of such policies being in some cases overlooked by the holders owing to their insignificance, or of the relatives thinking the amount too small to be worth the trouble and expense of taking out a grant of representation, so that a number of them might remain on the books of the Office loug after the deaths of the assured.

\section{PAID-UP POLICY COMPARED WITH PREMIUMS PAID.}

One Office guarantees a paid-up policy without profits, for an amount equal to the premiums paid, plus any existing bonus additions, provided that the assurance has been in force for at least five years, that at least $£ 20$ has been paid in premiums, and that the age of the assured does not exceed 60 years. No statement is made regarding its practice in cases where this age limit is exceeded. This system was investigated by Dr. T. B. Sprague in 1857 (J. I. $A$., vii, 58), and he showed that, according to the tables then in use, it gave too liberal values when the age at entry exceeded 50 years; and it will be seen from Table B that when the age at entry exceeds 40 , it gives larger values for whole-life assurances than those now proposed by me, while for younger ages it gives less, the difference being in many cases of substantial amount. Therefore, although the method has the advantage of simplicity, I do not think it can be recommended for general adoption.

\section{SURRENDER VALUES.}

\section{NON-PARTICIPATING PAID-UP POLICIES.}

It appears to me that the surrender of a policy is virtually the purchase by the Office of a thoroughly well-secured absolute 


\section{Paid-up Policies and Surrender Values}

reversion free from liability to estate duty or expenses of realisation, the amount of the reversion being the amount of the paid-up policy that the Office would allow in lieu of the original assurance. On this footing the rate of interest used in the calculation should be an investment rate approximating to the market rate for such transactions, which is probably about $4 \frac{1}{2} \%$, or possibly a little less. My own view is that $4 \frac{1}{2} \%$ is a suitable rate to employ ; but as some may consider the values brought out on this basis to be rather too low, I have calculated corresponding values on a $4 \%$ basis in order to exhibit the effect of using a lower rate of interest. (See Tables J-S.)

For the reasons given above, and because the mortality among lifetenants is known to be light (see the paper by Mr. Neil Campbell, T. F. A., vol. i. p. 79), I think the Office should assume that the assured are still "select" lives at the date of surrender, and that their mortality will not exceed that shown by the $\mathrm{O}^{[\mathrm{M}]}$ table. That is to say, I propose that the surrender value should be equal to the paid-up policy as found by the above rules, multiplied by the appropriate net Single Premium according to the $\mathrm{O}^{[\mathrm{M}]}$ tables with $4 \frac{1}{2} \%$ interest; and $I$ append tables of $A_{[x]}$ and $A_{[x]: \bar{r} ;}$ on this basis which have been calculated by Mr. J. A. Rankin (Appendix I.). It will be noticed that this rule gives the same cash value for a paid-up non-participating policy as for an equal amount of simple bonus, and this appears to me to be correct since the two benefits are identical. Some authorities have held the view that a higher cash value should be allowed in the latter case, on the ground that the policyholder is only drawing out his share of the accrued profits and not terminating his connection with the Office: but $I$ have never been able to satisfy myself of the validity of this plea.

The following Tables, then, show the Surrender Values (excluding bonus) of Whole-life, Limited Payment and Endowment Assurance Policies for 1000 each, deduced from the abovementioned Paid-up Policies on the bases of $\mathrm{O}^{\mathrm{rm}}$ " select" mortality and interest at $4 \frac{1}{2}$ per cent and 4 per cent per annum; compared with the $\mathrm{O}^{\mathrm{M}} 3$ per cent Net Values of the original assurances, and (in the case of Limited-Payment and Endowment Assurance Policies) with the $\mathrm{O}^{\mathrm{M}} 3$ per cent net values of the corresponding "proportionate" paid-up policies. 
SURRENDER VALUES OF POLICIRS FOR 1000

TaBle J.-Whole Life-Whole-Life Premiums.

\begin{tabular}{|c|c|c|c|c|c|c|c|c|}
\hline \multirow{3}{*}{ Durstion. } & \multicolumn{4}{|c|}{ Age at entry ro. } & \multicolumn{4}{|c|}{ Age at entry 20.} \\
\hline & \multirow{2}{*}{$\begin{array}{l}\mathbf{O}^{\mathcal{M}} \mathbf{3} \% \\
\text { Reserve. }\end{array}$} & \multicolumn{2}{|c|}{ Surrender Value } & \multirow{2}{*}{$\begin{array}{c}\text { Total } \\
\text { Premiums } \\
\text { paid. }\end{array}$} & \multirow{2}{*}{$\begin{array}{r}\text { OM 3\% } \\
\text { Reserve }\end{array}$} & \multicolumn{2}{|c|}{ Surrender Value } & \multirow{2}{*}{$\begin{array}{l}\text { Total } \\
\text { Premiums } \\
\text { paid. }\end{array}$} \\
\hline & & $4 \frac{1}{2} \%$ & $4 \%$ & & & $4 \frac{1}{2} \%$ & $4 \%$ & \\
\hline $\begin{array}{l}5 \\
10 \\
15 \\
20 \\
30 \\
40 \\
50 \\
60 \\
70 \\
80 \\
90\end{array}$ & \begin{tabular}{|r}
$35 \cdot 8$ \\
76.5 \\
$121 \cdot 9$ \\
$171 \cdot 6$ \\
$283 \cdot 4$ \\
413.5 \\
556.5 \\
$695 \cdot 7$ \\
811.3 \\
$891 \cdot 2$ \\
$939 \cdot 6$
\end{tabular} & $\begin{array}{r}13 \cdot 6 \\
34 \cdot 0 \\
59 \cdot 4 \\
90 \cdot 8 \\
173 \cdot 9 \\
287 \cdot 4 \\
431 \cdot 5 \\
574 \cdot 5 \\
709 \cdot 3 \\
814 \cdot 0 \\
885 \cdot 5\end{array}$ & $\begin{array}{r}15 \cdot 8 \\
39 \cdot 1 \\
68 \cdot 0 \\
103 \cdot 1 \\
193 \cdot 5 \\
312 \cdot 7 \\
459 \cdot 2 \\
599 \cdot 7 \\
729 \cdot 4 \\
826 \cdot 1 \\
894 \cdot 8\end{array}$ & $\begin{array}{r}65 \\
131 \\
196 \\
262 \\
393 \\
524 \\
655 \\
785 \\
916 \\
1047 \\
1178\end{array}$ & \begin{tabular}{|}
$49 \cdot 2$ \\
$103 \cdot 0$ \\
$161 \cdot 1$ \\
$224 \cdot 0$ \\
$364 \cdot 9$ \\
$519 \cdot 8$ \\
$670 \cdot 5$ \\
$795 \cdot 7$ \\
$882 \cdot 1$ \\
$934 \cdot 6$
\end{tabular} & \begin{tabular}{|r|}
$21 \cdot 3$ \\
$53 \cdot 0$ \\
$91 \cdot 8$ \\
$138 \cdot 8$ \\
$256 \cdot 1$ \\
$400 \cdot 9$ \\
$555 \cdot 5$ \\
$696 \cdot 3$ \\
$805 \cdot 5$ \\
$880 \cdot 0$
\end{tabular} & $\begin{array}{r}24 \cdot 4 \\
60 \cdot 2 \\
103 \cdot 2 \\
154 \cdot 4 \\
278 \cdot 6 \\
426 \cdot 6 \\
579 \cdot 8 \\
716 \cdot 0 \\
819 \cdot 5 \\
889 \cdot 3\end{array}$ & $\begin{array}{r}80 \\
160 \\
240 \\
320 \\
480 \\
640 \\
800 \\
960 \\
1120 \\
1280\end{array}$ \\
\hline \multirow[b]{2}{*}{$\begin{array}{r}5 \\
10 \\
15 \\
20 \\
30 \\
40 \\
50 \\
60 \\
70\end{array}$} & \multicolumn{4}{|c|}{ Age at entry 30.} & \multicolumn{4}{|c|}{ Age at entry 40.} \\
\hline & $\begin{array}{r}64 \cdot 9 \\
135 \cdot 0 \\
210 \cdot 8 \\
292 \cdot 0 \\
464 \cdot 6 \\
632 \cdot 7 \\
772 \cdot 2 \\
868 \cdot 6 \\
927 \cdot 1\end{array}$ & $\begin{array}{r}32 \cdot 9 \\
82 \cdot 0 \\
139 \cdot 6 \\
206 \cdot 0 \\
360 \cdot 0 \\
524 \cdot 6 \\
675 \cdot 7 \\
792 \cdot 8 \\
871 \cdot 9\end{array}$ & $\begin{array}{r}37 \cdot 0 \\
91 \cdot 3 \\
153 \cdot 6 \\
224 \cdot 2 \\
383 \cdot 1 \\
547 \cdot 6 \\
694 \cdot 7 \\
806 \cdot 6 \\
881 \cdot 0\end{array}$ & $\begin{array}{r}103 \\
207 \\
310 \\
413 \\
620 \\
827 \\
1034 \\
1240 \\
1447\end{array}$ & $\begin{array}{r}87 \cdot 7 \\
181 \cdot 6 \\
280 \cdot 3 \\
381 \cdot 1 \\
575 \cdot 4 \\
736 \cdot 7 \\
848 \cdot 1 \\
915 \cdot 7\end{array}$ & $\begin{array}{r}50 \cdot 8 \cdot \\
122 \cdot 9 \\
204 \cdot 2 \\
291 \cdot 6 \\
474 \cdot 6 \\
641 \cdot 2 \\
770 \cdot 7 \\
858 \cdot 3\end{array}$ & $\begin{array}{r}55 \cdot 9 \\
133 \cdot 8 \\
219 \cdot 7 \\
310 \cdot 3 \\
495 \cdot 4 \\
659 \cdot 3 \\
784 \cdot 1 \\
867 \cdot 3\end{array}$ & $\begin{array}{r}142 \\
284 \\
415 \\
567 \\
851 \\
1134 \\
1418 \\
1701\end{array}$ \\
\hline \multirow{3}{*}{$\begin{array}{r}5 \\
10 \\
15 \\
20 \\
30 \\
40 \\
50\end{array}$} & \multicolumn{4}{|c|}{ Age at entry 50.} & \multicolumn{4}{|c|}{ Age at entry 60 . } \\
\hline & \begin{tabular}{|l}
$120 \cdot 6$ \\
$243 \cdot 8$ \\
$365 \cdot 5$ \\
$481 \cdot 2$ \\
$678 \cdot 3$ \\
$814 \cdot 4$ \\
$897 \cdot 0$
\end{tabular} & $\begin{array}{r}75 \cdot 3 \\
1765 \\
282 \cdot 9 \\
388 \cdot 5 \\
583 \cdot 1 \\
734 \cdot 1 \\
835 \cdot 6\end{array}$ & $\begin{array}{r}81 \cdot 0 \\
187.8 \\
298 \cdot 0 \\
405 \cdot 5 \\
599.5 \\
\mathbf{7 4 6 . 9} \\
844.3\end{array}$ & $\begin{array}{r}207 \\
414 \\
620 \\
827 \\
1241 \\
1654 \\
2068\end{array}$ & \begin{tabular}{|c|}
$161 \cdot 0$ \\
$313 \cdot 9$ \\
$453 \cdot 3$ \\
$574 \cdot 6$ \\
$754 \cdot 6$ \\
$863 \cdot 8$
\end{tabular} & \begin{tabular}{|l}
$105 \cdot 9$ \\
$238 \cdot 0$ \\
$364 \cdot 7$ \\
$476 \cdot 7$ \\
$669 \cdot 6$ \\
$794 \cdot 8$
\end{tabular} & $\begin{array}{l}111 \cdot 5 \\
248 \cdot 4 \\
377 \cdot 6 \\
490 \cdot 2 \\
681 \cdot 2 \\
803 \cdot 1\end{array}$ & $\begin{array}{r}321 \\
642 \\
963 \\
1283 \\
1925 \\
2567\end{array}$ \\
\hline & \multicolumn{4}{|c|}{ Age at entry 70.} & \multicolumn{4}{|c|}{ Age at entry 75} \\
\hline $\begin{array}{r}5 \\
10 \\
15 \\
20 \\
25 \\
30\end{array}$ & \begin{tabular}{|l|}
$203 \cdot 1$ \\
$379 \cdot 9$ \\
$526 \cdot 6$ \\
$642 \cdot 3$ \\
$728 \cdot 3$ \\
$801 \cdot 4$
\end{tabular} & $\begin{array}{l}137 \cdot 7 \\
296 \cdot 1 \\
434 \cdot 6 \\
551 \cdot 5 \\
647 \cdot 2 \\
722 \cdot 2\end{array}$ & $\begin{array}{l}142 \cdot 6 \\
304 \cdot 5 \\
444 \cdot 2 \\
561 \cdot 0 \\
656 \cdot 0 \\
729 \cdot 7\end{array}$ & $\begin{array}{r}527 \\
1055 \\
1582 \\
2110 \\
2637 \\
3164\end{array}$ & $\begin{array}{l}221 \cdot 9 \\
406 \cdot 0 \\
551 \cdot 1 \\
659 \cdot 1 \\
750 \cdot 8\end{array}$ & \begin{tabular}{|l}
151.5 \\
318.6 \\
$459 \cdot 7$ \\
574.9 \\
665.0
\end{tabular} & \begin{tabular}{|l|}
$155 \cdot 8$ \\
$325 \cdot 7$ \\
$467 \cdot 7$ \\
$582 \cdot 7$ \\
$672 \cdot 0$
\end{tabular} & $\begin{array}{r}688 \\
1377 \\
2065 \\
2754 \\
3442\end{array}$ \\
\hline
\end{tabular}




\section{$230 \quad$ Paid-up Policies and Surrender Vaimes}

TABLE K.-Whole Life-10 Payments.

\begin{tabular}{|c|c|c|c|c|c|c|c|c|}
\hline \multirow{3}{*}{$\begin{array}{l}\text { Dura- } \\
\text { tion. }\end{array}$} & \multicolumn{4}{|c|}{ Age at entry 20 . } & \multicolumn{4}{|c|}{ Age at entry 30.} \\
\hline & \multicolumn{2}{|c|}{$0^{M} 3 \%$ net value of } & \multicolumn{2}{|c|}{ Surrender Value } & \multicolumn{2}{|c|}{ ON $8 \%$ net value of } & \multicolumn{2}{|c|}{ Surrender Value } \\
\hline & $\begin{array}{c}\text { Original } \\
\text { Policy. }\end{array}$ & $\begin{array}{l}\text { Propor. } \\
\text { tionate } \\
\text { Paid-up } \\
\text { Policy. }\end{array}$ & $4 \frac{1}{2} \%$ & $4 \%$ & $\begin{array}{l}\text { Original } \\
\text { Policy. }\end{array}$ & $\begin{array}{l}\text { Propor- } \\
\text { tionate } \\
\text { Paid-up } \\
\text { Policy. }\end{array}$ & $4 \frac{1}{2} \%$ & $4 \%$ \\
\hline $\begin{array}{l}1^{*} \\
2 \\
3 \\
4 \\
5 \\
6 \\
7 \\
8 \\
9\end{array}$ & $\begin{array}{r}\mathbf{3 3} \\
\mathbf{6 7} \\
\mathbf{1 0 2} \\
\mathbf{1 3 8} \\
\mathbf{1 7 6} \\
\mathbf{2 1 4} \\
\mathbf{2 5 4} \\
\mathbf{2 9 5} \\
\mathbf{3 3 7}\end{array}$ & $\begin{array}{r}\mathbf{3 2} \\
\mathbf{6 5} \\
\mathbf{9 9} \\
\mathbf{1 3 4} \\
\mathbf{1 7 2} \\
\mathbf{2 1 0} \\
\mathbf{2 5 1} \\
\mathbf{2 9 2} \\
\mathbf{3 3 6}\end{array}$ & $\begin{array}{r}21 \\
42 \\
65 \\
88 \\
113 \\
139 \\
166 \\
194 \\
220\end{array}$ & $\begin{array}{r}24 \\
49 \\
74 \\
102 \\
130 \\
159 \\
190 \\
221 \\
255\end{array}$ & $\begin{array}{r}40 \\
82 \\
124 \\
168 \\
214 \\
261 \\
309 \\
359 \\
411\end{array}$ & $\begin{array}{r}39 \\
79 \\
121 \\
165 \\
210 \\
257 \\
306 \\
357 \\
410\end{array}$ & $\begin{array}{r}26 \\
54 \\
82 \\
112 \\
144 \\
178 \\
212 \\
249 \\
287\end{array}$ & $\begin{array}{r}\mathbf{3 0} \\
\mathbf{6 1} \\
\mathbf{9 3} \\
\mathbf{1 2 7} \\
\mathbf{1 6 2} \\
\mathbf{1 9 9} \\
\mathbf{2 3 8} \\
\mathbf{2 7 8} \\
\mathbf{3 2 0}\end{array}$ \\
\hline & & ge at e & $\operatorname{try} 40$ & & & ge at & try 5 & \\
\hline $\begin{array}{l}I^{*} \\
2 \\
3 \\
4 \\
5 \\
6 \\
7 \\
8 \\
9\end{array}$ & $\begin{array}{r}48 \\
98 \\
149 \\
202 \\
257 \\
314 \\
372 \\
433 \\
496\end{array}$ & $\begin{array}{r}47 \\
97 \\
148 \\
200 \\
256 \\
313 \\
372 \\
433 \\
496\end{array}$ & $\begin{array}{r}34 \\
69 \\
106 \\
145 \\
187 \\
230 \\
275 \\
322 \\
372\end{array}$ & $\begin{array}{r}37 \\
77 \\
118 \\
160 \\
205 \\
252 \\
301 \\
352 \\
405\end{array}$ & $\begin{array}{r}57 \\
115 \\
176 \\
238 \\
303 \\
370 \\
440 \\
513 \\
589\end{array}$ & $\begin{array}{r}57 \\
116 \\
178 \\
241 \\
307 \\
375 \\
445 \\
517 \\
591\end{array}$ & $\begin{array}{r}43 \\
89 \\
137 \\
187 \\
240 \\
295 \\
352 \\
411 \\
473\end{array}$ & $\begin{array}{r}47 \\
97 \\
148 \\
202 \\
258 \\
316 \\
377 \\
440 \\
505\end{array}$ \\
\hline & & ge at e & try 60 & & & ge at & itry 7 & \\
\hline $\begin{array}{l}1^{*} \\
2 \\
3 \\
4 \\
5 \\
6 \\
7 \\
8 \\
9\end{array}$ & $\begin{array}{r}64 \\
129 \\
197 \\
268 \\
341 \\
418 \\
498 \\
583 \\
675\end{array}$ & $\begin{array}{r}68 \\
138 \\
210 \\
284 \\
\mathbf{3 6 1} \\
\mathbf{4 3 9} \\
520 \\
602 \\
686\end{array}$ & $\begin{array}{r}55 \\
112 \\
172 \\
234 \\
299 \\
366 \\
\mathbf{4 3 5} \\
506 \\
581\end{array}$ & $\begin{array}{r}58 \\
119 \\
182 \\
247 \\
315 \\
385 \\
456 \\
531 \\
608\end{array}$ & $\begin{array}{r}66 \\
133 \\
203 \\
275 \\
352 \\
434 \\
523 \\
621 \\
731\end{array}$ & $\begin{array}{r}78 \\
158 \\
240 \\
324 \\
409 \\
496 \\
585 \\
674 \\
766\end{array}$ & $\begin{array}{r}67 \\
136 \\
207 \\
281 \\
357 \\
435 \\
514 \\
596 \\
680\end{array}$ & $\begin{array}{r}70 \\
142 \\
216 \\
291 \\
369 \\
449 \\
531 \\
615 \\
700\end{array}$ \\
\hline
\end{tabular}

* It is not proposed to allow a paid.up policy or surrender value until two years' premiums are paid, and these values are merely inserted for the sake of completeness. 
Paid-up Policies and Surrender Values

TABLE L. - Whole Life-20 Payments.

\begin{tabular}{|c|c|c|c|c|c|c|c|c|}
\hline \multirow{3}{*}{$\begin{array}{l}\text { Dura- } \\
\text { tion. }\end{array}$} & \multicolumn{4}{|c|}{ Age at entry 20.} & \multicolumn{4}{|c|}{ Age at entry 30.} \\
\hline & \multicolumn{2}{|c|}{ ON $3 \%$ net value of } & \multicolumn{2}{|c|}{ Surrender Value } & \multicolumn{2}{|c|}{ OM $3 \%$ net value of } & \multicolumn{2}{|c|}{ Surrender Value } \\
\hline & $\begin{array}{l}\text { Original } \\
\text { Policy. }\end{array}$ & $\begin{array}{l}\text { Propor- } \\
\text { tionate } \\
\text { Paid-up } \\
\text { Poliey. }\end{array}$ & $4 \frac{1}{2} \%$ & $4 \%$ & $\begin{array}{l}\text { Original } \\
\text { Policy. }\end{array}$ & $\begin{array}{l}\text { Propor- } \\
\text { tionate } \\
\text { Paid-up } \\
\text { Policy. }\end{array}$ & $4 \frac{1}{2} \%$ & $4 \%$ \\
\hline $\begin{array}{r}2 \\
4 \\
6 \\
8 \\
10 \\
12 \\
14 \\
16 \\
18\end{array}$ & $\begin{array}{r}36 \\
74 \\
114 \\
156 \\
201 \\
247 \\
297 \\
349 \\
405\end{array}$ & $\begin{array}{r}32 \\
67 \\
105 \\
146 \\
190 \\
238 \\
289 \\
343 \\
402\end{array}$ & $\begin{array}{r}21 \\
44 \\
70 \\
97 \\
128 \\
161 \\
197 \\
237 \\
280\end{array}$ & $\begin{array}{r}24 \\
51 \\
80 \\
111 \\
145 \\
181 \\
222 \\
266 \\
313\end{array}$ & $\begin{array}{r}44 \\
89 \\
137 \\
188 \\
241 \\
298 \\
358 \\
421 \\
489\end{array}$ & $\begin{array}{r}40 \\
83 \\
129 \\
179 \\
232 \\
289 \\
351 \\
417 \\
487\end{array}$ & $\begin{array}{r}27 \\
56 \\
89 \\
125 \\
164 \\
207 \\
254 \\
306 \\
363\end{array}$ & $\begin{array}{r}30 \\
63 \\
100 \\
139 \\
183 \\
229 \\
281 \\
336 \\
396\end{array}$ \\
\hline & \multicolumn{4}{|c|}{ Age at entry 40.} & \multicolumn{4}{|c|}{ Age at entry 50.} \\
\hline $\begin{array}{r}2 \\
4 \\
6 \\
8 \\
10 \\
12 \\
14 \\
16 \\
18\end{array}$ & $\begin{array}{r}52 \\
107 \\
164 \\
224 \\
288 \\
355 \\
425 \\
501 \\
581\end{array}$ & $\begin{array}{r}48 \\
100 \\
156 \\
216 \\
2081 \\
349 \\
422 \\
500 \\
582\end{array}$ & $\begin{array}{r}35 \\
73 \\
115 \\
161 \\
212 \\
267 \\
328 \\
393 \\
463\end{array}$ & $\begin{array}{r}38 \\
80 \\
126 \\
176 \\
231 \\
289 \\
353 \\
421 \\
495\end{array}$ & $\begin{array}{r}62 \\
126 \\
193 \\
262 \\
335 \\
410 \\
490 \\
575 \\
668\end{array}$ & $\begin{array}{r}58 \\
121 \\
188 \\
259 \\
334 \\
414 \\
498 \\
586 \\
677\end{array}$ & $\begin{array}{r}45 \\
94 \\
147 \\
206 \\
269 \\
337 \\
410 \\
\mathbf{4 8 8} \\
\mathbf{5 7 0}\end{array}$ & $\begin{array}{r}48 \\
101 \\
158 \\
220 \\
286 \\
357 \\
433 \\
513 \\
598\end{array}$ \\
\hline & \multicolumn{4}{|c|}{ Age at entry 60.} & & & & \\
\hline $\begin{array}{r}2 \\
4 \\
6 \\
8 \\
10 \\
12 \\
14 \\
16 \\
18\end{array}$ & $\begin{array}{r}73 \\
147 \\
220 \\
295 \\
371 \\
450 \\
532 \\
623 \\
728\end{array}$ & $\begin{array}{r}69 \\
142 \\
220 \\
301 \\
386 \\
470 \\
567 \\
662 \\
759\end{array}$ & $\begin{array}{r}56 \\
117 \\
183 \\
254 \\
329 \\
408 \\
492 \\
\mathbf{5 7 9} \\
671\end{array}$ & $\begin{array}{r}60 \\
124 \\
192 \\
266 \\
343 \\
425 \\
510 \\
599 \\
691\end{array}$ & & & & \\
\hline
\end{tabular}




\section{Paid-up Policies and Surrender Values}

Table M.-Whole Life-30 Payments.

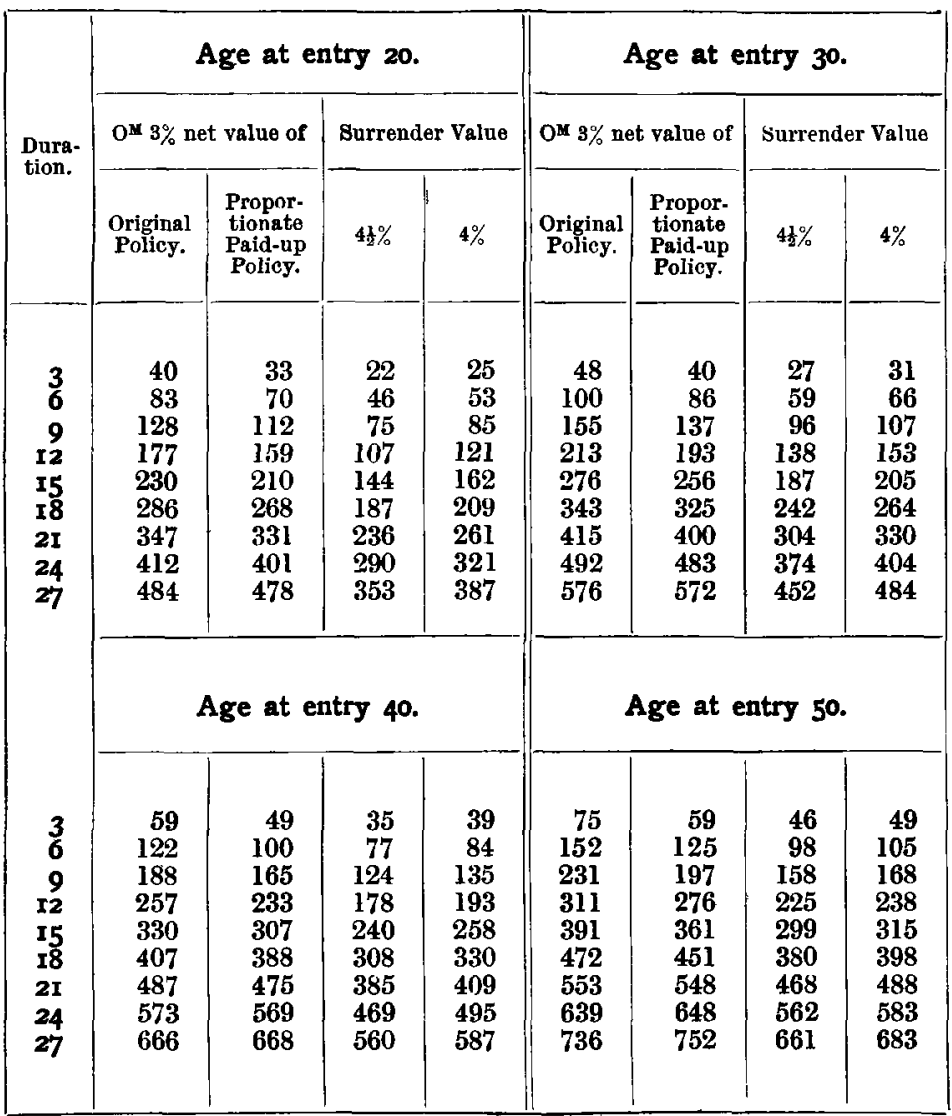


TABLE N._Endowment Assurances-10 Years.

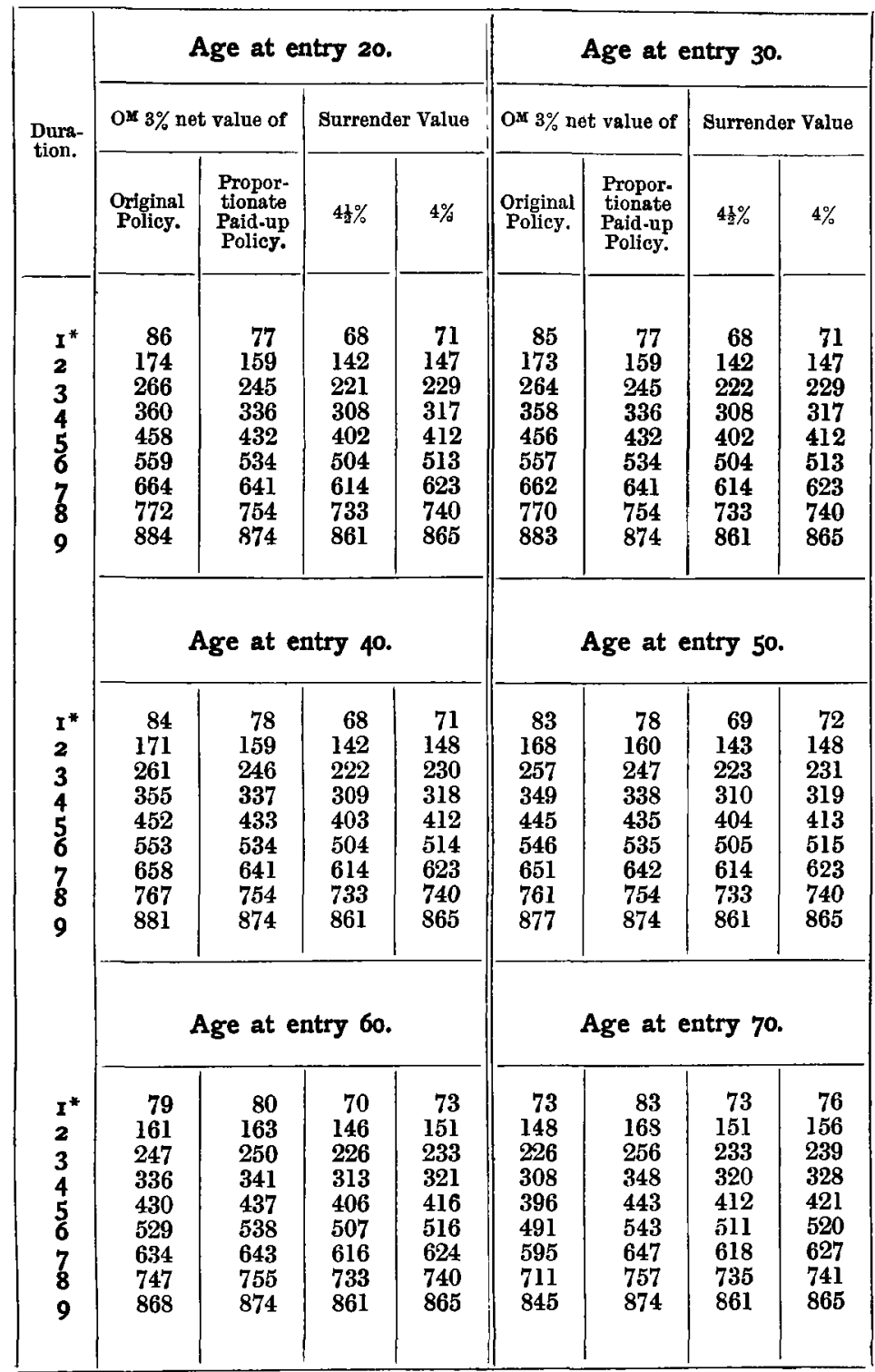

* It is not proposed to allow a paid-up policy or surrender value until two years' premiums are paid, and these values are merely inserted for the sake of completeness.

VOL. III. 
234 Paid-up Policies and Surrender Values

TABLE O.-Endowment Assurances-20 Years.

\begin{tabular}{|c|c|c|c|c|c|c|c|c|}
\hline \multirow{3}{*}{$\begin{array}{l}\text { Dura- } \\
\text { tion. }\end{array}$} & \multicolumn{4}{|c|}{ Age at entry 20.} & \multicolumn{4}{|c|}{ Age at entry 30 . } \\
\hline & \multicolumn{2}{|c|}{ OM $3 \%$ net value of } & \multicolumn{2}{|c|}{ Surrender Value } & \multicolumn{2}{|c|}{$0^{\mathrm{M}} 8 \%$ net value of } & \multicolumn{2}{|c|}{ Surrender Value } \\
\hline & $\begin{array}{l}\text { Original } \\
\text { Policy. }\end{array}$ & $\begin{array}{c}\text { Propor- } \\
\text { tionate } \\
\text { Paid-up } \\
\text { Policy. }\end{array}$ & $4 \frac{1}{2} \%$ & $4 \%$ & $\begin{array}{l}\text { Original } \\
\text { Policy. }\end{array}$ & $\begin{array}{l}\text { Propor- } \\
\text { tionate } \\
\text { Paid-up } \\
\text { Poliey. }\end{array}$ & $4 \frac{1}{2} \%$ & $4 \%$ \\
\hline $\begin{array}{r}2 \\
4 \\
6 \\
8 \\
10 \\
12 \\
14 \\
16 \\
18\end{array}$ & $\begin{array}{r}\mathbf{7 4} \\
152 \\
\mathbf{2 3 5} \\
\mathbf{3 2 4} \\
\mathbf{4 1 8} \\
\mathbf{5 1 9} \\
\mathbf{6 2 7} \\
\mathbf{7 4 2} \\
\mathbf{8 6 6}\end{array}$ & $\begin{array}{r}60 \\
127 \\
202 \\
284 \\
376 \\
477 \\
588 \\
712 \\
848\end{array}$ & $\begin{array}{r}48 \\
103 \\
167 \\
240 \\
326 \\
425 \\
540 \\
672 \\
824\end{array}$ & $\begin{array}{r}52 \\
110 \\
177 \\
254 \\
342 \\
441 \\
555 \\
685 \\
832\end{array}$ & $\begin{array}{r}73 \\
151 \\
233 \\
321 \\
414 \\
515 \\
622 \\
738 \\
864\end{array}$ & $\begin{array}{r}61 \\
129 \\
204 \\
286 \\
378 \\
478 \\
590 \\
713 \\
848\end{array}$ & $\begin{array}{r}48 \\
104 \\
168 \\
242 \\
328 \\
426 \\
540 \\
672 \\
824\end{array}$ & $\begin{array}{r}52 \\
111 \\
179 \\
256 \\
343 \\
\mathbf{4 4 3} \\
556 \\
685 \\
832\end{array}$ \\
\hline & \multicolumn{4}{|c|}{ Age at entry 40.} & \multicolumn{4}{|c|}{ Age at entry 50.} \\
\hline $\begin{array}{r}2 \\
4 \\
6 \\
8 \\
10 \\
12 \\
14 \\
16 \\
18\end{array}$ & $\begin{array}{r}72 \\
149 \\
231 \\
317 \\
410 \\
509 \\
616 \\
732 \\
859\end{array}$ & $\begin{array}{r}63 \\
131 \\
207 \\
290 \\
381 \\
\mathbf{4 8 1} \\
\mathbf{5 9 2} \\
\mathbf{7 1 4} \\
\mathbf{8 4 9}\end{array}$ & $\begin{array}{r}50 \\
106 \\
171 \\
246 \\
331 \\
429 \\
543 \\
673 \\
825\end{array}$ & $\begin{array}{r}53 \\
114 \\
182 \\
259 \\
346 \\
445 \\
558 \\
686 \\
833\end{array}$ & $\begin{array}{r}73 \\
150 \\
231 \\
316 \\
405 \\
501 \\
605 \\
720 \\
849\end{array}$ & $\begin{array}{r}66 \\
137 \\
214 \\
298 \\
390 \\
489 \\
597 \\
718 \\
850\end{array}$ & $\begin{array}{r}53 \\
112 \\
179 \\
254 \\
340 \\
437 \\
548 \\
676 \\
825\end{array}$ & $\begin{array}{r}\mathbf{5 6} \\
\mathbf{1 1 9} \\
\mathbf{1 8 9} \\
\mathbf{2 6 7} \\
\mathbf{3 5 4} \\
\mathbf{4 5 2} \\
\mathbf{5 6 3} \\
\mathbf{6 8 9} \\
\mathbf{8 3 3}\end{array}$ \\
\hline & \multicolumn{4}{|c|}{ Age at entry 60.} & & & & \\
\hline $\begin{array}{r}2 \\
4 \\
6 \\
8 \\
10 \\
12 \\
14 \\
16 \\
18\end{array}$ & $\begin{array}{r}77 \\
155 \\
234 \\
316 \\
400 \\
488 \\
585 \\
694 \\
827\end{array}$ & $\begin{array}{r}71 \\
147 \\
228 \\
315 \\
406 \\
504 \\
609 \\
724 \\
851\end{array}$ & $\begin{array}{r}59 \\
124 \\
194 \\
272 \\
358 \\
453 \\
560 \\
682 \\
827\end{array}$ & $\begin{array}{r}62 \\
130 \\
203 \\
283 \\
371 \\
467 \\
573 \\
694 \\
834\end{array}$ & & & & \\
\hline
\end{tabular}


TABLE P._Endowment Assurances-30 Years.

\begin{tabular}{|c|c|c|c|c|c|c|c|c|}
\hline \multirow{3}{*}{$\begin{array}{l}\text { Dura- } \\
\text { tion. }\end{array}$} & \multicolumn{4}{|c|}{ Age at entry 20.} & \multicolumn{4}{|c|}{ Age at entry 30.} \\
\hline & \multicolumn{2}{|c|}{ Ox $3 \%$ net value of } & \multicolumn{2}{|c|}{ Surrender Value } & \multicolumn{2}{|c|}{ OM $3 \%$ net value of } & \multicolumn{2}{|c|}{ Surrender Value } \\
\hline & $\begin{array}{l}\text { Original } \\
\text { Policy. }\end{array}$ & $\begin{array}{l}\text { Propor- } \\
\text { tionate } \\
\text { Paid-up } \\
\text { Policy. }\end{array}$ & $4 \frac{1}{2} \%$ & $4 \%$ & $\begin{array}{l}\text { Original } \\
\text { Policy. }\end{array}$ & $\begin{array}{l}\text { Propor- } \\
\text { tionate } \\
\text { Paid-up } \\
\text { Policy. }\end{array}$ & $4+\frac{1}{2} \%$ & $4 \%$ \\
\hline \multirow[t]{2}{*}{$\begin{array}{r}3 \\
6 \\
9 \\
12 \\
15 \\
18 \\
21 \\
24 \\
27\end{array}$} & $\begin{array}{r}64 \\
134 \\
210 \\
292 \\
382 \\
481 \\
590 \\
712 \\
847\end{array}$ & $\begin{array}{r}49 \\
105 \\
170 \\
245 \\
331 \\
430 \\
543 \\
674 \\
825\end{array}$ & $\begin{array}{r}35 \\
78 \\
129 \\
192 \\
269 \\
363 \\
478 \\
618 \\
789\end{array}$ & $\begin{array}{r}39 \\
86 \\
142 \\
208 \\
\mathbf{2 8 8} \\
\mathbf{3 8 3} \\
\mathbf{4 9 8} \\
635 \\
801\end{array}$ & $\begin{array}{r}65 \\
135 \\
210 \\
292 \\
381 \\
479 \\
587 \\
707 \\
843\end{array}$ & $\begin{array}{r}51 \\
109 \\
175 \\
251 \\
337 \\
435 \\
547 \\
676 \\
825\end{array}$ & $\begin{array}{r}37 \\
81 \\
134 \\
198 \\
275 \\
369 \\
482 \\
620 \\
790\end{array}$ & $\begin{array}{r}41 \\
89 \\
146 \\
213 \\
294 \\
389 \\
502 \\
638 \\
801\end{array}$ \\
\hline & \multicolumn{4}{|c|}{ Age at entry 40.} & \multicolumn{4}{|c|}{ Age at entry 50.} \\
\hline $\begin{array}{r}3 \\
6 \\
9 \\
12 \\
15 \\
18 \\
21 \\
24 \\
27\end{array}$ & $\begin{array}{r}68 \\
140 \\
217 \\
300 \\
388 \\
483 \\
586 \\
702 \\
836\end{array}$ & $\begin{array}{r}54 \\
116 \\
185 \\
262 \\
350 \\
447 \\
558 \\
683 \\
827\end{array}$ & $\begin{array}{r}40 \\
88 \\
144 \\
211 \\
289 \\
382 \\
492 \\
626 \\
792\end{array}$ & $\begin{array}{r}44 \\
96 \\
156 \\
225 \\
306 \\
401 \\
511 \\
643 \\
803\end{array}$ & $\begin{array}{r}78 \\
158 \\
241 \\
325 \\
411 \\
500 \\
593 \\
696 \\
822\end{array}$ & $\begin{array}{r}61 \\
128 \\
203 \\
285 \\
374 \\
472 \\
578 \\
696 \\
832\end{array}$ & $\begin{array}{r}47 \\
102 \\
164 \\
235 \\
316 \\
408 \\
514 \\
639 \\
795\end{array}$ & $\begin{array}{r}51 \\
109 \\
175 \\
249 \\
332 \\
425 \\
531 \\
655 \\
806\end{array}$ \\
\hline
\end{tabular}

TABLE Q.-Endowment Assurances-40 Years.

\begin{tabular}{|c|c|c|c|c|c|c|c|c|}
\hline \multirow[b]{2}{*}{$\begin{array}{r}4 \\
8 \\
12 \\
16 \\
20 \\
24 \\
28 \\
32 \\
36\end{array}$} & \multicolumn{4}{|c|}{ Age at entry 20.} & \multicolumn{4}{|c|}{ Age at entry 30 . } \\
\hline & $\begin{array}{r}58 \\
122 \\
193 \\
270 \\
\mathbf{3 5 6} \\
\mathbf{4 5 2} \\
\mathbf{5 6 1} \\
\mathbf{6 8 4} \\
\mathbf{8 2 7}\end{array}$ & $\begin{array}{r}41 \\
90 \\
149 \\
218 \\
299 \\
395 \\
508 \\
642 \\
803\end{array}$ & $\begin{array}{r}28 \\
63 \\
107 \\
162 \\
231 \\
319 \\
430 \\
572 \\
757\end{array}$ & $\begin{array}{r}32 \\
71 \\
119 \\
178 \\
251 \\
341 \\
453 \\
594 \\
772\end{array}$ & $\begin{array}{r}62 \\
\mathbf{1 3 0} \\
203 \\
282 \\
\mathbf{3 6 9} \\
\mathbf{4 6 4} \\
\mathbf{5 6 8} \\
\mathbf{6 8 5} \\
\mathbf{8 2 3}\end{array}$ & $\begin{array}{r}45 \\
98 \\
159 \\
231 \\
314 \\
411 \\
522 \\
652 \\
806\end{array}$ & $\begin{array}{r}31 \\
70 \\
117 \\
176 \\
248 \\
336 \\
445 \\
582 \\
761\end{array}$ & $\begin{array}{r}35 \\
77 \\
129 \\
191 \\
\mathbf{2 6 7} \\
\mathbf{3 5 7} \\
\mathbf{4 6 7} \\
602 \\
\mathbf{7 7 5}\end{array}$ \\
\hline
\end{tabular}




\section{Paid-up Policies and Surrender Values}

Endowment Assurances-40 Years, continued.

\begin{tabular}{|c|c|c|c|c|c|c|c|c|}
\hline \multirow{3}{*}{$\begin{array}{l}\text { Dura- } \\
\text { tion. }\end{array}$} & \multicolumn{4}{|c|}{ Age at entry 40.} & & & & \\
\hline & \multicolumn{2}{|c|}{$\mathrm{O}^{\mathrm{M}} 3 \%$ net value of } & \multicolumn{2}{|c|}{ Surrender Value } & \multicolumn{2}{|c|}{ OM $3 \%$ net value of } & \multicolumn{2}{|c|}{ Surrender Value } \\
\hline & $\begin{array}{l}\text { Original } \\
\text { Policy. }\end{array}$ & $\begin{array}{c}\text { Propor- } \\
\text { tionate } \\
\text { Paid-up } \\
\text { Policy. }\end{array}$ & $4 \frac{1}{2} \%$ & $4 \%$ & $\begin{array}{l}\text { Original } \\
\text { Policy. }\end{array}$ & $\begin{array}{c}\text { Propor- } \\
\text { tionate } \\
\text { Paid-up } \\
\text { Policy. }\end{array}$ & $4 \frac{1}{2} \%$ & $4 \%$ \\
\hline $\begin{array}{r}4 \\
8 \\
12 \\
16 \\
20 \\
24 \\
28 \\
32 \\
36\end{array}$ & $\begin{array}{r}73 \\
151 \\
234 \\
320 \\
409 \\
501 \\
596 \\
697 \\
819\end{array}$ & $\begin{array}{r}51 \\
110 \\
179 \\
256 \\
344 \\
442 \\
550 \\
672 \\
814\end{array}$ & $\begin{array}{r}37 \\
83 \\
138 \\
203 \\
280 \\
370 \\
476 \\
603 \\
767\end{array}$ & $\begin{array}{r}41 \\
90 \\
149 \\
218 \\
298 \\
390 \\
496 \\
622 \\
780\end{array}$ & & & & \\
\hline
\end{tabular}

TABLE R.-Endowment Assurances-50 Years.

\begin{tabular}{|c|c|c|c|c|c|c|c|c|}
\hline \multirow[b]{2}{*}{$\begin{array}{r}5 \\
10 \\
15 \\
20 \\
25 \\
30 \\
35 \\
40 \\
45\end{array}$} & \multicolumn{4}{|c|}{ Age at entry 20 . } & \multicolumn{4}{|c|}{ Age at entry 30.} \\
\hline & $\begin{array}{r}57 \\
\mathbf{1 2 0} \\
\mathbf{1 8 9} \\
\mathbf{2 6 5} \\
\mathbf{3 5 0} \\
\mathbf{4 4 5} \\
\mathbf{5 5 0} \\
\mathbf{6 7 0} \\
812\end{array}$ & $\begin{array}{r}37 \\
82 \\
\mathbf{1 3 7} \\
204 \\
283 \\
377 \\
489 \\
623 \\
787\end{array}$ & $\begin{array}{r}25 \\
56 \\
96 \\
147 \\
213 \\
297 \\
405 \\
544 \\
731\end{array}$ & $\begin{array}{r}28 \\
63 \\
107 \\
163 \\
233 \\
320 \\
429 \\
567 \\
748\end{array}$ & $\begin{array}{r}67 \\
140 \\
219 \\
305 \\
396 \\
492 \\
591 \\
695 \\
816\end{array}$ & $\begin{array}{r}43 \\
94 \\
156 \\
229 \\
315 \\
413 \\
524 \\
650 \\
798\end{array}$ & $\begin{array}{r}29 \\
67 \\
115 \\
174 \\
248 \\
336 \\
443 \\
572 \\
742\end{array}$ & $\begin{array}{r}33 \\
74 \\
126 \\
189 \\
266 \\
357 \\
464 \\
593 \\
758\end{array}$ \\
\hline
\end{tabular}

TABLe S.-Endowment Assurances-60 Years.

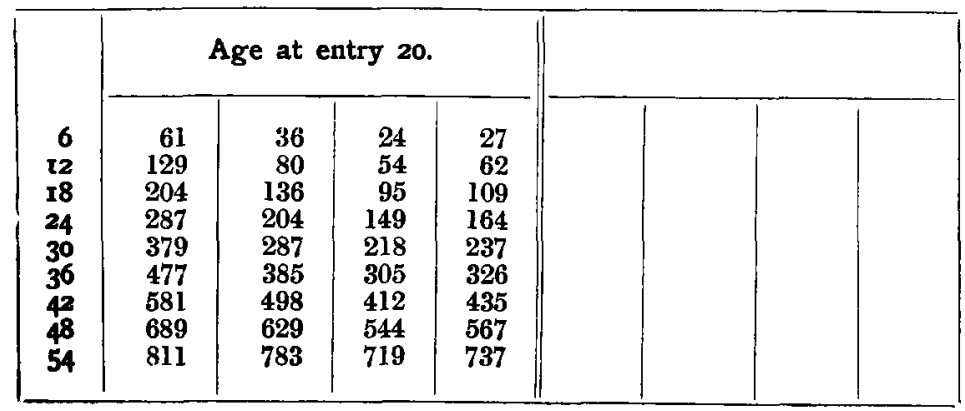


An examination of these tables shows that the proposed surrender values are less than the $0^{\text {MI }} 3$ per cent net values in all whole-life cases; and that the same holds good for limited payment and endowment assurance policies except when the term is 10 years and the age at entry is 70 . In the case of the limitedpayment policies the excess of the proposed surrender value over the reserve is comparatively small, never exceeding $2 \frac{1}{2}$ per cent of the latter, and it disappears after six years. In the endowment assurances the excess is greater, and lasts throughout the whole duration of the policy, but does not exceed 5 per cent of the reserve. Of course, in both cases, if the age at entry were more than 70 years, the excess would be greater. It will also be noticed that in the case of the 50-year endowment assurances, where the age at entry is 30 years, the proposed surrender value is in some cases less than that proposed for a whole-life assurance effected at the same age. These are undoubted defects in the proposed methods; but they are inherent in the system of "proportionate" paid-up policies, and cannot be entirely avoided if that system be adopted. Moreover, the errors are of comparatively small magnitude and of very rare occurrence (as such assurances are seldom effected), and I think, therefore, that any objection to the proposed methods on this account, is far more than outweighed by the great gain in simplicity which the methods secure.

\section{PARTICIPATING PAID-UP POLICIES.}

In cases where the paid-up policy carries the right to future profits (for example, a limited-payment policy with profits on which all the premiums have been paid) a higher value should be given, as the reversion (being an increasing one) is more valuable; and in order to allow for this it is necessary to assume a future rate of bonus. Obviously this should be less than the rate which the Office expects to maintain, as the policyholder, by surrendering, is exchanging a contingent benefit which may never be realised, for a definite and certain sum of cash. There must necessarily be considerable difference of opinion regarding the rate to be assumed for this purpose; but probably most authorities will agree that it should not be much less than one-half nor much more than three-quarters of the rate which the Office is likely to maintain. The exact proportion to be allowed must be largely a matter of opinion, influenced by considerations such as the strength and progress of the Office. Most Offices make an allowance of a somewhat similar nature to this, by 


\section{$238 \quad$ Paid-up Policies and Surrender Values}

granting interim bonuses on policies which become claims between two valuation years; the interim bonus being generally from twothirds to three-fourths of the bonus which the Office expects to declare at its next valuation. In the case of a surrender of the bonuses for the whole future lifetime of a policyholder, it seems to me that a smaller proportion of the estimated bonuses should be allowed than is granted in the case of interim bonus-say, from one-half to two-thirds. Thus, if an Office is likely to maintain a rate of bonus varying between 30 s. and $40 \mathrm{~s}$., I think it might value its purticipating paid-up policies for surrender by treating them as assurances increasing at the rate of, say, 1 per cent per annum; and if the bonus is likely to range between 25s. and $30 \mathrm{~s}$., or $20 \mathrm{~s}$. and $25 \mathrm{~s}$., the rates of increase in the assurance might be taken as, say, $\frac{3}{4}$ per cent and $\frac{1}{2}$ per cent respectively. Having assumed a rate of future bonus, the formulas for valuing such policies as increasing assurances can be readily deduced; but they involve a good deal of work, being rather lengthy and complex. For the sake of simplicity I propose to substitute for the increasing assurance a uniform assurance valued at a lower rate of interest, the difference in the rate of interest being about the same as the rate of future bonus assumed. If the bonus be compounded annually this gives a very close approximation; and an exact value can be obtained by making a slightly larger difference in the rate of interest. Thus, if the assumed rate of bonus be $b$ per unit per annum from the outset, the value of the increasing assurance is $v(1+b) q_{1}+v^{2}(1+b)^{2} q_{2}+v^{3}(1+b)^{3} q_{3}+\ldots$ where $q_{1}, q_{2}, q_{3}$, ... are the probabilities of the assurance becoming payable in the 1st, 2nd, 3rd . . years respectively. Putting $v(1+b)=\frac{1}{1+j}$ this expression becomes $\frac{q_{1}}{1+j}+\frac{q_{2}}{(1+j)^{2}}+\frac{q_{3}}{(1+j)^{3}}+\ldots$ which is the value of a uniform assurance when the rate of interest is $j$.

Now $1+j=\frac{1}{v(1+b)}=\frac{1+i}{1+b}$, therefore $j=\frac{i-b}{1+b}$, and as $b$ will always be small, seldom if ever exceeding 02 , we have very approximately $j=i-b$.

Accordingly the value of such an increasing assurance, at rate of interest $i$, is very nearly equal to the value of a uniform assurance at rate of interest $i-b$, and is exactly equal to the value of a uniform assurance at rate of interest $\frac{i-b}{1+b}$. In practice, bonuses are frequently "simple"; and even when "compound," the compounding does not take place annually, but as a rule only 
once every five years, and the interim bonus is usually at a lower rate, so that the above approximation would tend to place a slightly higher value on a participating policy than would be given by a more exact calculation. The difference, however, is small, as is shown by the following table; and as a substantial margin should be allowed in fixing the assumed rate of future bonus, I think it may safely be disregarded.

\section{TABLE T._Values of Uniform and Increasing Whole-life Assurances of 1 .}

\begin{tabular}{|c|c|c|c|c|c|}
\hline \multirow[b]{2}{*}{ Age. } & \multicolumn{4}{|c|}{ Value by $\mathrm{O}^{[\mathrm{M}]} \mathrm{Table}$ at $4 \frac{1}{2} \%$ interest of } & \multirow{2}{*}{$\begin{array}{c}\begin{array}{c}\text { Value by } O^{[M]} \text { Table at } \\
3 \frac{1}{2} \% \text { interest of }\end{array} \\
\text { Uniform Assurance. } \\
\text { (5) }\end{array}$} \\
\hline & $\begin{array}{c}\text { Uniform } \\
\text { Assurance } \\
\text { (1) }\end{array}$ & $\begin{array}{l}\text { Assurance with } \\
\text { simple bonus } \\
\text { of } 1 \% \text { per } \\
\text { annum. } \\
\text { (2) }\end{array}$ & $\begin{array}{c}\text { Assurance with } \\
\text { bonus of } 1 \% \text { per } \\
\text { annum com- } \\
\text { pounding } \\
\text { annually. } \\
\text { (3) } \\
\end{array}$ & $\begin{array}{c}(3)-(2) \\
(4) \\
\end{array}$ & \\
\hline $\begin{array}{l}10 \\
15 \\
20 \\
25 \\
30 \\
35 \\
40 \\
45 \\
50 \\
55 \\
60 \\
65 \\
70 \\
75 \\
80 \\
85 \\
90 \\
95 \\
100\end{array}$ & $\begin{array}{l}\cdot \mathbf{1 6 8 6 4} \\
\cdot \mathbf{1 8 4 2 3} \\
\cdot 20339 \\
-22677 \\
-25502 \\
\cdot 28865 \\
-32806 \\
\cdot 37322 \\
\cdot 42396 \\
\cdot 47938 \\
\cdot 53807 \\
\cdot 59810 \\
\cdot 65736 \\
\cdot 71364 \\
\cdot 76518 \\
\cdot 81074 \\
\cdot 84971 \\
\cdot 88179 \\
\cdot 90726\end{array}$ & $\begin{array}{l}\cdot 21927 \\
\cdot 23864 \\
\cdot 26174 \\
\cdot 28906 \\
\cdot 32104 \\
\cdot \mathbf{3 5 7 9 6} \\
\cdot 39992 \\
\cdot 44659 \\
\cdot 49748 \\
\cdot 55149 \\
\cdot 60710 \\
\cdot 66248 \\
\cdot 71577 \\
\cdot 76519 \\
\cdot 80947 \\
\cdot 84787 \\
\cdot 88017\end{array}$ & $\begin{array}{r}\cdot 23022 \\
\cdot 24958 \\
\cdot 27255 \\
\cdot 29954 \\
\cdot 33100 \\
\cdot 36719 \\
\cdot 40818 \\
\cdot 45379 \\
\cdot 50346 \\
\cdot 55616 \\
\cdot 61055 \\
\cdot 66482 \\
\cdot 71714 \\
\cdot 76583\end{array}$ & $\begin{array}{l}\cdot 01095 \\
\cdot 01094 \\
\cdot 01081 \\
\cdot 01048 \\
\cdot 00996 \\
\cdot 00923 \\
\cdot 00826 \\
\cdot 00720 \\
\cdot 00598 \\
\cdot 00467 \\
\cdot 00345 \\
\cdot 00234 \\
\cdot 00137 \\
\cdot 00064\end{array}$ & $\begin{array}{c}\cdot 22993 \\
\cdot 24928 \\
\cdot 27224 \\
\cdot 29922 \\
\cdot 33067 \\
\cdot 36686 \\
\cdot 40784 \\
\cdot 45346 \\
\cdot 50314 \\
\cdot 55586 \\
\cdot 61027 \\
\cdot 66456 \\
\cdot 71691 \\
\cdot 76564\end{array}$ \\
\hline
\end{tabular}

It will be noticed that the difference between the values of an assurance with "compound" and with " simple" bonus is greatest at the youngest age, but that even then it is less than 5 per cent of the latter value; and that it steadily decreases throughout life until after age 75 it becomes almost negligible in comparison with the value of the assurance.

Although the above table only gives figures for whole-life assurances, the same principle holds good for endowment assurances; and in the latter case the values of "simple" and "compound " bonuses will be even closer to each other, as the term of 
the assurance is shorter. On these grounds, therefore, I propose that the cash value of a "participating" paid-up policy should be equal to the amount of the policy multiplied by the "select" value of $\mathbf{A}$ according to the $\mathrm{O}^{[\mathrm{M}]}$ table at some such rate of interest as follows :-

If bonus likely to range between $20 \mathrm{~s}$. and $25 \mathrm{~s}$., say 4 per cent.

If bonus likely to range between 25 s. and 30 s, , say $3 \frac{3}{4}$ per cent.

If bonus likely to range between $30 \mathrm{~s}$. and $40 \mathrm{~s}$., say $3 \frac{1}{2}$ per cent.

These figures are given more for the sake of illustrating the method than as indicating the exact rates that should be adopted in practice, and there are circumstances which might render their modification desirable. For example, a compound bonus might (other things being equal) be valued at a slightly lower rate of interest than a simple bonus, in order to make some allowance for the greater intrinsic value of the former.

\section{CASH VALUES OF COMPOUND BONUS.}

Seeing that a compound bonus and a participating paid-up policy of the same Office, and for the same amount, secure identical benefits, I think they should have the same cash values; and I therefore propose that the above rules be applied also to find the cash values of bonuses in Offices dividing their profits on the compound reversionary bonus plan.

\section{DOUBLE ENDOWMENTS.}

The surrender values of these may be got from the "proportionate " paid-up double endowments by a precisely similar method, namely, by multiplying them by the $\mathrm{O}^{[\mathrm{M}]} 4 \frac{1}{2}$ per cent (or 4 per cent) value of $A_{[x]: \bar{n} \mid}+A_{[x]: \bar{n} \mid \cdot}$. It will be found, however, when the date of maturity is approaching, that this gives a cash value in excess of the sum that would be payable if the paid-up double endowment were to become a claim by death. Accordingly, if the rule were to be applied without modification in such cases, any holder of a double-endowment policy who fell into bad health might be able, by surrendering, to obtain a larger sum than his representatives would receive at his death; and there would be a tendency for this option to be exercised. The Office would thus lose part of the profit expected on the transactions of this kind which turn out in its favour; and as this profit is discounted in the calculation of the premium, it might find that this class of 
business resulted in a loss. It would therefore be a wise precaution (in the absence of evidence of health) to limit the amount of cash surrender value to the amount of the assurance portion of the benefit, and to apply the balance, if any, of the value given by the rule, in the purchase of a paid-up endowment. The amount of this endowment should be calculated on the same basis as the surrender value, namely, $\mathrm{O}^{[\mathrm{M}]} 4 \frac{1}{2}$ per cent-not by the use of an Office single premium. Although at first sight it may appear that this is equivalent to granting the endowment at less than cost price, it is easily seen that this view is erroneous; the fact being that a sufficient part of the paid-up double endowment is surrendered on an $\mathrm{O}^{[\mathrm{M}]} 4 \frac{1}{2}$ per cent basis to yield the maximum cash value, and the balance is allowed to remain as a paid-up endowment for a still further reduced amount. For, suppose that the proportionate paid-up policy secures $S$ at death, or $2 S$ on survivance to age $x+n, x$ being the present age, then its cash value by the rule would be $S\left(A_{[x]: \bar{n}}+A_{\left.[x]: \frac{1}{n}\right)}\right)$; and suppose that this value is greater than $S$, say $S+R$. Now, if the endowment assurance portion of the benefit be surrendered for its cash value $S \times A_{[x] ; \bar{n} \mid}$, there remains a pure endowment of $S$ whose cash value is $S \times A_{[x] ; \frac{1}{n}}$, and a part of this pure endowment may also be surrendered so as to bring the total cash value up to $S$ (but not more, unless proof of health be furnished). Therefore the part to be surrendered must have a cash value of $S-S \times A_{[x] ; \bar{n}]}$, and by simple proportion its amount must be $\frac{S-S \times A_{[x] ! \bar{n}]}}{A_{[x]: \bar{n}]}}$. This leaves us (having paid $S$ in cash) with a pure endowment of $\mathbf{S}-\frac{\mathbf{S}-\mathbf{S} \times \mathbf{A}_{[x]: \bar{n}]}}{\left.\mathbf{A}_{[x]} \cdot \frac{1}{n}\right]}$, or $\frac{S\left(A_{[x]: \bar{n}]}+A_{[x] ! \frac{1}{n}}\right)-S}{A_{[x] \cdot \frac{1}{n^{\prime}}}}$ which is equal to $\frac{R}{A_{\left.[x]: \frac{1}{n}\right]}}$, since by hypothesis the first term of the numerator is equal to $S+R$. That is to say, the balance, $R$, of the surrender value, after paying over $S$ in cash, must be cast into reversion by the net $\mathrm{O}^{[M]} 4 \frac{1}{2}$ per cent "select" single premium.

If, however, the policyholder is able to prove to the satisfaction of the Office that the assured is still in good health, there is no objection to paying over the full surrender value in cash when it exceeds the sum that will become payable in the event of death; but it would be well in such a case to require a certificate of health by a competent medical man, his fee, of course, being paid by the policyholder. 


\section{BENEFITS CONTINGENT UPON SURVIVANCE.}

Similar considerations apply to all classes of benefit where the sum payable in the event of survivance exceeds the sum payable in the event of death ; and we may therefore lay down the general principle that unless proof of health be furnished, the cash surrender value should never exceed the latter amount. Apply. ing this principle to endowments, and to deferred assurances and annuities during the period of deferment, we see that when the premiums are returnable in the event of death, the surrender value of these benefits should not exceed the total premiums paid; and therefore the rule adopted by some Offices, of allowing a cash value equal to all the premiums paid after the first year, with interest thereon, will give too large values when the duration of the policy has been long-unless proof of health be insisted upon in such cases. When the premiums on such benefits are not returnable in the event of death, no cash surrender value should be allowed unless proof of health be furnished; but instead thereof, a paid-up policy should be offered. The well-known necessity of requiring proof of health before purchasing a life-interest, or paying a surrender value for a life-annuity, is merely a particular case of this general principle, since the benefit disappears in the event of death, and therefore the cash value should be zero unless proof of health be furnished. Even when such proof is fortheoming, it is perhaps doubtful whether the Office should treat the life as "select" for the purpose of surrender value. If it be accepted as a general principle that policyholders who have any option allowed them will, on the average, exercise it in a manner advantageous to themselves and adverse to the Office, it follows that a withdrawing holder of a "non-returnable" endowment or deferred annuity should not receive the "select" value of his benefit, even if he submits to the most searching medical examination. I propose that the $\mathrm{O}^{\text {(M) }} 4 \frac{1}{2}$ per cent "ultimate" value of the paid-up benefit should be allowed in such a case-this procedure being analogous to that hereafter suggested for adoption in the case of lifeannuities.

\section{ENDOWMENTS, AND DEFERRED ASSURANCES AND ANNUITIES, WITH "RETURNABLE" PREMIUMS.}

It appears to me that the best course to follow in dealing with endowments, and with deferred assurances and annuities during the period of deferment, on which the premiums are returnable, is to adopt some simple arbitrary rule for arriving at the surrender 
value. As there is no mortality risk under such policies, and the initial commission thereon is usually small, it is clear that a considerable proportion of the premiums can safely be refunded on surrender. On the other hand, it appears only fair that such policies should contribute something to the general expenses of obtaining new business, and therefore that in their early years the surrender value should be less than the total premiums paid. In order to secure this, and to follow as closely as possible the principles proposed in the case of whole-life assurances, I propose to leave the first year's premium out of account and to return the remaining premiums on surrender with a small addition for interest; but to limit the surrender value to the total premiums paid. On these principles I have adjusted the following arbitrary scales :-

TABLE U.-Surrender Values of Endowments; and of Deferred Assurances and Annuities before the period of deferment has expiredpremiums "returnable."

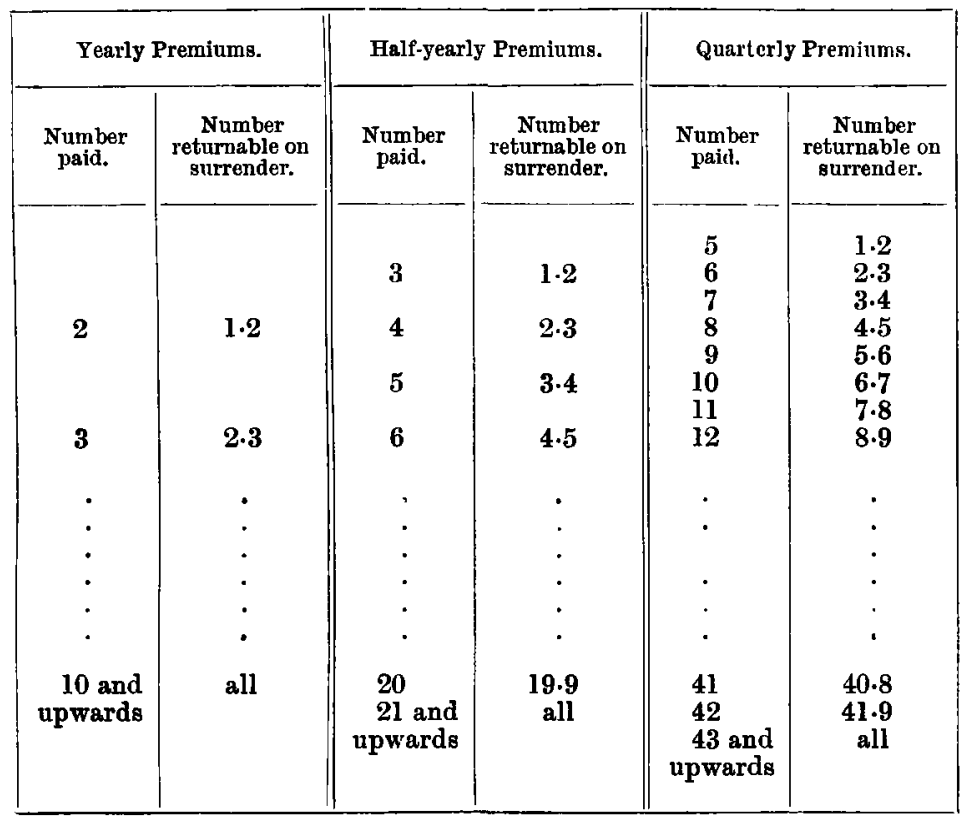

These scales are so constructed as to return a rather smaller proportion of the premiums paid in half-yearly than in yearly cases, and a still smaller proportion if the premiums be payable 


\section{Paid-up Policies and Surrender Values}

quarterly, in order to allow for the additional expense caused by the more frequent collection of premiums, and the loss of interest caused by part of the premiums being deferred for a portion of a year. This may, however, be considered by some to be an unnecessary refinement; and the following rule, which is somewhat simpler, is therefore suggested as an alternative :-

If the duration be less than 11 years, allow all the premiums paid after the first year, increased by 10 per cent.

If the duration be 11 years or more, allow all the premiums paid.

\section{CHILDREN'S DEFERRED ASSURANCES ON, OR AFTER, THE EXPIRY OF THE PERIOD OF DEFERMENT.}

As stated above, these benefits are equivalent to an endowment combined with a deferred assurance; and some Offices allow the option, at the commencement of the assurance, of withdrawing in cash the full amount of the endowment that could have been secured according to their published rates, by the premium that has actually been paid. It seems to me that this gives the holder of such a policy an unfair advantage over the holder of an endowment; and it is obvious that no one would effect an endowment with such an Office if he were aware that for the same premium he could secure an endowment for the same amount, plus the option to continue the policy, after maturity, as an ordinary assurance at a low rate of premium and without medical examination. I therefore think that on surrender at this stage of the contract, some deduction (say 5 per cent) should be made from the amount of the endowment in question. After the expiry of some years the $\mathrm{O}^{[M]} 4 \frac{1}{2}$ per cent "select" value of the paid-up policy as found by the proposed method, will give a larger surrender value; and when this happens, the larger value should be allowed on surrender.

\section{LIFE ANNUITIES.}

The mortality among annuitants is on the whole lighter than that among assured lives, and this fact seems to show that the medical selection by an Office is less effective than the selfselection exercised by persons who buy annuities. Accordingly, when an annuitant proposes to surrender his annuity, and tenders medical evidence that he is in good health, this does not necessarily prove that he is as good a life as a "select" annuitant. The most stringent medical examination may be said to do no more than 
prove that he is as good as a "select" assured life; and the Office might treat the matter on this footing, and calculate the surrender value in the same manner as the price of a life-interest, using the Office premium for a whole-life assurance. It is, however, simpler to value the annuity on a net basis; and I propose to allow the net value by the $\mathrm{O}^{[a m]}$ or $\mathrm{O}^{[a f]}$ Table, as the case may be, using the "ultimate" values at $4 \frac{1}{2}$ per cent interest.

Of course an Office is not obliged to pay any surrender value for an annuity, and may refuse to allow the contract to be broken.

\section{SINGLE-PREMIUM POLICIES.}

The net $O^{[M]} 4 \frac{1}{2}$ per cent "select" value would be too small during the early years of a policy effected by a single premium, inasmuch as that premium contains a commuted loading to cover expenses during the whole term of the policy, and it is clear that some of this should be refunded unless it has all been absorbed. Further, if the policy be "with profits," the premium will contain a bonus loading; and some portion of this ought to be returned if the policy be surrendered before any bonuses have been added to it. I have not been able to arrive at a more satisfactory way of dealing with these cases than the rule of allowing an arbitrary percentage of the single premium; say 85 per cent if the policy be "non-participating," and 90 per cent if it be "participating." One objection to this course is that it perhaps tends to press with undue weight upon endowment assurances, especially where the term of the assurance is short. It may be said that the Office runs practically the same mortality risk whether the policy. be a whole-life or an endowment assurance, and that it should in consequence deduct from the single premium the same amount in both cases (instead of a larger amount in the latter) and hand over the balance to the policyholder. If the surrender value in a whole-life case without profits be, as suggested above, 85 per cent of the single premium, the Office retains 15 per cent thereof for its trouble and risk; and it might therefore be argued that in any other case the surrender value should be equal to the single premium actually paid less 15 per cent of the "whole-life without profits" premium for the same age at entry. A rule of this kind would be simple, and of easy application in practice; but it would not allow for the fact that the expenses of the Office depend largely on the amount of premium. Thus if the commission in such cases be a percentage of the premium, it is clear that the Office is put to greater expense in respect of an endowment assurance than a whole-life policy, and 
that it should accordingly retain a larger amount out of the premium in the former case. Of course, after the lapse of a number of years the net $\mathrm{O}^{[\mathrm{M}]} 4 \frac{1}{2}$ per cent " select" value (allowing, in the case of participating policies, for the right to future profits) will give a larger surrender value than the arbitrary percentage of the single premium; and when this happens, the larger value should be allowed on surrender.

\section{GUARANTEED MINIMUM SURRENDER VALUES.}

In view of the common practice of guaranteeing on surrender a return of not less than a fixed arbitrary percentage of the premiums paid, I examined the prospectuses and Board of Trade Returns of the 59 Offices mentioned above, in order to ascertain their practice on this point. This is so diverse that it cannot be fully represented within the limits of a short table, but the following statement shows the general features:-

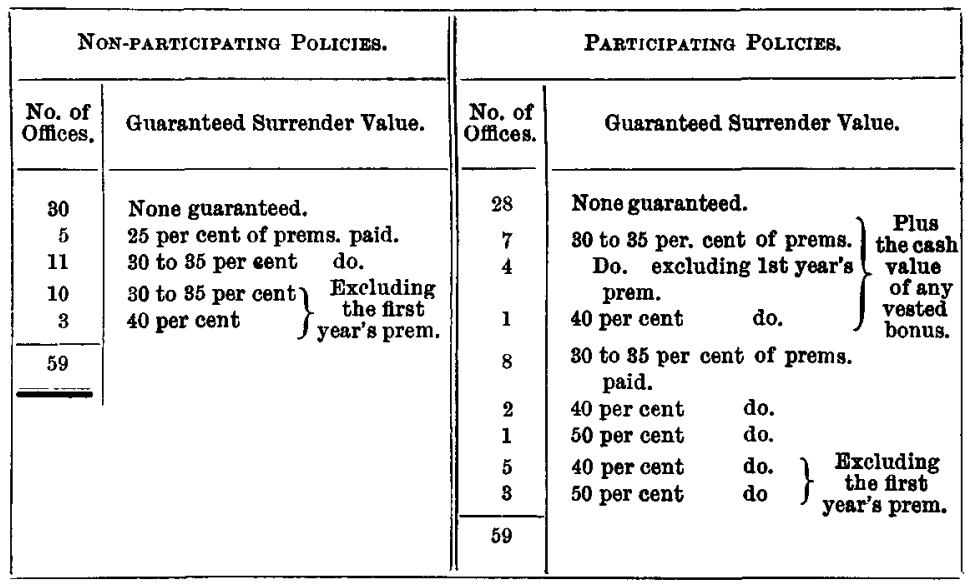

There are many minor variations, such as a limitation of the guarantee to cases where the age at entry does not exceed $\mathbf{5 5}$ or 60 years; the allowance of a larger percentage in the case of endowment assurances; and in one case the exclusion of the premiums for the first two years. The general result is that about half the Offices guarantee a minimum surrender value of (on the average) about one-third of the premiums paid under a non-participating policy, and rather more in the case of a policy with profits; and that the remaining half make no such guarantee. A study of my tables of paid-up policies and 
surrender values shows that one-third of the premiums paid may exceed, not only the reserve value, but even the amount of the full theoretical paid-up policy, when the age at entry is advanced; and this occurs to a greater extent in joint-life cases, as the risk thereunder is from the outset greater than that under a single-life policy. Accordingly every Office which gives such a guarantee without qualification, is liable to suffer a considerable loss whenever an entrant of advanced age surrenders his policy. In one case which came under my notice, a gentleman aged over 70 effected a large assurance, and surrendered it a few years later, when the Office found that the guaranteed cash value exceeded the amount they could have afforded to give as a paid-up policy. This shows that those Offices which limit their guaranteed surrender value to cases where the age at entry does not exceed say 55 or 60 , have good reason for so doing. Of course, every limitation or qualification of a general rule causes more trouble and increases the chance of errors occurring; but I do not think that this consideration is sufficient to warrant an Office in giving an unqualified guaranteed surrender value of one-third of the premiums paid. Further, I doubt whether such a guarantee, even with suitable limitations, is of such advantage to an Office as to outweigh the serious drawbacks attendant upon it.

The circumstances are very different from those attending a guaranteed "proportionate" paid-up policy, as that is a benefit which can be appreciated by the man in the street, and is likely to help to popularise the Offices which grant it, and thus add to their prosperity by assisting them to obtain a satisfactory flow of new business. But the prospect of getting back one-third of the premiums on surrender can hardly be said to be attractive, as it involves the "loss" of the remaining two-thirds; and therefore I do not approve of guaranteeing a fixed arbitrary percentage of the premiums paid. It seems to me better to adopt some simple but more scientific method, such as that proposed above, so adjusted as to give reasonably accurate results at all ages from the youngest to the oldest, and thus to have one uniform rule for calculating the surrender value of each class of assurance. The arbitrary method involves the necessity of having other rules for cases where the arbitrary value would be too small; and this again means in many, if not most cases, that two or more separate calculations have to be made by the different rules in order to ascertain which gives the largest value. Any one who has had much practical experience of the calculation 


\section{$248 \quad$ Paid-up Policies and Surrender Values}

of surrender values in a large Office will admit that it takes a great deal of time and trouble, and that simplification of the existing methods is very desirable, provided it can be effected without undue loss of accuracy.

It is usual not to allow any surrender value or paid-up policy until after a certain minimum number of premiums have been paid; and the following table exhibits in a general way the practice of the above-mentioned 59 Offices in this respect:-

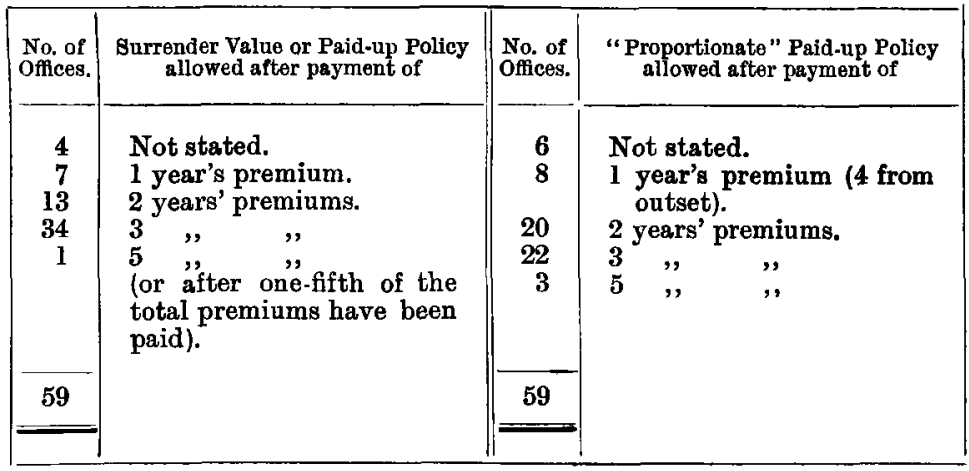

There are many minor variations which it would take too long to describe in detail. For example, several Offices allow a surrender value one year sooner in the case of limited payments or endowment assurances than in whole-life assurances. Others draw a similar distinction between "participating" and "nonparticipating" policies; and one Office makes a difference of two years, granting a surrender value after payment of one year's premium under a "participating" policy, but not until three years' premiums have been paid in the case of a "non-participating" policy. The second portion of the table, relating as it does to the grant of a "proportionate" paid-up policy, applies only to limitedpayment and endowment assurance policies, and therefore reflects the above-mentioned distinction. It is clear from these figures that the majority of Offices consider the limit should be fixed at two or three years, and that there is a decided preponderance in favour of the latter limit for whole-life cases; but that in respect of limited payments and endowment assurances opinion is fairly evenly divided between the two. One or two Offices make a point of allowing a paid-up policy and surrender value even if only one premium has been paid, and this presumably includes half-yearly and quarterly premiums; but probably most of us will agree that 
this is too liberal. My own opinion is that a limit of two years is justifiable for limited-payment and endowment assurance policies, as the premiums thereon usually leave a large margin for expenses after meeting the mortality risk of the first year or two. In whole-life cases the margin available for expenses is very much less, and this constitutes a good reason for treating them in a different manner; but I do not think that this should take the form of having different limits for the two classes. It seems to me preferable to have the one rule for all classes, namely, to grant a surrender value after two years' premiums have been paid; and to allow for the difference by giving a smaller proportion of the reserve in whole-life cases. This is achieved, according to the methods now proposed, by omitting the first year's premium in those cases, while in the case of limited-payment and endowment assurance policies all the premiums are taken into account in the calculation of the surrender value or paid-up policy. Whichever limit may be fixed upon, whether two or three years, it will occasionally happen that a surrender value should be allowed at an earlier dateespecially in half-yearly or quarterly cases. This will occur whenever the surrender value that will be allowed at the end of the two years (or three, as the case may be) exceeds the amount of one premium. For example, suppose the Office guarantees, after three years, a surrender value equal to one-third of all the premiums paid, and assume that the premiums are payable quarterly, each instalment being $P$. At the end of three years, 12 premiums will have been paid, and the guaranteed surrender value will be $4 \mathrm{P}$. Now, if the policyholder has only paid 9 premiums, he could come to the Office, tender payment of three more premiums at once, and then demand the surrender value. That is to say, the Office should in sach a case allow a surrender value equal to the amount of one premium, after the policy has been only $2 \frac{1}{4}$ years in force. Similarly, after $2 \frac{1}{2}$ years the value should, on the same supposition, be equal to two premiums, and after $2 \frac{3}{4}$ years it should be equal to three premiums.

\section{INTERIM BONUS.}

It is a question of some importance whether any allowance in respect of interim bonus should be made in the case of paid-up policies and surrender values. Further, as a bonus cannot be surrendered until it has vested, it becomes necessary to consider what conditions, if any, should attach to its vesting. Excluding two Offices whose constitutions provide for a tontine bonus, the 


\section{0 Paid-up Policies and Surrender Values}

following table shows in a general way the practice of the abovementioned Offices on these points :-

\begin{tabular}{|c|c|c|c|}
\hline $\begin{array}{l}\text { No. of } \\
\text { Offices. }\end{array}$ & Interim Bonus allowed & $\begin{array}{l}\text { No. of } \\
\text { Offices. }\end{array}$ & Bonus vests \\
\hline 3 & \multirow{7}{*}{$\begin{array}{l}\text { Nil. } \\
\text { If premiums accumulated at } 4 \text { per cent } \\
\text { exceed the sum assured. } \\
\text { Either about one-half of last bonus or of } \\
\text { indefinite amount. } \\
\text { About two-thirds of last bonus. } \\
\text { About three-fourths of last bonue. } \\
\text { Nearly equal to last bonus. } \\
\text { Make an annual declaration of bonus. }\end{array}$} & 18 & \multirow{6}{*}{ 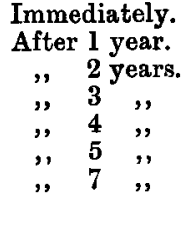 } \\
\hline 1 & & $\begin{array}{r}6 \\
12\end{array}$ & \\
\hline 11 & & 3 & \\
\hline 17 & & 12 & \\
\hline 11 & & l & \\
\hline $\begin{array}{l}8 \\
6\end{array}$ & & 57 & \\
\hline 57 & & & \\
\hline
\end{tabular}

This shows that interim bonus in one shape or another is allowed by the great majority of Offices; and there seems to be a decided tendency to allow the periodical bonuses to vest immediately they are declared. The object of any restriction in the latter respect, is to secure a modified tontine arrangement for the benefit of policies which do not become early claims; and also to facilitate the start and early progress of a new Office by keeping down the amount of its claims during the early years of its existence. So long as the bonus distribution rules of the Office are applied impartially, and the assured clearly understand the nature of the contracts, I do not see any objection in principle to this ; but it is undoubtedly the fact that in many cases the smallness of an interim, or the forfeiture of a non-vested bonus, calses keen disappointment to claimants, and this must tend to prejudice the Office. To my mind the ideal system would be one which avoids as far as possible any violent fluctuations in the rates of bonus added from time to time throughout the duration of a policy; and the system of quinquennial valuations has this great advantage that it helps largely to avoid the fluctuations which would otherwise be much more frequently experienced by all Offices except perhaps those of the largest size. By allowing bonuses to vest immediately they are declared, and giving from the outset an interim bonus approximating to the rate which the Office is likely to maintain, still greater uniformity would be obtained in the rate of increase of any participating policy; and I am inclined to think that this is desirable, and that the same interim bonus should be allowed on surrender or the grant of a paid-up policy. The result of this would be (1) a much greater uniformity in the rate of increase of 
the sum assured, paid-up policy, and surrender value, which under the ordinary methods are all apt to increase slowly during a valuation period, with a bound upward immediately on the declaration of the next bonus; and (2) that each holder of a participating policy would receive a bonus for each premium paid, whether the policy became a claim, or were made paid-up, or surrendered. The dra wbacks to this procedure are of course (1) the cost, as it would tend, by distributing the profits more uniformly among the participating policyholders, to reduce the rates of bonus declared at the periodical valuations; and (2) the fact that it would necessitate the allowance of a surrender value (equal to the cash value of the interim bonus) after only one premium had been paid. This last consideration perhaps indicates that if an Office adopts the rule of not allowing any surrender value until after, say, two years, its bonuses should not vest, and interim bonus should not be added, until after the lapse of that time.

\section{"RATED-UP" LIVES.}

When a life has, on account of some defect in personal or family history, been accepted at a rate of premium higher than the normal, the usual method of fixing that rate is to add an arbitrary number of years to the age and to charge the premium applicable to the age thus increased. The Office thus makes the assumption that, at the commencement of the assurance, the life is equivalent to that of a healthy person of the "rated-up" age; and though this is only an assumption, it is a very convenient one, and has been found to work well in practice. A number of Companies virtually make the further assumption that this equivalence will continue throughout the existence of the contract, for they make the same reserve for such policies as they do for policies on firstclass lives of the "rated-up" age; and it appears to me that the proper course in such circumstances is to calculate the surrender value and paid-up policy on the same footing. On the other hand, many Companies, when making their periodical valuations, omit the extra premium from their calculations, and thus reserve the same amount in respect of a "rated-up" policy as in the case of a similar policy on a life accepted at ordinary rates; and in these circumstances it seems proper to allow simply the normal surrender value and paid-up policy. It would be outside the scope of this paper to discuss the respective advantages of these two methods, and I therefore confine myself to pointing out the fact that the former method gives the larger reserves, if other things be equal and the valuation tables be well graduated. 


\section{Paid-up Policies and Surrender Values}

COMMUTATION OF PREMIUMS: NORMAL AND "RATED-UP" LIVES.

When a policyholder desires to commute future premiums wholly or in part, either by a cash payment or by surrender of bonus, it should be assumed that he is in good health, since the transaction is virtually the purchase of an annuity. The rate of interest should be not greater than the Office is likely to realise on its funds, and $3 \frac{1}{2}$ per cent seems suitable under present conditions, being the rate at which premiums are calculated by a number of the best authorities. When a "rated-up" life effects a policy by a single payment or by limited payments, he virtually commutes the premiums at the outset; and as the premium is calculated at the "rated-up" age, the commutation involved therein is also on that basis. I think that the same principle should be followed if the commutation take place, not at the date of entry, but subsequent thereto, as otherwise inconsistencies would result and a "rated-up" policyholder commuting his premiums shortly after entry would be unduly penalised as compared with one who did so at the outset.

\section{CHANGES OF CLASS : "RATED-UP" LIVES.}

Similar considerations apply when a policyholder desires to change the class of his assurance; and I therefore think it a good plan in all cases of "under average" lives to take the "rated-up" age as the basis of all the calculations relating to the policy, whether these relate to the paid-up policy; surrender value; cash value of bonus; commutation of premiums by cash or surrender of bonus; division of profits on the "contribution" plan; change of class ; or reserve.

\section{NON-FORFEITURE.}

I have no sympathy with the view that a surrender value partakes of the nature of an ex gratid payment by the Office. It seems to me that the statements in the prospectuses and policies of most Offices form a binding contract that a surrender value will be allowed on certain conditions, and that when a value has been quoted correctly according to the Office's ordinary rules, the Office has no moral right to forfeit this value on the ground merely that the policyholder fails to apply for it within a definite time. Unless the value be applied to keep the policy in force, I consider that it should be held at the disposal of the policyholder, and should be paid over on application and proof of title, however long that may be delayed. 
There are three well-known ways of applying the value to keep the policy in force :-

(1) By advancing unpaid premiums and keeping the policy in force for the full amount, subject to a debt which can be repaid at any time during the currency of the policy. This has the disadvantage of gradually decreasing the net surrender value; and in most cases, if the debt be not repaid, it sooner or later exhausts the whole value, and the policy perforce becomes void.

(2) By providing a paid-up temporary assurance for the full amount. This is objectionable, as it deprives the assured of the right to pay up arrears and have the policy reinstated on its original footing, irrespective of the state of his health.

(3) By providing a paid-up assurance of the same class as the original policy but for a reduced amount. This presses very hardly upon those who accidentally omit to pay a premium, and who desire to pay the arrears, but are not in good enough health to justify the Office in accepting payment.

From a short investigation into some hundreds of cases of unpaid premiums, I am satisfied that the majority of these arose through inadvertence or negligence, and not from any intention of dropping the policies; and that an arrangement whereby the assurance is kept in force for a limited time, say one year, is sufficient to protect the interests of almost every policyholder. At the end of that time, if the policyholder disregards all notices issued by the Office on the subject, I think that on the whole the best course is to employ the net surrender value in providing a paid-up assurance of reduced amount. This not only leaves the surrender value intact, but causes it to become gradually larger as the age increases; and a portion of the assurance is also preserved. Whatever course be adopted, notice should be sent to all persons who appear to be interested in the policy, stating the position of matters in plain language, so as to remove as far as possible all risk of misunderstanding.

\section{LOANS.}

It is usual to grant loans to the extent of 95 per cent of the surrender value, and this is a convenient rule in practice, though a smaller margin would generally suffice. The loan should be of 


\section{Paid-up Policies and Surrender Values}

such an amount that the total loan with interest to the next renewal date will be not greater than the surrender value at that date; and as the rate of interest is often less than 5 per cent, and the next renewal date frequently falls less than a year from the date of granting the loan, it is elear that a margin of 5 per cent is in such circumstances more than sufficient. If the policyholder has, however, the right to extend the days of grace for payment of the premium and interest on the loan, by paying a small fee, the margin should be larger, so as to allow for the longer period during which interest will accrue, and for any decrease in the surrender value that may be caused by the additional mortality risk run by the Office during that period.

If a policyholder has only borrowed a portion of the available value, there will be a balance, or net surrender value, to which he is entitled on surrender of the policy. Sometimes the policyholder prefers to take a paid-up policy free of loan instead of the net surrender value, and the following is the obvious method of calculating this. Find the gross paid-up policy; that is, the amount that would be allowed if there were no loan : then find what proportion of this must be surrendered in order to produce sufficient cash to repay the loan with interest; and the remainder is the net paid-up policy that can be granted free of loan. This leads to the equation $\frac{\text { net paid-up policy }}{\text { gross do. }}=\frac{\text { net surrender value }}{\text { gross do. }}$, and as the gross surrender value is got from the gross paid-up policy by multiplying the latter by $A$, the $\mathrm{O}^{[\mathrm{MJ}]} 4 \frac{1}{2}$ per cent net single "select" premium, it follows that the net paid-up policy is equal to the net surrender value divided by A. A remark similar to that on p. 241 regarding Double Endowments applies to this case also; as the reasoning shows that the transaction is not the grant of an assurance on an $\mathrm{O}^{[\mathrm{M}]} 4 \frac{1}{2}$ per cent net basis, but a partial surrender on those terms.

\section{PRACTICAL APPLICATION.}

In the practical application of the proposed methods it is of great importance to arrange the work so that it can be performed with a minimum expenditure of time and labour, and the application of the Card system helps largely towards the attainment of this object. The old-fashioned plan of entering the calculations in books was more expensive, as it entailed the cost of binding; and more laborious, as it involved the necessity of indexing every calculation. Also it had the great drawback that only one clerk 


\section{Paid-up Policies and Surrender Values}

could use the hook at a time, and when any one else wished to refer to a calculation contained in it, he had either to wait or to interrupt the work, both of which courses result in the long run in a considerable waste of time. The calculations should therefore be made on loose sheets or cards, kept in numerical order according to policy number, and an example of such a card will be found in Appendix II. The particulars should be filled in from the principal records of the Office, care being taken, in the case of endowment assurances maturing at a stated age, that this age be placed above the age at entry. This enables the computer to subtract more readily the latter from the former, thus getting the full number of years' premiums originally payable-which is wanted for the purpose of calculating the "proportionate" paid-up policy. A complete table of $1-\frac{\mathrm{P}_{x+1}}{\mathrm{P}_{x+n}}$ should be constructed from the Office table of premiums for whole-life assurances without profits, and if these do not proceed with sufficient smoothness they should be adjusted so as to remove any marked irregularities, and to secure that for any given duration the paid-up policy shall increase with the age at entry. As the table of Office premiums rarely extends beyond age 80 , if so far, it should be continued to the extreme limit likely to be met with in practice, so that the table of paid-up policies may be sufficiently extensive to cover every case that is likely to arise.

When the premium is half-yearly it will be found that $1-\frac{\mathbf{P}_{x+1}}{\mathbf{P}_{x+n}}$ is not always equal to $1-\frac{\mathrm{P}_{x+1}^{(2)}}{\mathrm{P}_{x+n}^{(2)}}$; but it seems quite unnecessary to take into account any such small differences: and when (as is now common) the half-yearly are got from the yearly premiums by the addition of a constant percentage thereto, the two values will coincide. Similar considerations apply to quarterly premiums ; and I therefore propose to use the one table whether the premiums be payable yearly, half-yearly, or quarterly ; interpolating by first differences when the duration (or the age at entry) is fractional.

A table of $\frac{n}{r}$ should also be constructed, for the purpose of finding the "proportionate" paid-up policies allowed in the case of limited-payment and endowment assurance policies ; and the limits of this table should be wide enough to include every ease likely to arise. It is useless to make an affectation of accuracy by carrying the calculation to a large number of decimal places, as the fundamental mortality tables are themselves only approxi- 


\section{Paid-up Policies and Surrender Values}

mately accurate; and I think it is quite sufficient to quote paid-up policies to the nearest integral number of pounds, and thus avoid the trouble caused by the insertion of a large number of shillings and pence in the "sum assured" columns of the Office Registers. Further, $I$ think it is sufficient to tabulate the values of $1-\frac{P_{x+1}}{P_{x+n}}$ and of $\frac{n}{r}$ to three and four decimal places respectively. To avoid any possible confusion between the two tables, and the insertion of a number of decimal points and zeros, I would suggest tabulating to the nearest integer the function $1000\left(1-\frac{P_{x+1}}{P_{x+n}}\right)$ in the former case-that is to say, to construct a table showing the amount of paid-up policy that will be allowed for a whole-life assurance of 1000 . The reason for tabulating the function $\frac{n}{r}$ to four decimal places, is that if the table only extended to three decimal places, slight errors would sometimes be introduced if the original assurance were for a large amount; and although these would be of trifling consequence having regard to the amounts involved, they might cause complaints by those policyholders who calculated the "proportionate" paid-up policy for themselves. A simple mental multiplication of the value in one or other of these tables will give the paid-up policy to be allowed for a "non-participating" assurance of any ordinary amount. In the case of a "participating" assurance, the amount of the bonus is added, and this gives the total paid-up policy that can be granted without right to future profits. If the bonus be "compound," it virtually forms a participating paid-up assurance, and as it is converted into a non-participating assurance on the grant of the paid-up policy, its amount should be increased, so as to allow for the surrender of the right to future profits thereon. As already explained (p. 224), this increase should be of such an amount that the cash value remains unaltered by the change; that is to say, the bonus should be multiplied by $\frac{A^{\prime}}{A}$, where $A^{\prime}$ and $A$ respectively represent the surrender values allowed for 'participating' and for "non-participating" paid-up policies of an otherwise similar nature ; and accordingly a table of this ratio should be constructed. It might be argued that the increase should be in the ratio $\frac{(\mathrm{SP})^{\prime}}{(\mathrm{SP})}$ where (SP)' and (SP) represent respectively the Office single premiums for such policies; but this will generally be greater than 
$\mathrm{A}^{\prime}$ owing to the difference between selling and buying; the single premiums being the pricess at which the Office sells assurances, and the surrender values being the prices at which it is willing to buy them back again from the public.

The surrender value is got by multiplying the paid-up policy by the net single premium for the benefit $\left(\mathrm{O}^{(\mathrm{m})} 4 \frac{1}{2}\right.$ per cent " select" value), and this operation may be performed in the ordinary way, or by the use of logarithms or an arithmometer, by contracted multiplication, or by inspection of a slide rule. The first of these methods causes, as a rule, about twice as much work as is necessary, and therefore it should never be employed. For a single multiplication involving a few figures, the use of logarithms or an arithmometer does not result in much saving of labour; and I think the two last-mentioned methods are the best, as with a very little practice they are both remarkably quick and quite accurate enough for the purpose. It seems to me quite sufficient to carry the multiplication to one decimal place, and thus to calculate the surrender value to the nearest integral number of florins.

In the case of whole-life policies on single lives an alternative method would be to construct a table of surrender values by the formula $\mathbb{1}_{[x+n]}^{\text {O[M] } 14 \%} \times\left(1-\frac{\mathrm{P}_{x+1}}{\mathrm{P}_{x+n}}\right)$. The surrender value would then be got by entering this table, and adding the cash value of the bonus, if any. This would save some tronble if the Office declared bonuses on the "compound" system and the surrender value alone were required ; but if the bonus be "simple," I doubt whether the table would repay the trouble of constructing it. As most policies are "with profits," the calculation of the surrender value generally involves the necessity of one multiplication in order to get the cash value of the bonus; so that the only saving effected by the table would be that one of the factors would be reduced. On the other hand, this method would give the cash value of the bonus and the surrender value, while the former method would give the paid-up policy and surrender value, which is the combination more generally required.

In the case of limited-payment and endowment assurance policies it would be impracticable to construct complete tables of surrender values, as the introduction of a third variable, namely the term of the assurance, would make them too extensive. The values of $A_{[x] ; \bar{r} \mid}$ should be tabulated according to the values of $x$, the age at valuation; and $x+r$, the age at maturity. This is more convenient than using the variables $x$ and $r$, because 


\section{Paid-up Policies and Surrender Values}

the age at maturity remains constant throughout the whole existence of the policy and can be noted in the primary records of the Office, so that $x$ is the only quantity to be ascertained before entering the table. If $r$ were taken as one of the variables, it would be necessary to find the original term of the assurance and to subtract therefrom the "duration" in order to get the term with which to enter the table. Accordingly a policy effected at age 27 say, and payable in 30 years or on previous death, should be classified not as a "30-year endowment assurance," but as a "Death or (57)" policy, the brackets being a convenient way of denoting that the assurance is payable not upon the 57 th birthday, but upon the preceding anniversary of the policy.

In order to exhibit in a concise form the methods now proposed, I append a summary in the shape of a series of rules for calculating paid-up policies and surrender values.

Before quoting any value it should be checked by an independent calculation, not by an examination of the original work, as that is apt to lead the examiner to repeat any error therein; and the value should be compared with any previous quotation, and with the total amount of premiums paid. Care should be taken to see that the person making the inquiry is entitled to the information, as it sometimes happens that an unauthorised person inquires about a policy in which he has no interest, and the polieyholder would have good cause for complaint if confidential information regarding his affairs were given to everybody who might ask for it.

The net value of a policy does not increase steadily with the duration, but as each premium is paid it immediately increases by the amount of the net premium. Thus at the end of $n$ years, before the $(n+1)$ th premium is paid, the net value is ${ }_{n} \mathrm{~V}_{x}$, but immediately thereafter it is ${ }_{n} \mathrm{~V}_{x}+\pi_{x}$. Now, unless a policy has been a considerable number of years in force, it will be found that ${ }_{n} \mathrm{~V}_{x}+\pi_{x}$ is greater than ${ }_{n+1} \mathrm{~V}_{x}$, so that the value decreases during the year, owing to the interest on the reserve being less than the cost of the current mortality risk. It would be theoretically correct to give effect to this principle in the calculation of surrender values; but it would cause a great deal of complication in the work, and would almost certainly raise questions with the policyholders, who would have great difficulty in understanding why the surrender value should decrease. I therefore think it is desirable in all ordinary cases to calculate the surrender value as at the date when the next premium will fall due, and to adhere to this value even if the policy be surrendered before that date. On the other 
hand, when a policy has been many years in force, it will be found that ${ }_{n} \mathrm{~V}_{x}+\pi_{x}$ is less than ${ }_{n+1} \nabla_{x}$, so that the value actually increases during the year, the interest on the reserve being greater than the cost of the current mortality risk. In these circumstances it would perhaps be too liberal to allow the surrender value calculated as at the next renewal date, if the policy were surrendered several months prior thereto ; and in such cases the Office might allow the value as at the previous renewal date, plus the premium then paid. This would, however, cause a good deal of trouble, and it is a question whether it would be worth while. If in every case the value as at next renewal date were allowed, there would be the advantage of having one rule applicable to all cases; and any loss sustained on the older policies in consequence of this rule would be more than balanced by the gain in the much more numerous eases where the rule operates in favour of the Office. Also, as the proposed surrender values leave a substantial margin for contingencies, the Office can perhaps well afford this small concession.

There are always some policyholders who fancy that premiums paid to an Assurance Office are like deposits in a bank, and that they should be returnable on demand, with the bonuses added and sometimes also with interest. These people will grumble even if their surrender values are calculated on the most liberal scale possible; and those of us whose daily work lies in connection with such matters, know that it is by no means easy to give an explanation which they can understand, and which will satisfy them that the Office is not taking an unfair advantage of them. The appended statement (Appendix III.) was drawn up and printed in leaflet form in order to meet such eases, and it has proved successful in several instances. I think it is desirable that Offices should circulate statements of this kind, giving explanations of the nature of life assurance business, for they cannot fail to have a certain educative effect upon the public, which in its turn ought to prove beneficial to the Offices.

\section{GENERAL REMARKS.}

Objection may possibly be taken to some of the methods now proposed, on the ground that in some cases the results are admittedly mere approximations, more or less rough. A little consideration, however, shows that no calculations in connection with life assurance can be strictly accurate, as the data upon which they are based are themselves only approximate. It is impossible 


\section{Paid-up Policies and Surrender Values}

to determine the future rate of interest or expenditure; and even if it be assumed that the past rates of mortality will be unaltered in the future, the fact that our mortality tables require graduation is sufficient to show that they are mere approximations. There is therefore room for considerable difference of opinion even in such a comparatively simple matter as the calculation of premiums, and still more so in the case of surrenders where the question is much more complex. Even the statement that the surrender value should not exceed the reserve, though apparently almost axiomatic, cannot be accepted without qualification. At first sight it appears to be a necessary consequence of the fact that if the total surrender values exceed the total funds, and all the assured were to surrender their policies at once or within, say, a year, the Office would be unable to pay them; but a little consideration will show that this argument is not logically sound. It is undeniably true that if all the policyholders were to die within a year, the Office would be unable to pay the claims if its total funds were less than the face value of the policies; and that this is a risk we all run every day without the least anxiety, because experience teaches us that the chance of that event occurring is so minute as to be incapable of measurement. But experience also teaches us that the chance of all the policies being surrendered within a year, though certainly greater than the chance of all the lives dying in the same time, is also so minute as to be incapable of measurement; so that if we can safely disregard the one risk, it is not necessarily illogical to disregard the other. Again, if it be the case that the lives who withdraw are worse than those of the same age who remain, the true values of the surrendered policies will be greater, and the true values of the remaining policies will be less than the reserves respectively held against them. It might conceivably, on this hypothesis, pay an Office to give surrender values in excess of its reserves, and thus get rid of its undesirable risks; and as a matter of fact Offices do occasionally and quite properly give specially large surrender values in cases where they have reason to believe that the lives assured are in bad health.

It is impossible to frame a mathematically accurate scheme of surrender values based purely on theoretical considerations, and we must therefore be largely guided by considerations of expediency and practice. In fact, it seems to me that though we ought to work out the theory of our business with the utmost accuracy attainable, when we come to apply it in practice it is perhaps of more importance to devise rules which secure simplicity and ease of working, than by the use of elaborate formulas to 
strive after a degree of mathemaical exactitude which is necessarily unattainable. These rules should, of course, conform as far as practicable with theory, and if they tend to give an error, care should be taken to see that it is on the whole on the right side.

It will probably be generally admitted that (save in exceptional cases where a risk is manifestly undesirable) the surrender value should not exceed the reserve; that in the early years of the policy it should be substantially less-say from one-half to threequarters thereof; that as the duration increases, a larger proportion may be allowed; and that at very advanced ages it should approximate to the full reserve. The values brought out by the methods I propose, comply on the whole with these conditions; the methods are applicable at all ages from the youngest to the oldest; the paid-up policies and surrender values are consistent with each other; and the necessary calculations are extremely simple, the system probably being less complicated than any other hitherto published in this country, so that it can be applied in practice with a minimum of labour. At the same time it undoubtedly leaves ample scope for improvement, and I hope that the discussion upon it will indicate the directions in which such improvements can best be made.

\section{S U M M A R Y}

Proposed Rules for calculating Paid-up Policies, Surrender Values, Cash Values of Bonus, and Commutations of Premium.

\section{PAID-UP POLICIES.}

(1) Construct a table of $1000\left(1-\frac{P_{x+1}}{P_{x+n}}\right)$ and call this Table I.(say).

(2) Construct a table of $\frac{n}{r}$ and call this Table II. (say) (p. 255).

(3) Do not allow any paid-up policy unless two full years' premiums have been paid under the original contract, except in those few cases where payment of the sum necessary to complete two years' premiums, would secure a paid-up policy whose cash value would exceed that sum; and do not allow any, if the amount thereof would be less than $£ 20$ (pp. 227, 249). 


\title{
262 Paid-up Policies and Surrender Values
}

\author{
WHOLE-LIFE ASSURANCES ON SINGLE LIVES.
}

Find the Office age at entry $(x)$ and the duration of the policy $(n)$, and with these variables enter Table I., multiply the result by the sum assured and divide by 1000 . If $x$ be less than 10 , enter the table with the variables 10 and $n$ (p. 206).

\section{DISCOUNTED BONUS SYSTEM.}

Proceed as above and reduce the result in the ratio

$$
\frac{A_{[x+n]}\left(O^{[M]} 4 \frac{1}{2} \%\right)}{A_{[x+n]}\left(O^{[M]} k \%\right)}
$$

where the rate $k$ is so chosen that $4 \frac{1}{2}-k$ is, say, from one-half to onethird of the anticipated annual rate of bonus.

Add to this any existing additions to the sum assured, or the reversionary equivalent of any further reduction of future premiums (p. 226).

WHOLE-LIFE ASSURANCES ON TWO OR MORE (sAY $m$ ) JOINT LIVES.

Find the Office ages at entry $x, y, z$, . ( $m$ terms), and from these find (to the nearest integer) an age $w$ such that $c^{x}+c^{y}+c^{z}+\ldots$ ( $m$ terms $)=m c^{w}$. With $w$ as the age at entry and $n$ the actual duration of the policy, enter Table I. Multiply the result by the sum assured and divide by 1000 . If there are not more than four lives, $w$ can be got by inspection of the tables of "Uniform Seniority" on pages $244-251$ of the "Experience" $\left(\mathrm{O}^{\mathrm{M}}\right.$ and $\left.\mathrm{O}^{\mathbf{M}(5)}\right)$ Tables (p. 211).

\section{WHOLE-LIFE ASSURANCES ON THE LAST SURVIVOR OF TWO LIVES.}

(a) While both the Assured survive.-Find the Office ages at entry; and with the lesser of these, and the actual duration of the policy, enter Table I. Multiply the result by the sum assured and divide by 1000 (p. 215).

(b) After one of the Assured has died.-Find the Office age at entry (say $y$ ) of the survivor, and the actual duration of the policy (say $n$ ). Then find (to the nearest integer) a number $r$ such that $\mathbf{P}_{y-r}=\mathbf{P}_{x: y}$, and with $y-r$ as the age at entry and $n+r$ as the duration, enter Table I. and proceed as above (p. 215).

\section{WHOLE-LIFE ASSURANCES ON THE LAST SURVIVOR OF THREE LIVES.}

(a) While all the Assured survive.-Find the Office ages at entry, and with the least of these, and the actual duration of the policy, enter Table I. and proceed as above (p. 215).

(b) After one of the Assured has died.-Find the Office ages at entry of the two survivors (say $y$ and $z$ ), and the actual duration (say $n$ ). Then find (to the nearest integer) a number $s$ such that $\mathrm{P}_{y-s: z-s}=\mathrm{P}_{\bar{x}: y: z}$, and with the lesser of the two numbers $y-s$ and $z-s$ as the age at entry, and $n+s$ as the duration, enter Table I. and proceed as above (p. 215). 


\section{Paid-up Policies and Surrender Values 263}

(c) After two of the Assured have died.--Find the Office age at entry of the survivor (say $z$ ) and the actual duration (say $n$ ). Then find (to the nearest integer) a number $t$ such that $\mathrm{P}_{z \rightarrow t}=\mathrm{P}_{\bar{x}: \bar{y} \cdot z}$. With the variables $z-t, n+t$ proceed as above (p. 216).

LIMITED-PAYMENT AND ENDOWMENT ASSURANCE POLICIES, DOUBLE

ENDOWMENTS, PURE ENDOWMENTS, AND DEFERRED ANNUITIES.

Find the original number of premiums payable $(r)$ and the number actually paid $(n)$, and with these variables enter Table II. Multiply the result by the sum (or sums) assured or endowed, or the annuity, as the case may be (p. 217).

\section{HALF ENDOWMENTS}

are to be treated as if they were endowment assurances for the amount payable in the event of survivance. That is to say, no additional paid-up policy is to be granted in respect of the additional temporary assurance.

\section{FOUR PER CENT. DEBENTURE POLICIES.}

If it is specially desired that the paid-up policy be on this plan, its amount is to be found by the above rules. In general, however, the paid-up policy should be payable in one sum, and its amount should be $1 \cdot 15$ times the amount given by those rules (p. 219).

\section{FIVE PER CENT. INCOME POLIOIES,}

If it is specially desired that the paid-up policy be on this plan, its amount is to be found by the above rules. In general, however, the paid-up policy should be payable in one sum, and its amount should be $\cdot 7662$ of the amount given by those rules (p. 219).

\section{CHILDREN'S DEFERRED ASSURANCES.}

(a) At or after the Commencement of the Assurance.-Divide the premium actually payable, by the Office premium at the attained age for each unit of the benefit as it then exists, and subtract the quotient from the sum assured (p. 220).

(b) Before the Commencement of the Assurance.-Find the paid-up policy that would be allowed, as above, at its commencement; then multiply this by the number of premiums actually paid, and divide the product by the number of premiums payable under the original contract until the commencement of the assurance (p. 220).

Allow no paid-up policy. 


\title{
264 Paid-up Policies and Surrender Values
}

\author{
BONUSES.
}

If the original policy be "with profits," add to the amount given by the above rules the amount of the existing bonus additions, including interim bonuses to date (pp. 224, 249).

If the bonus be "compound," increase its amount in the ratio $\bar{A}$ $\frac{\mathrm{A}^{\prime}}{\mathrm{A}}$

before adding it to the paid-up policy given by the above rules.

( $\mathrm{A}^{\prime}$ and $\mathrm{A}$ denote respectively the cash values of "compound" and "simple" bonuses; or, what is the same thing, of "participating" and "non-participating" paid-up policies) (p. 256).

\section{FRACTIONS OF A POUND.}

In order to avoid as far as possible the insertion of shillings and pence in the lists of sums assured, the paid-up policy is in every case to be calculated to the nearest $£$ (p. 256).

\section{FUTURE PROFITS.}

The paid-up policies found by the above rules are not to share in future profits (p. 223).

If in any case it is specially desired that the paid-up policy should share in future profits, its amount should be got by reducing in the ratio $\frac{A}{A^{\prime}}$ the amount given by the above rules (p. 256).

\section{SURRENDER VALUES.}

WHOLE-LIFE (single, joint, or last-survivor), LIMTTED-PAYMENT, ENDOWMENT ASSURANCE, HALF ENDOWMENT, 4\% DEBENTURE and $5 \%$ INCOME POLICIES.

Find the "non-participating" paid-up policy by the above rules, and multiply it by the net single premium ( $\mathrm{O}^{\mathrm{MM}} 4 \frac{1}{2} \%$ " select" value) for the corresponding benefit. (See Tables in Appendix I.) (p. 228).

(Nore.-Values of $\mathrm{A}_{[x]:[x]}\left(\mathrm{O}^{[\mathrm{M}]} 4 \frac{1}{2} \%\right.$ ) will be found in a volume now in course of preparation by Mr. H. H. Austin, F.I.A., and Mr. F. P. Symmons, F.I.A., which will be published in a few months.)

\section{DOUBLE ENDOWMENTS.}

When the value given by the above rule exceeds the amount payable under the original contract in the event of death, the latter sum only is to be paid in cash (unless strict evidence of health be furnished). Any excess above this amount is to be converted into a paid-up endowment, payable at the date of maturity of the original policy, and with no return in the event of death before that date. 


\section{Paid-up Policies and Surrender Values $\quad 265$}

This conversion is to be made by dividing the excess by $\mathrm{A}_{[x]: \frac{1}{n \mid}}$ $\left(O^{[M]} 4 \frac{1}{2} \%\right.$ ), where $x=$ age at date of conversion, and $x+n=$ age at maturity (p. 240).

PURE ENDOWMENTS, DEFERRED ANNOITIES, AND CHIDDREN'S DEFERRED AsSURANCES (before the commencement of the assurance), WITH NON-RETURNABLE PREMIUMS.

No cash surrender value is to be allowed unless strict proof of health be furnished. When this is forthcoming, find the amount of the paid-up benefit by the above rules, and multiply it by the net single premium ( $\mathrm{O}^{[\mathrm{M}]} 4 \frac{1}{2} \%$ " ultimate" value) for the corresponding benefit (p. 242).

PURE ENDOWMENTS, DEFERRED ANNUITIES, AND CHILDREN'S DEFERRED ASSURANOES (before the commencement of the assurance), WITH RETURNABLE PREMIUMS.

If the duration be less than 11 years, the surrender value is to be equal to the amount of premiums paid after the first year, increased by $10 \%$. If the duration be 11 years or more, the surrender value is to be equal to the whole of the premiums paid (p. 244). Alternatively, the scale on p. 243 might be used.

\section{CHILDREN'S DEFERRED ASSURANCES.}

(a) At the commencement of the assurance and until the following rule $(b)$ would give a larger value, the surrender value is to be $95 \%$ of the amount of the pure endowment (with or without return of premiums, as the case may be) that could have been secured by the premiums actually paid ; and thereafter

(b) Find the paid-up policy by the above rules, and multiply it by the net single premium ( $\mathrm{O}^{[\mathrm{M}]} 4 \frac{1}{2} \%$ "select" value) for the corresponding benefit (p. 244).

\section{TEMPORARY AND SURVIVORSHIP ASSURANCES.}

When the premiums are periodical, allow no surrender value. When the premium is single, allow (1) for a temporary assurance the net single premium ( $\mathrm{O}^{\text {[M] }} 4 \frac{1}{2} \%$ " select" value) for the remainder of the term, omitting therefrom fractions of a year; and (2) for a survivorship assurance the net single premium for the benefit $\left(\mathrm{O}^{\mathrm{M}]} 4 \frac{1}{2} \%\right.$ value, assuming the life assured to be "select" and the counter life to be "ultimate"; and require proof of health of the latter). 


\section{Paid-up Policies and Surrender Values}

"ASCENDING SCALE" policies [i.e. policies where the premium for the first few years is just (or little more than) sufficient to cover the risk, expenses, and option to continue the assurance without further proof of health].

Treat these as if they were level premium policies effected at the date the first increased premium fell due.

\section{SINGLE PREMIUM POLICIES.}

If "non-participating," allow $85 \%$ of the single premium-until such time as the above rules give larger values (p. 245).

If "participating," allow $90 \%$ of the single premium-until such time as the net $\mathrm{O}^{[\mathbf{M}]}$ "select" value at rate $j$ would be larger. [The rate $j$ to be chosen so that $\cdot 045-j$ is, say, from one-half to twothirds of the annual rate of bonus (per unit) likely to be maintained in the future] (p. 237).

\section{FRACTIONS OF A POUND.}

The calculation of surrender values is not to be carried to more than one place of decimals. That is to say, the value is to be taken to the nearest florin (p 257).

\section{dASH VALUES OF BONUS.}

Treat a simple bonus as a "non-participating," and a compound bonus as a "participating" paid-up assurance (pp. 228, 240).

\section{COMMUTATION OF PREMIUMS BY CASH OR SURRENDER OF BONUS.}

The amount of cash, or the cash value of the bonus, divided by the net $\mathrm{O}^{[M]} 3 \frac{1}{2} \%$ annuity ("select" value) gives the annual reduction of premium. If the premium be half-yearly or quarterly, divide the annual reduction by 2 or by 4 , as the case may be (p. 252).

\section{"RATED-UP" LIVES.}

For the purpose of calculating paid-up policies, surrender values, cash values of bonus and commutations of premium, "rated-up" lives are to be treated as if actually of the "rated-up" age; provided they are so treated in the periodical valuations of the Office (pp. 251, 252). 
Pard-up Policies and Surrender Values 267

APPENDIX I.

$A_{[x]}-O^{[m]} 4 \frac{1}{2} \%$.

\begin{tabular}{|c|c|c|c|c|c|c|c|}
\hline Age. & $\Delta_{[x]}$ & Age. & $\mathbf{A}_{[x]}$ & Age. & $A_{[x] .}$ & Age. & $\mathbf{A}_{[x]}$ \\
\hline $\begin{array}{l}10 \\
11 \\
12 \\
13 \\
14\end{array}$ & $\begin{array}{r}\cdot 16864 \\
\cdot 17158 \\
\cdot 17450 \\
\cdot 17755 \\
\cdot 18083\end{array}$ & $\begin{array}{l}35 \\
36 \\
37 \\
38 \\
39\end{array}$ & $\begin{array}{r}\cdot 28865 \\
\cdot 29606 \\
\cdot 30372 \\
\cdot 31161 \\
\cdot 31966\end{array}$ & $\begin{array}{l}60 \\
61 \\
62 \\
63 \\
64\end{array}$ & $\begin{array}{r}\cdot 53807 \\
\cdot 55004 \\
\cdot 56206 \\
\cdot 57402 \\
\cdot 58608\end{array}$ & $\begin{array}{l}85 \\
86 \\
87 \\
88 \\
89\end{array}$ & $\begin{array}{l}\cdot 81074 \\
.81905 \\
.82710 \\
\cdot 83490 \\
\cdot 84248\end{array}$ \\
\hline $\begin{array}{l}15 \\
16 \\
17 \\
18 \\
19\end{array}$ & $\begin{array}{r}\cdot 18423 \\
\cdot 18772 \\
\cdot 19142 \\
\cdot 19526 \\
\cdot 19921\end{array}$ & $\begin{array}{l}40 \\
41 \\
42 \\
43 \\
44\end{array}$ & $\begin{array}{r}\cdot 32806 \\
\cdot 33662 \\
\cdot 34541 \\
\cdot 35450 \\
\cdot 36375\end{array}$ & $\begin{array}{l}65 \\
66 \\
67 \\
68 \\
69\end{array}$ & $\begin{array}{r}59810 \\
691007 \\
-62200 \\
.63388 \\
\cdot 64564\end{array}$ & $\begin{array}{l}90 \\
91 \\
92 \\
93 \\
94\end{array}$ & $\begin{array}{r}\cdot 84971 \\
-85669 \\
\cdot 86336 \\
\cdot 86978 \\
\cdot 87589\end{array}$ \\
\hline $\begin{array}{l}20 \\
21 \\
22 \\
23 \\
24\end{array}$ & $\begin{array}{r}\cdot 20339 \\
\cdot 20770 \\
\cdot 21222 \\
\cdot 21687 \\
\cdot 22174\end{array}$ & $\begin{array}{l}45 \\
46 \\
47 \\
48 \\
49\end{array}$ & $\begin{array}{r}\cdot 37322 \\
\cdot 38301 \\
\cdot 39291 \\
\cdot 40307 \\
\cdot 41345\end{array}$ & $\begin{array}{l}70 \\
71 \\
72 \\
73 \\
74\end{array}$ & $\begin{array}{r}65736 \\
\cdot 66889 \\
\cdot 68031 \\
\cdot 69158 \\
\cdot 70270\end{array}$ & $\begin{array}{l}95 \\
96 \\
97 \\
98 \\
99\end{array}$ & $\begin{array}{l}\cdot 88179 \\
\cdot 88739 \\
\cdot 89278 \\
\cdot 89785 \\
\cdot 90268\end{array}$ \\
\hline $\begin{array}{l}25 \\
26 \\
27 \\
28 \\
29\end{array}$ & $\begin{array}{l}\cdot 22677 \\
\cdot 23203 \\
\cdot 23750 \\
\cdot 24314 \\
\cdot 24900\end{array}$ & $\begin{array}{l}50 \\
51 \\
52 \\
53 \\
54\end{array}$ & $\begin{array}{l}\cdot 42396 \\
\cdot 43472 \\
\cdot 44566 \\
\cdot 45673 \\
\cdot 46801\end{array}$ & $\begin{array}{l}75 \\
76 \\
77 \\
78 \\
79\end{array}$ & $\begin{array}{l}77364 \\
\cdot 72436 \\
\cdot 73491 \\
\cdot 74520 \\
\cdot 75528\end{array}$ & 100 & 90726 \\
\hline $\begin{array}{l}30 \\
31 \\
32 \\
33 \\
\mathbf{3 4}\end{array}$ & $\begin{array}{l}\cdot 25502 \\
\cdot 26131 \\
\cdot 26781 \\
\cdot 27453 \\
\cdot 28146\end{array}$ & $\begin{array}{l}55 \\
56 \\
57 \\
58 \\
59\end{array}$ & $\begin{array}{r}\cdot 47938 \\
\cdot 49091 \\
\cdot 50254 \\
\cdot 51430 \\
\cdot 52615\end{array}$ & $\begin{array}{l}80 \\
81 \\
82 \\
83 \\
84\end{array}$ & $\begin{array}{r}\cdot 76518 \\
\cdot 77478 \\
\cdot 78417 \\
\cdot 79330 \\
\cdot 80212\end{array}$ & & \\
\hline
\end{tabular}


268 Paid-up Policies and Surrender Values

$A_{[x] \div \bar{r}:}-O^{[M]} 4 \frac{1}{2} \%$

\begin{tabular}{|c|c|c|c|c|c|}
\hline \multirow{2}{*}{$x$} & \multicolumn{4}{|c|}{$x+r$} & \multirow{2}{*}{$x$} \\
\hline & 30 & 35 & 40 & 46 & \\
\hline 20 & $\cdot 65090$ & 53244 & $\cdot 44122$ & $\cdot 37150$ & 20 \\
\hline 21 & $\cdot 67854$ & $\cdot 55392$ & $\cdot 45798$ & $\cdot 38460$ & 21 \\
\hline 22 & $\cdot 70757$ & .57648 & $\cdot 47554$ & ·39833 & 22 \\
\hline 23 & $\cdot 73814$ & $\cdot 60021$ & $\cdot 49398$ & $\cdot 41272$ & 23 \\
\hline 24 & $\cdot 77026$ & 62514 & $\cdot 51336$ & $\cdot 42787$ & 24 \\
\hline 25 & $\cdot 80398$ & $\cdot 65137$ & $\cdot 53373$ & $\cdot 44373$ & 25 \\
\hline 26 & $\cdot 83947$ & $\cdot 67897$ & •55513 & $\cdot 46039$ & 26 \\
\hline 27 & $\cdot 87671$ & $\cdot 70795$ & $\cdot 57756$ & $\cdot 47787$ & 27 \\
\hline 28 & .91586 & $\cdot 73839$ & $\cdot 60120$ & '4962] & 28 \\
\hline 29 & $\cdot 95694$ & $\cdot 77048$ & $\cdot 62605$ & $\cdot 51546$ & 29 \\
\hline 30 & .. & ·80416 & $\cdot 65215$ & $\cdot 53570$ & 30 \\
\hline 31 & $\cdots$ & $\cdot \mathbf{3 3 9 5 5}$ & •67962 & $\cdot 55698$ & $3 I$ \\
\hline $3^{2}$ & $\ldots$ & $\cdot 87675$ & $\cdot 70847$ & $\cdot 57928$ & 32 \\
\hline 33 & $\ldots$ & $\cdot 91587$ & $\cdot 73887$ & $\cdot 60275$ & 33 \\
\hline 34 & .. & $\cdot 95694$ & $\cdot 77078$ & $\cdot 62742$ & 34 \\
\hline 35 & & $\cdots$ & $\cdot 80437$ & $\cdot 65335$ & 35 \\
\hline 36 & $\cdots$ & .. & '83968 & $\cdot 68065$ & 36 \\
\hline 37 & $\cdots$ & $\cdots$ & $\cdot 87684$ & $\cdot 70933$ & 37 \\
\hline $3^{8}$ & - & •• & $\cdot 91590$ & $\cdot 73951$ & $3^{8}$ \\
\hline 39 & . & $\cdots$ & $\cdot 95694$ & $\cdot 77130$ & 39 \\
\hline 40 & . & $\ldots$ & ... & 80476 & 40 \\
\hline $4 I$ & $\cdots$ & $\cdots$ & $\ldots$ & $\bullet 83994$ & 4I \\
\hline 42 & $\cdots$ & $\cdots$ & . & $\cdot 87697$ & 42 \\
\hline 43 & - & $\cdots$ & .. & $\cdot 91594$ & 43 \\
\hline 44 & .. & .. & $\cdot \cdot$ & $\cdot 95694$ & 44 \\
\hline
\end{tabular}




\section{Paid-up Policies and Surrender Values 269}

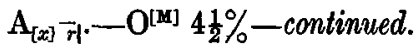

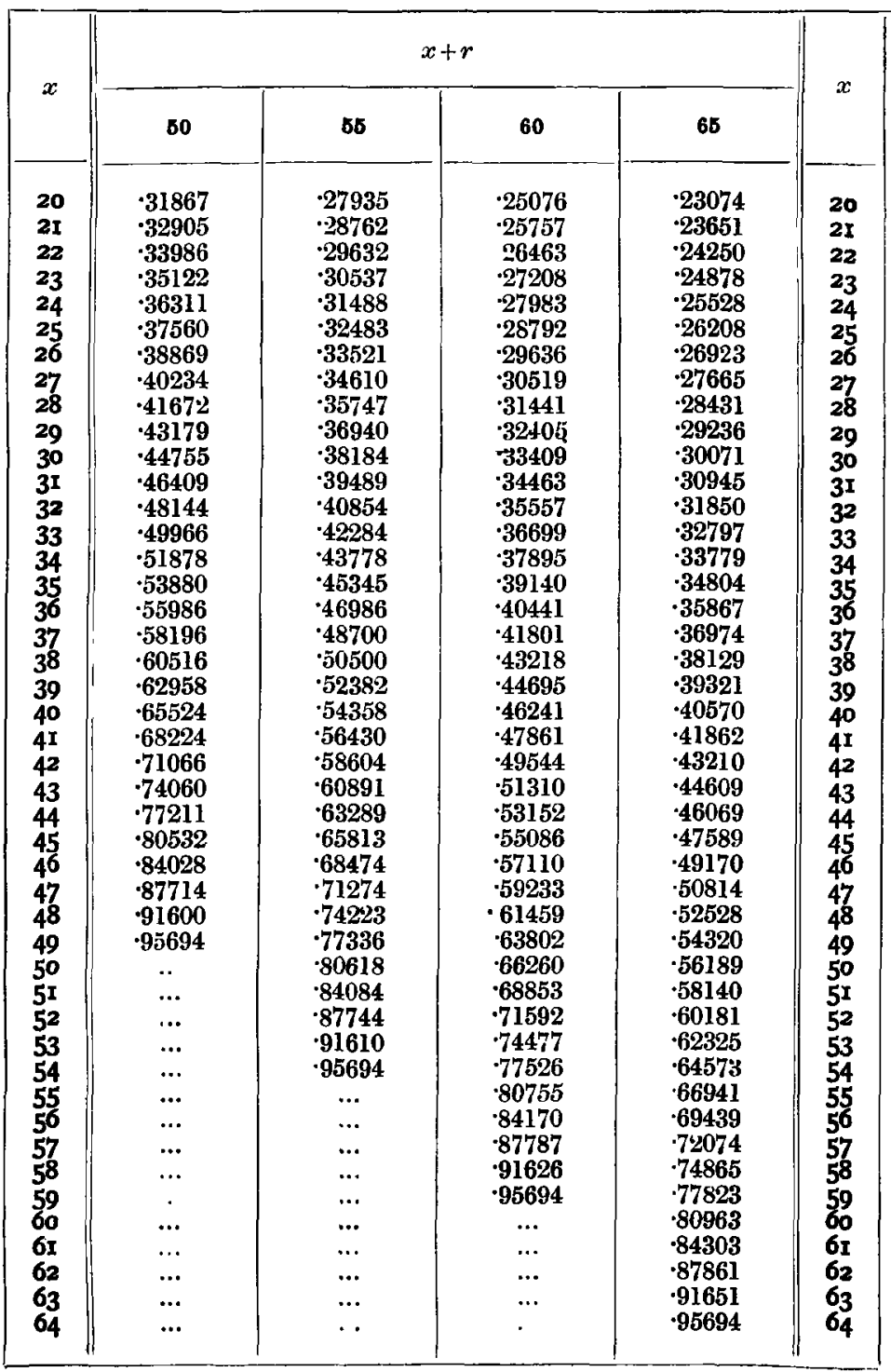


270 Paud-up Policies and Surrender Values

\author{
A P PEN DIX II. \\ SPECIMEN CARD AND CALCULATION.
}

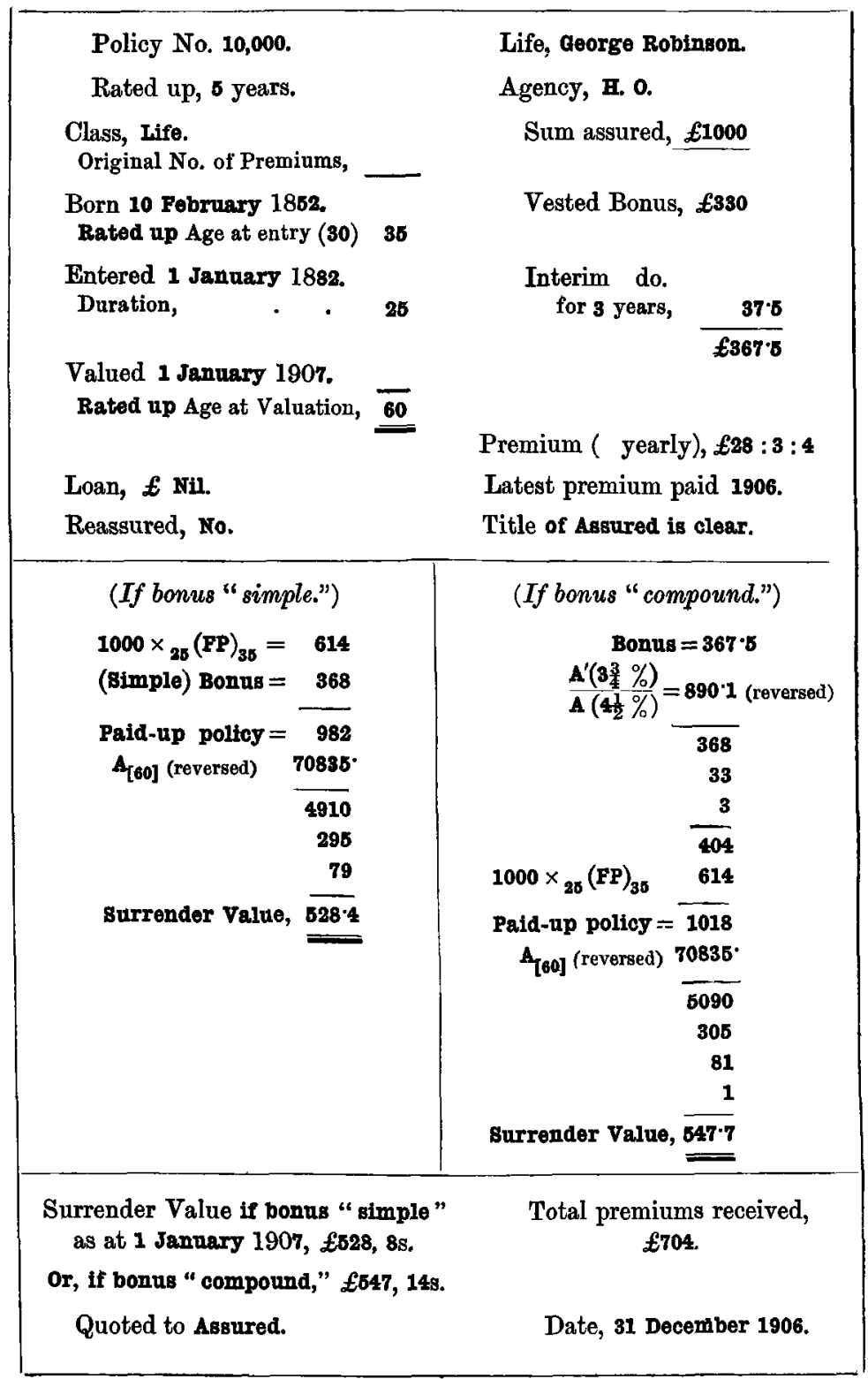




\title{
APPENDIX III.
}

\author{
Popular Explanation of the Nature of a Surrender Value.
}

The business of Insurance is based on the principle of averages-a large number of persons contributing sums into a common fund or "pool," which is divided amongst those members who sustain loss by the happening of the event insured against. For example, the owner of a house is liable to the risk of his property being destroyed by fire, and such a loss would be heavy if it fell entirely upon the individual. The risk of fire is small, and by means of Fire Insurance it is spread over so large a number of persons that the burden upon each is trifling. Each holder of a Fire policy pays a small periodical premium to the Office, and the total premiums thus received enable the Office to make good the losses of those policyholders whose property is burnt. That is to say, the losses of the few are met almost entirely out of the premiums paid by the many policyholders whose property is not burnt. By paying the small premium the individual policyholder is to that extent out of pocket, but he receives in exchange the assurance that if a fire does take place the loss will be borne for him. In other words, he incurs the certainty of a trifling outlay in order to remove the possibility of a serious loss. As the premiums paid to the Office each year are only sufficient to meet the claims arising in that year, and remunerate the Office for its trouble aud expense in managing the business, it is clear that no return of premium can be made to those persons who suffer no loss by fire. This is now generally understood by business men who continue to pay fire premiums year after year without getting any tangible return for their money. They recognise the fact that the premiums they have paid have gone to recoup the losses of other policyholders less fortunate than themselves, and to meet the necessary expenses of management.

When Life Assurance, however, is in question, some people still find it difficult to understand why the Office is unable to refund all the premiums paid by any policyholder who wishes to discontinue his policy. They overlook the fundamental principle of the business, which is, as already explained, the payment of claims out of contributions received from other policyholders, in order to spread the individual losses over a large area and thus minimise their effect. It is certain that out of a large number of persons some will die in a year, and, although the proportion of deaths can be predicted with comparative accuracy, it is impossible to foresee which individuals will die. The Assurance Office collects premiums from a large body of policyholders on the condition that it will pay, as and when they die, certain sums to their representatives. If the probability of death were the same at all ages, the premiums required to enable the Office to pay the claims as they arise would be the same at all ages, and the transaction would be precisely similar to fire insurance-each year's premium meeting each year's claims, expenses, etc., and leaving nothing over which could be returned as a "surrender value." As is well known, however, the probability of death increases with each year that passes, the increase being very marked as old age approaches. The premium paid for life insurance usually remains of the same amount during the whole term of the policy, being "levelled up" in such a way that in the long-run the Office receives enough to pay all the claims. This 
"levelling up" has the effect of making the premium greater at the beginning of the assurance but less towards the end of life than is necessary to cover the risk ; and therefore the claims of the first few years' assurance are less than the premiums received in that time, so that the Office gradually accumulates a fund or "reserve" as it is called. After the lapse of a number of years, when the lives become old and die more rapidly, the claims will necessarily exceed the premiums, and the difference has therefore to be met out of the fund accumulated in the earlier years. This fund is held by the Office for the benefit of the policyholders as a whole, and if one of them wishes to discontinue his policy it is only equitable that he should be entitled to a share of it. This share is what is known as the "surrender value" of the policy.

Now, as the fund is formed only from the balance of the premiums left over after payment of the claims, expenses, etc., it is clear that the total fund will, as a rule, be much less than the total premiums paid, and during the early years it will be only a very small proportion thereof. It follows that each individual's share of the fund (i.e. the surrender value of his policy) must generally be much less than the premiums paid.

Looking at the matter in another way, if a policybolder die within a few years of effecting the policy, his representatives will receive from the Company a sum many times larger than the amount of premiums he has paid. The difference of course is made up out of the premiums of other policyholders, in accordance with the fundamental principle that the claims of those who die early are paid largely by those who live longer. Accordingly if a policyholder does not die but wishes to withdraw from the Company after a few years, he cannot get back all the premiums he has paid, because a part of them has gone in payment of claims under other policies, and part in payment of expenses.

The premiums charged by Assurance Offices leave little or no margin after paying the first year's claims and expenses ; and consequently Offices cannot as a rule allow any surrender value during that or even the second year. A rough-and-ready estimate of the surrender value allowed by the best British Offices may be arrived at by taking, say, one-half of the premiums paid after the first year under a whole-of-life policy which carries the right to bonuses, or one-third of the premiums paid after the first year under a policy without bonuses. Many Offices make it a condition that no surrender value shall be allowed unless at least three years' full premiums have been paid. 


\section{ISCUSSION.}

Mr. Chatham.-I regret that I have not been able to devote as much time to the study of Dr. Ernest Sprague's paper as its importance deserves. There are, however, several points I should like to deal with. In the first place, I quite agree with him that none of the methods of calculating surrender values set forth in the papers to which he refers are entirely satisfactory. The method he proposes is simple indeed. $\mathrm{He}$ finds the paid-up policy, and values it at $4 \frac{1}{2}$ per cent. In the case of an assurance by whole-life premiums his paid-up policy is $1-\frac{P_{x+1}}{P_{x+n}}$. The substitution of $\mathbf{P}_{x+1}$ for $\mathbf{P}_{x}$, the Office premium for the age at entry, is, as he has stated, due to Dr. T. B. Sprague. I may mention that in practice the latter used the formula $1-\frac{P_{x}}{P_{x+n-1}}$, which enabled him to make use of the premium actually payable. On the other hand, Dr. Ernest Sprague's ingenious application of the table of single life paid-up policies to joint and last-survivor assurances is original, and we are indebted to him for such a simple method of dealing with them. In the case of limited-payment and endowment assurance policies, the surrender value is based upon the "proportionate" paid-up policy and I am the more interested in this part of the paper since, as far as I know, I was the first to suggest this method, and apply it in practice. You may remember that in my paper on Endowment Assurances about a year ago I brought it forward and explained its advantages, comparing it with other methods. It is in this matter of comparison that the paper strikes me as being somewhat defective. He does indeed tabulate the net $\mathrm{O}^{\mathrm{M}} 3$ per cent Reserve, but it would have been very desirable if he had given the results of other methods of calculating surrender values and set them alongside his own for comparison. Now I found that in the case of limited-payment and endowment assurances, there was no method which gave such good results as that which I adopted, and naturally I have nothing but praise for it as now recommended in the paper. There is, however, a slight difference between Dr. Ernest Sprague's application of the method and my own. His valuation function is a "select" and mine an "aggregate" single premium. In this connection he refers to Mr. G. F. Hardy's paper (J.I. A., xxiii, 1), in which it was shown that the policyholders of the "British Empire" Office who surrendered their bonuses for cash were better lives than those who did not, and Dr. Sprague puts that forward as a reason why we should use a "select" table in calculating surrender values of policies. Now I cannot see why that should follow. The results of Mr. Hardy's investigation were just what any Actuary would, I think, have expected. I should have been surprised had they been otherwise, because an option is exercised, and wherever that is done, it is against the Office. But in the paper I wrote in $1890(J . I . A$., xxix, 81), and which Dr. Sprague does me the honour of referring to, I showed that withdrawals had a favourable effect on the mortality of assured lives. Since then, moreover, developments have taken place to which no allusion is made in the paper. I refer to the question of "maximum mortality percentages." You will remember the conclusion which Dr. T. B. Sprague originally drew from these, viz. that withdrawing lives were on the whole better than those which remained. Mr. Macaulay, however, in a letter in 1895 (J. I. A., xxxii, 117), 


\section{Paid-up Policies and Surrender Values}

showed that that feature was in all probability due to the table of mortality used in calculating the "expected deaths," and that it was possible to obtain a "maximum" by adding together individual groups in none of which a "maximum" appeared. Dr. T. B. Sprague, in his reply (J. I. A., xxxii, 197), admitted the force of Mr. Macaulay's remarks, and said, "I now entertain considerable doubt on this point," viz. as to whether the figures in question proved that the lives which withdrew were on the average better than those which remained. He then went on to refer to the results of my own investigation already mentioned, in regard to which he said, "Mr. Chatham's conclusion, if correct, is of great importance, but the difference between the rates of mortality in the Scotch and in the total experience is small; and the conclusion seems to me to require confirmation from other sources before it can be accepted without reserve." All this will be found set forth at length in my remarks in the discussion which took place at the Institute on Mr. Fulford's paper in 1900 (J.I. A., xxxv, 236), to which I need only refer. But Mr. Besant, in the same discussion, gave the results of an investigation into the causes of the surrender of policies. He found that, out of 1085 cases, 840 , or 77.4 per cent of the whole, were given up entirely from impecuniosity, that is to say, there was no option in the matter; and he thought it might be said that those lives were at least below the average of the general body. The others were probably above the average, and, taking the body as a whole, he thought it was a fair conclusion to come to that cheir mortality did not differ much from that of the general body of policyholders. The position of matters is therefore this: ( 1 ) I found that, in circumstances as nearly similar as possible, the higher rate of withdrawal brought out a lighter rate of mortality ; (2) Dr. T. B. Sprague's basis upon which he founded his theory has been shown to be erroneous; (3) Mr. Besant's investigation showed that three-fourths of those withdrawing had no option in the matter, and were likely to be worse lives than those that remained. So far as I know, nothing has been done since then to disprove my conclusion that those who surrender their policies are certainly not better lives than those who remain. Therefore I do not agree with Dr. Ernest Sprague in his use of a "select" table, and I think an "aggregate" table such as the $\mathrm{H}^{\mathrm{M}}$ or $\mathrm{O}^{\mathrm{M}}$ is more correct. I see he recommends the adoption of loose cards or sheets for the calculation of surrender values. This plan has been in operation in a number of Offices for many years past. In some Offices the calculations are put up with the proposal papers, and are thus easy of access. With regard to the desirability of educating the public in Life Assurance matters I quite agree with the author, and I welcome the model "explanation of a surrender value" which he offers with that object in view. I prefer, however, and have been in the habit of using, a much simpler form ; still his suggestion is a step in the right direction. Taking the paper as a whole, I think one cannot help being struck with its thoroughness; and the clear and lucid manner in which the details are worked out reminds me of his father's contributions. The paper is a very valuable one indeed, and we are all greatly indebted to Dr. Ernest Sprague for it.

Mr. Gonn.-Dr. Sprague's paper is an eminently suggestive one, and is well worthy of careful study. I agree with him when he says that surrender values should be calculated on the footing that the policyholder is entitled to his equitable share of the funds of the Assurance Office. In former days the view was fairly prevalent that the Office was entitled to make a handsome profit out of surrenders, but I am glad to observe that we are approximating to the opinion held in America that the reserve value should be paid as surrender value. This, of course, is going too far, and the question is, what constitutes the policyholder's share of the funds in the event of surrender? Dr. Ernest Sprague says we have to take 
into account the cost which has been incurred by the Office, and I think, notwithstanding the remarks of $\mathrm{Mr}$. Chatham, that we must also assume that a certain amount of selection against the Office exists. Subject to these qualifications, therefore, the surrender value should have some relation to the table of mortality and rate of interest on which the Office values its liabilities. Dr. Ernest Sprague's explanation of his system is admirable, but there is one point on which I should have been glad of some explanation : both the paid-up policy and its value are calculated at an arbitrary rate of interest-i.e. a rate not actually earned by the Office. Is not the policyholder unduly taxed by the double calculation? If the surrender value were based directly on an actual surrender-value formula which took into account the various elements, would not the resulting surrender value be larger? In conclusion, I wish to re-echo what Mr. Chatham has said with reference to the value of the paper, and to the great care and thoronghness with which it has been prepared.

Mr. Low.-I was a little afraid when Mr. Gunn was speaking that he was going on to say he approved of allowing the full reserve as surrender value, but $I$ was relieved to find he did not go so far. Something of the kind was done, I think, by State legislation in America. It is, of course, quite out of the question. I think that the surrender value should bear some reasonable relationship to the reserve value. And I agree with Dr. Sprague that it ought also to bear some relation to the value of the paid-up policy to which the assured may be entitled. In regard to the question of " breach of contract," I cannot help thinking that Dr. Sprague rather too hastily rejects the idea that the Company is entitled to some compensation on this account. I admit that the expression "breach of contract" is not quite appropriate. But barring the defect of that particular expression, there is an idea underlying it which I think an Office is quite entitled to take into account. The Society is formed for the particular object of granting Assurances, and if a member, for his own advantage or from his own necessity, wishes to resile from the contract the Society has made with him, I do think this question of "compensation" is one which they may legitimately take into consideration in fixing the surrender value. I was rather puzzled with the figures given in the paper with reference to "select" and "mixed" lives. Dr. Sprague seems to assume that the possession of a Select Life Table enables him to say what proportion of "select" lives will be in existence out of a given number of "mixed" lives. I am unable to follow that. I do not think, for example, it is a priori reasonable to assume that out of 94974 lives who assured at 10 and are alive at 20 there are 93696 "select" and 1278 "damaged." I doubt whether a Select Table warrants such an assumption, and I should like to hear something on that point, because it seems to me impossible to base any argument on such figures. I think it is putting an unwarranted interpretation on the figures a Select Table contains.* As to the general object of the paper-if one can find on further investigation that it solves the question of the proper relation between the paid-up policy and the surrender value, and at the same time gives suitable values for practical purposes, it will prove a very valuable contribution to the Transactions, the more so as Dr. Sprague goes so fully into detail and works out his methods so thoroughly.

Mr. M'Lauchlar. - This will, I am sure, be a most useful paper. One cannot help feeling that the question of surrender values is much more important than it used to be. Many intending assurers are careful to inquire before taking out a policy what their position will be in the event of their desiring to discontinue their payments, and the information supplied by the Office would no doubt be regarded as part of the contract. This being so,

* We understand that the author of the paper is giving consideration to this point.-ED. 


\section{Paid-up Policies and Surrender Values}

it is very desirable that the system of surrender values and paid-up policies should be a consistent one. I agree with $\mathrm{Mr}$. Chatham as to the importance, in the case of surrender values or paid-up policies, of having the results of various methods of calculation set down and compared. In coming to a decision on questions such as those dealt with in this paper, it is important to look at them from different points of view, including, possibly, that of the man in the street. But the fact that Dr. Sprague's paper is a long and elaborate one may be sufficient reason for his omitting any comparison of his results with those obtained by other methods.

Mr. J. R. HART, F.I.A.-Dr. Sprague has presented what appears to be a very complete and satisfactory system of dealing with surrenders and paid-up policies, based, as I understand it, upon the consideration that the formulæ should allow for adverse selection and expenses. The method is one that can be applied with great facility. I notice, however, that at the end of the paper the author states, "It is impossible to frame a mathematically accurate scheme . . . and we must therefore be largely guided by considerations of expediency and practice." Now it has always appeared to me that one of the most striking features of our business is the huge expenditure of energy and time to secure a proposal compared with the ease with which a policy is allowed to slip off the books. Would it not be possible to deflect some of the force employed in the shape of our agency organisations towards maintaining a policy instead of allowing the question of surrender to be dealt with almost entirely by the Actuary ? There is indeed the renewal commission, which acts as an incentive to the agent to work for the up-keeping of the policy, but for the main part of our agency machinery new business is the all-absorbing question. Interest in a proposer is apt to cease as soon as his policy has been placed on the books. In my opinion it should be our endeavour to get into closer touch with policyholders contemplating surrender, with the view of ascertaining more accurately the circumstances under which the policy is being dropped. These circumstances are probably different in earlier and in later years. As regards "selection," I should say that in cases where paid-up policies are taken, the assured, as a whole, are probably in worse health than those who actually surrender, and a similar conclusion might reasonably be drawn in the case of policyholders taking loans. I way mention one small point in connection with policy loans. It may happen that the assured has borrowed on two or more policies and wishes to repay so much of the loan as will release one of them. In such a case it is advisable to get payment at the same time of the accrued interest on the principal repaid, or if not, to make sure that there is sufficient cover for it in event of the other policy lapsing. As regards guaranteed surrender values, I agree with Dr. Ernest Sprague that one-third or 40 per cent of the premiums is hardly likely to appeal to the public as an attractive feature of life assurance. From my experience of outside work, it is better to keep such a feature in the background, and when an intending assurer raises the question, to explain that after a policy has been a number of years in force, the surrender value will be a good deal more. A statement like that in Appendix III. might very usefully be put into our prospectuses. In conclusion, I may mention the relationship, if any, between the market value and the surrender value of a policy as a point on which it would have been interesting to have had Dr. Ernest Sprague's views.

Mr. J. A. Rankin.-Dr. Frnest Sprague's plan of finding the surrender value from a tabulated paid-up policy has the advantage of shortening work, and, as he shows, the mule can be applied with good results in all ordinary, as well as in many special cases. The effect of substituting $\mathbf{P}+$ for $P_{x}$ in the formula to allow for initial expenditure is, as he points out, to allow no paid-up policy or surrender value for assurances of only one year's 


\section{Paid-up Policies and Surrender Values}

duration. That it also has the advantage of making the charge decrease with the duration, can be shown as follows: Using net functions throughout, after $n$ years the value of the deduction is of course $\left(\pi_{x+1}-\pi_{x}\right) a_{x+n}$ or (multiplying and dividing by $\left.a_{x+1}\right),{ }_{1} V_{x}^{-}\left(1-{ }_{n-1} \nabla_{x+1}\right)$, which is obviously a decreasing quantity. For a paid-up policy in the case of a whole-life assurance Dr, T. B. Sprague suggested the alternative formula $1-\frac{P_{x}}{P_{x+n-1}}$ less 10 per cent. I calculated a few examples by this formula and found that, apart from the percentage deduction, the results only differed from about 4 to 1 per cent when compared with those given in the paper.

It is shown that the "without profit" premiums in Table A obtained from the $O^{[N M]}$ Table, with a loading of 10 per cent and $2 \mathrm{~s}$. per $£ 100$ of sum assured, represent fairly well the average "without profit" rates actually charged by Officcs. I may point out as an interesting coincidence that if the "without profit" premiums so obtained be similarly loaded, the results, up to at least age 65, are remarkably near the average Office premiums "with profits." For example, column (1) below contains the values of $100\left(1 \cdot 1 \mathrm{P}_{x}+\cdot 001\right), \mathrm{P}_{x}$ being Dr. Ernest Sprague's "without profit" premium, and column (2) gives the average published Office rates with profits :

$\begin{array}{cccr}\text { Age. } & (1) & (2) & (1)-(2) \\ 20 & 1.920 & 1.967 & -047 \\ 30 & 2 \cdot 374 & 2.467 & -093 \\ 40 & \mathbf{3} 219 & \mathbf{3} \cdot 258 & -039 \\ 50 & 4.650 & 4.567 & +.083 \\ 60 & 7 \cdot 159 & 7.042 & +\cdot 117 \\ 65 & \mathbf{9} 090 & 8.996 & +094\end{array}$

Now it is shown in the paper (p. 206) that the paid-up policies deduced from the "without profit" Office premiums (as loaded with a uniform percentage and constant) are less than those deduced from the corresponding net premiums. If, then, the "with profit" premiums could be obtained from the "without profit" ones similarly loaded, the same proof (apart from the ratio brought out in Tables $F, G$, and $H$ ) would hold for the relationship between paid-up policies based upon "with" and "without" profit premiums respectively, viz. that excluding existing bonuses the former are less than the latter.

In regard to double endowments, Dr. Ernest Sprague sees no objection to paying a surrender value in excess of the sum payable at death provided the assured be in good health. As the endowment portion is payable only on survivance, it would appear at first sight that the Office must lose in those cases where the assured dies before the date of maturity. The proviso as to medical examination, while lessening the loss, cannot entirely obviate it, as some of the lives, even though select at the time of surrender, will fail in the interval before maturity. This may be counterbalanced by the profit in respect of those who surrender and survive, but it is doubtful if the Office will gain on the whole by paying the excess surrender value in such cases, for it must be borne in mind that the self-selection by the assured is possibly more effectual than the selection exercised by the Office. I notice that for an ordinary pure endowment without return the $O^{[M]} 4 \frac{1}{2}$ per cent "ultimate" value is recommended, subject to proof of good health, while in the case of a double endowment the value of the excess portion $R$ is obtained by uising an $O^{[M]}$ "select" basis. I take it, however, that the "select" value is conditional on the whole double endowment being surrendered at once, and that if the pure endowment portion were not surrendered till afterwards, the "ultimate" value would apply.

Dr. Sprague would be inclined to allow interim bonus in cases of surrender. 


\section{Paid-up Policies and Surrender Values}

If, however, a fair surrender value for the policy and existing bonuses is uiven, it is quite conceivable that it might be better for the Office not to include interim additions. As a consequence of such ullowance tho Office's quinquennial rate of bonus would be slightly reduced. This might cause a greater number of policies to be surrendered, and it is possible that the offer of larger surrender values would then act in the same direction.

Mr. Maxwell. -Dr. Sprague draws our attention (p. 237) to the facts that, in certain cases, his surrender values for limited-payment and endowment assurance policies exceed the 3 per cent reserve values, and that the surrender values of some long term endowment assurances are less than those proposed for whole-life policies effected at the same age. He characterises these as undoubted defects in his methods, but he does not propose to get rid of them. My view is that such defects as these are sufficient in themselves to condemn the structure on which they grow. It is obvious that either the surrender values of the whole-life policies are too large, or those of the endowment assurances are too small. Taking for example a whole-life policy effected at age 30, the paid-up policy which Dr. Spague would allow on attainment of age 70 is no less than $97 \frac{1}{8}$ per cent of the same function calculated on the $0^{\mathrm{M}} 3$ per cent basis. If we look on the difference as profit, the Office may thus be said to benefit by only $2 \frac{1}{2}$ per cent on the cancellation of all future premiums, and if it is a proprietary Company the shareholders would derive a mere tithe of this. Such treatment (of which this is by no means an isolated instince) appears to me to be too generous, and a much larger deduction should, in my opinion, be made from the reserve held bj the Office. If such deduction took in practice the form of a percentage of the reserve, it is not necessary that it should be a fixed percentage, as mentioned by the author; it inight be a varying proportion according (say) to the age attained.

A more detailed comparison of the values in the various tables shows the inconsistency between the treatment of the whole-life and the endowment assurances to be spread over a much wider area as will be seen from the following specimen percentage ratios of the values proposed to those calculated at $0^{M} 3$ per cent and quoted in the paper-evidently for comparison :-

\begin{tabular}{|c|c|c|c|c|c|c|c|}
\hline \multirow[t]{2}{*}{$x$} & \multirow[t]{2}{*}{$n$} & \multicolumn{2}{|c|}{$\begin{array}{l}\text { Paid-up Policy, } \\
\text { per cent of } \mathrm{O}^{\mathbb{M}} 3 \%\end{array}$} & \multirow[t]{2}{*}{$\begin{array}{l}\text { Difference } \\
\text { in favour of } \\
\text { Whole-Life. }\end{array}$} & \multicolumn{2}{|c|}{$\begin{array}{l}\text { Surrender Value, } \\
\text { per cent of } 0 \mathbf{x} \% \text {. }\end{array}$} & $\begin{array}{l}\text { Difference } \\
\text { in favour of } \\
\text { Whole-Life. }\end{array}$ \\
\hline & & Life & E. A.40yrs, & & & & \\
\hline \multirow[t]{2}{*}{20} & \multirow[t]{2}{*}{20} & 88 & 84 & \multirow[t]{2}{*}{4} & 62 & 65 & -3 \\
\hline & & Life & E.A. 50 yrs. & & & & \\
\hline \multirow[t]{2}{*}{$\begin{array}{l}20 \\
" \\
" \\
"\end{array}$} & \multirow[t]{2}{*}{$\begin{array}{l}10 \\
20 \\
30 \\
40\end{array}$} & $\begin{array}{l}77 \\
88 \\
93 \\
96\end{array}$ & $\begin{array}{l}68 \\
77 \\
85 \\
93\end{array}$ & \multirow[t]{2}{*}{$\begin{array}{r}9 \\
11 \\
8 \\
3\end{array}$} & $\begin{array}{l}51 \\
62 \\
70 \\
77\end{array}$ & $\begin{array}{l}\mathbf{4 7} \\
55 \\
67 \\
81\end{array}$ & $\begin{array}{r}4 \\
7 \\
3 \\
-4\end{array}$ \\
\hline & & Life & E.A.30yrs. & & & & \\
\hline \multirow[t]{2}{*}{40} & \multirow[t]{2}{*}{15} & 94 & 90 & \multirow[t]{2}{*}{4} & 73 & 75 & \multirow[t]{2}{*}{-2} \\
\hline & & Life & E. A.40 yrs. & & & & \\
\hline 40 & 20 & 95 & 84 & 11 & 77 & 68 & 9 \\
\hline
\end{tabular}




\section{Paid-up Policies and Surrender Values}

The relutive injustice done to the general body of endowment assurance policyholders is clearly indicated in the above examples, which do not seem to call for further comment.

Mr. M'INTOSH.-In considering the suggestion that surrender values ought to be based on reserve values, the reasons for adopting any particular basis in estimating the Office liability should be borme in mind. An Office might, for instance, use assurance values and net premiums both loaded for bonus, in conjunction with a rate of interest near what is actually earned. But various writers have shown that much the same result can be obtained by valuing at a sufficiently low rate of interest, and using the ordinary assurance values and net premiums; and practically all offices adopt the latter plan. The Office, for the sake of uniformity, also employs the lower rate of interest in valuing "without profit" policies, and thereby makes a specially strong reserve for them. If, therefore, it be thought desirable to calculate surrender values by means of tables of reserve values, it would be quite proper in the case of "without profit" policies to use a higher rate of interest than the valuation rate-in fact, 4 or $4 \frac{1}{2}$ per cent, as indicated in the paper. This is apart from any deductions which may be made for other circumstances. The cost of putting a policy on the books and covering the first year's risk leaves little over to provide any paid-up policy in respect of the first year's premium. In view of this, it should be noted that, by taking a proportionate paid-up policy and assuring afresh for the balance, a policyholder may often be able to obtain assurance for the full original amount at a lower premium than he has hitherto been paying. The possibility of this could be shown from the published tables of various Offices. The proportionate paid-up policy for the early years may be looked upon as a popular concession, but when the surrender value is required, it would appear to be unnecessary to give the same advantage. An Office might easily fix its scale of surrender values for the early years so as to allow of its being recouped for the heavy initial expense, without much risk of being considered inconsistent. Again, in the case of an endowment assurance nearing maturity where the surrender value increases each year by more than the premium, it may possibly be found that under the proposed scale of surrender values it would be more advantageous for a person intending to surrender, to borrow the full loan value of his policy. He will thus get, say, 95 per cent of the surrender value at once, be able to borrow future premiums and interest as they fall due, and, in addition to having the advantage of assurance for the remainder of the term, ultimately have a small cash surplus in his favour. Thus, on the assumption that the option would be exercised against the Office, there would be little profit from surrenders of old policies to compensate the Office for any liberality in the early years.

Mr. Evans.-As one not now officially connected with life assurance I should like to say that I am glad to see there is a growing tendency in favour of allowing a surrender value as nearly as possible equal to the reserve value. Having talked a good deal with policyholders on the subject, I cannot help thinking that liberality in the matter of surrender values would materially increase the popularity of life assurance. Twenty years ago I favoured the allowance, in surrenders, of the values brought out by a "select" mortality table at a higher rate of interest than that used in calculating the reserves. This assumed, of course, that there were good grounds for the view that withdrawing policyholders were, on the whole, better lives than those who remained on the books. But even at that time $I$ had doubts as to the soundness of that view, and I am interested to bear from Mr. Chatham that there is some evidence against it.

Mr. Finlay J. Cambron wrote-The paper is a brilliant example of 


\section{Paid-up Policies and Surrender Values}

that combination of theoretical knowledge with practical application which is so necessary in actuarial work. I feel sure that Dr. Ernest Sprague's descriptions of his suggested methods of calculating paid-up policies and surrender values will be of great service, not only to students, but to all engaged in the duties of an actuarial department. With regard, however, to his general scheme of calculating the paid-up policy in the first instance, and then deriving the surrender value from it, there is room for difference of opinion. Such a plan is, I think, applicable rather to the case of policies with premiums limited to a term of years than to the case of policies with premiums payable during life. In the former the paid-up policy is usually "proportionate," and it is therefore dessirable as well as convenient to obtain the surrender value from the paid-up policy. There are, however, comparatively few British Offices which guarantee fixed paid-up policies in the case of whole-life assurances with premiums payable during life, and I think that the better plan in this class is to derive the paid-up policy and the surrender value independently, taking care that the two bases of computation are as consistent as possible. For the surrender value of an ordinary whole-life policy a convenient and equitable plan is to use the formula ${ }_{n-1} \mathrm{~V}_{x+1}$ (where $x=$ age at entry, and $n=$ duration). In this way allowance is made for the heavy initial expenditure. A "select" table such as the $O^{[M]}$ should, I think, be used when practicable. If an "aggregate" table such as the $0^{\mathrm{M}}$ be used, a small deduction might be made from the value on account of selection. With regard to the rate of interest, it is, I think, equitable to value at $4 \frac{1}{2}$ per cent (a good investment rate) in the case of non-participating policies, and in the case of participating policies to reduce the rate according to the bonus expected. I should like to mention that I have found the system advocated by Dr. Ernest Sprague, of computing surrender values on cards, both convenient and time-saving.

The President, in closing the discussion, said-I am glad Dr. Ernest Sprague has stated that the practice of Offices, based upon sound actuarial principles, is such that it commends itself to the "common-sense" of the assuring public. With reference to the brief explanatory leaflet about surrender values, I happen to know that where it is used it is having the desired effect-in "putting on the closure" to much unnecessary correspondence ; and, as it is not "copyright," all Offices are free to make use of it. I am one of those who believe that the better informed the public are in all matters relating to Life Assurance the better it will be for the publicand for the Life Offices. Dr. Ernest Sprague's methods, while theoretically sound, are eminently practical and easily worked out in the actuarial department, not only in respect to time and labour, but, more important still, in respect to accuracy - the risk of error being greatly reduced. With regard to the relation which should subsist between the Office surrender value and the actuarial reserve for an individual policy we have, I think, an analogy in the redemption of a rent-charge, $i e$. the buying back of a self-redeeming annuity granted in repayment-principal and interest-of a loan. When the borrower desires to bring the transaction to a close before its natural termination, he is not at liberty to do so by merely sending a cheque for the outstanding balance as per table. The Office in granting the loan practically bought the annuity on, say, a 4 per cent basis -now it is asked to sell it or what remains of it ; and this it might possibly do on, say, a 3 or $3 \frac{1}{2}$ per cent basis, the difference being compensation for giving up, at the call of the borrower, a good 4 per cent investment. I agree with Dr. Sprague that, in these days, it is useless to talk of the Office having a contract with the policyholder to continue the payment of premiums, and that on surrender he seeks to depart from his part of the 


\section{Paid-up Policies and Surrender Values}

contract. At the same time, as it is he who seeks to disturb matters, whether it suits the Office or not, it is only fair that the Office should consider the terms on which he may be permitted to withdraw, and, in doing so, allow for the labour and cost of placing his business on the books and of finding a new "member" to take his place.

With these considerations it is obvious that the full actuarial reserve ought not to be allowed on surrender. While I am sure Dr. Ernest Sprague would be the last to claim to have solved all the difficulties involved in this interesting and thoroughly practical question, I think we shall all admit that he has made a valuable contribution towards their solution. The time is undoubtedly come when in this world-wide business of Life Assurance we actuaries, educating the public, should bring our knowledge and practice into line with popular requirements-without, of course, departing from sound principles. I have very great pleasure in proposing that we give Dr. Ernest Sprague a most hearty vote of thanks for his extremely interesting and useful contribution to our Transactions : it is a paper of permanent value which we, and many others, will do well to refer to and carefully study at our leisure.

\section{Dr. Sprague's Reply.}

The principles adrocated in the paper are for the most part neither new nor original; and the paper is therefore to be regarded not as an original investigation, but rather as an attempt to evolve a simple and consistent practical scheme out of a somewhat chaotic mass of different formulas invented by different people at different times. The formula for a paid-up policy, $1-\frac{P_{x}}{P_{x+n}}$, was invented by Dr. T. B. Sprague (J.I.A., vii, 59), and first applied by him, with modifications, to the calculation of surrender values $(J . I . A .$, xxiv, 365$)$; and he was the first to advocate the use of the "select " policy value ${ }_{n}(h \mathrm{~V})_{x}$ in their calculation $(J . I$. A., xxii, 417 et seq.). The principle of getting surrender values direct from the "proportionate" paid-up policies in limited-payment and endowment assurance cases, was adopted by me early in 1901 , and for a long time I thought it was original; but I have heard recently that Mr. Chatham had adopted it some years previously, though it was not published till his paper of last session. To him, therefore, is due the credit of being the first to devise the method and to put it into practical operation. The fact that the value of a benefit carrying the right to bonus at a fixed rate is equal to the value of a uniform benefit at a certain lower rate of interest, must have been known to many actuaries, and the point has been touched upon by Dr. T. B. Sprague and Mr. G. F. Hardy ; but I do not know that the demonstration has been published hitherto.*

In reply to those gentlemen who wish to compare the values now proposed, with those given by other methods, I have to point out that elaborate tables of values by different methods are given in the papers to which I have referred by $\mathrm{Mr}$. Crisford, Mr. MacFiadyen, Mr. Fulford, and Mr. Chatham; and I do not think that much would have been gained by repeating the tables there given, for any one who wishes to study the subject will, naturally, not be content to accept the views of one writer without ascertaining those of the others who have worked at the subject, and comparing the different conclusions. The references to former papers are in-

* A demonstration similar to that on p. 238 was given by Mr. H. W. Brown in his paper (1899) on the Valuation of Special Class Policies (Transactions of the Actuarial Society of Bdinburgh, Vol. iv. No. 12). A similar demonstration will also be found in an unsigned review (1904), J. I. A., xxxviii. 375.-ED.

VOL. III. 


\section{$282 \quad$ Paid-up Policies and Surrender Values}

serted with the object of facilitating such reference and comparison, and thus avoiding a great deal of unnecessary repetition.

With regard to the rate of mortality among lives who surrender their policies, I find myself unable to agree with some of Mr. Chatham's conclusions. He holds (I understand) that because 840 withdrawals out of 1085 were due to impecuniosity, therefore no option is exercised in the matter of withdrawal. This conclusion seems to me to be logically unsound, firstly because the 245 surrenders due to other causes might be sufficient to cause an adverse selection, and secondly for the following reason : Out of a number of impecunious persons, say 100 , it is possible that 99 , say, might be select lives and surrender their policies, and that the remaining person might be in very bad health and either keep his policy in force by means of a loan, or sell it to a speculative purchaser for more than the surrender value. In these circumstances every surrender would be due to impecuniosity, and yet the option would be exercised to the maximum extent possible against the Office. Therefore, even if it were proved that every surrender was due to impecuniosity, it would not necessarily follow that no option is exercised, because the damaged lives might have exercised the option by continuing their policies or selling them to a third person who would do so. Mr. Chatham states that Mr. Besant's investigation showed that the abovementioned 840 withdrawals were likely to be worse lives than those who remained, but from the report of Mr. Besant's remarks it would appear that this was a mere opinion, and no facts are cited in support of it. It seems to me that if a man in bad health is reluctant to surrender his bonus, he will be still more reluctant to surrender his whole policy, and that for this reason Mr. G. F. Hardy's figures are evidence (though not conclusive proof) of a selection adverse to the Office. On the other hand, Mr. Chatham's figures, taken from the Scottish and British Experiences respectively, seem to me to be inconclusive, because it is possible that the rates of mortality in the two sections (apart from withdrawals) might be different. The fact that the rates of withdrawal are different indicates some difference in the circumstances of the lives in the two sections, and in view of this $I$ do not see what right we have to assume that the rates of mortality would be the same were it not for the influence of the withdrawals. The evidence, therefore, seems to me conflicting, and until conclusive evidence is produced, I think it is only prudent to give the Office the benefit of the doubt; but this is one of the controversial points on which we cannot expect at this stage to secure agreement. The rate of mortality among withdrawing lives is, however, a matter of fact, not of opinion, and it should therefore be capable of proof, one way or the other. In the transactions of the recent Actuarial Congress there is a reference to an investigation by Dr. Fredholm into the mortality among the withdrawals from the "Skandia," which is stated to have shown that the existence of an adverse selection is improbable ; but I have not yet seen Dr. Fredholm's report. A larger investigation is being made by a number of Scandinavian Companies into the same question, but I do not think that this has been completed yet, and it seems to me that the only way of settling the question would be to make a similar investigation among J3ritish Companies-provided it were found possible to trace the withdrawals with sufficient accuracy.

Assuming the existence of an adverse selection when bonuses are surrendered for cash, it follows that the use of an aggregate table for finding the cash values is wrong in principle, and would tend to give too small values at young ages and too large values later in life. Therefore it seems to me that the use of the $\mathrm{O}^{\mathrm{M}}$ table as adrocated by $\mathrm{Mr}$. Chatham leads to this difficulty, namely, that the cash values of bonus would tend in most cases to be too large : or if this tendency be corrected by using, say, select values 


\section{Paid-up Policies and Surrender Values}

for bonuses, and aggregate values for paid-up policies, then in most cases a bonus would have a smaller value than a paid-up policy of the same amount, which would almost certainly cause complaints by policyholders, and be very difficult of explanation.

I quite agree with $\mathrm{Mr}$. Chatham that the explanatory leaflet appended to the paper could be simplified, and my object in giving it was not that it might serve as a model, but that I hoped to receive suggestions for its improvement; and if any of you have similar leaflets I shall be grateful if you will favour me with copies. With regard to the expression "breach of contract," I may say that the prospectuses of all the 59 Companies mentioned in the paper, without exception, promise "liberal surrender values," or words to that effect, and in these circumstances I think it is clear that the right to surrender is part of the contract, and therefore that no deduction should be made on that ground. Whether a deduction should be made on account of disturbance of the Office's amangements is quite a different question, and "breach of contract" is not the correct expression to use in this connection.

I do not follow Mr. Gunn's remarks about the rate of interest used in the calculations. In whole-life assurance the paid-up policy is derived from the Office premiums, and the rate of interest involved is, $I$ suppose, usually about $3 \frac{1}{2}$ per cent, which is not widely different from the rate earned; and in limited-payment and endowment assurances the paid-up policy is arbitrary, and entirely independent of the rate of interest.

When the surrender value of a double endowment exceeds the sum pay. able at death, there is, as Mr. Rankin points out, a slight inconsistency between it and the surrender value proposed for a pure endowment, in that "select" functions are used throughout for the former, but an "ultimate" function for the latter. This had not escaped my notice; but I consider the proposed methods sufficiently good for practical purposes. The inconsistency could be removed by using a combination of "select" and "ultimate" functions in the former case, but I think that the disadvantage of this complication would outweigh any advantage gained thereby.

I would remind Mr. Maxwell that my reason for recommending a "proportionate" paid-up policy is the simplicity and popularity of the system, combined with the fact that, as a rule, it gives results which are sufficiently accurate for practical purposes. I do not claim that it is theoretically correct. Unless he is prepared to discard the system altogether and thus run counter to the general practice of most Offices, I think he will find that it is impossible to avoid some anomalies, and that it is difficult to confine them within smaller limits than I have done. It is, of course, a matter of opinion whether the advantages of the system outweigh its disadvantages, and therefore we cannot expect universal agreement regarding it; but I think there is no doubt that the discrepancies to which Mr. Maxwell draws attention are of very rare occurrence, and that in most cases which occur in practice the system works fairly well. In comparing the proposed values with the $0^{\mathrm{M}} 3$ per cent reserves, it must be borne in mind that those reserves are based on three assumptions, namely : (1) that the rate of interest is 3 per cent ; (2) that the future rates of mortality will be those shown by the aggregate $0^{\mathrm{M}}$ table; and (3) that the expenses are uniform throughout the duration of the policy and equal in amount to the difference between the Office and the $O^{M} 3$ per cent net premium. Now the rate of interest earned is nearer 4 per cent than 3 per cent; the rates of mortality are better represented by the $O^{[\mathrm{N}]}$ and $O^{[\mathrm{NM}]}$ (select) tables than by the $0^{x}$; and the expenses are certainly not uniform, but are very much heavier in the first than in subsequent years. That is to say, every assumption on which the $0^{M}$ reserves are based is incorrect, and as the three 


\section{Paid-up Policies and Surrender Values}

essential foundations of that reserve are wrong, the results cannot in every case be correct. It follows that although those reserves may, when all the contracts of a Company are taken together, be sufficiently accurate, the individual values will probably be in some cases too small and in others too large. Therefore we cannot place very great reliance upon a comparison of the individual values; and even if the surrender values in some cases exceed the reserves, it does not necessarily follow that the former are too large. This seems to me a weighty objection against basing the surrender value on the reserve by the net premium system, whether the percentage to be deducted therefrom be fixed or varying; but if Mr. Maxwell will indicate precisely what percentages he proposes to deduct, I shall be very pleased to consider his suggestions.

It is true, as Mr. M'Intosh points out, that sometimes (not often, I think) a policyholder may be able, by taking a proportionate paid-up policy and effecting a new policy, to obtain an assurance of the original amount at a reduced premium ; but $I$ do not think that this need deter us from granting proportionate paid-up policies. A similar feature is met with in all properly constructed tables of premiums for temporary assurances, owing to the fact that at many ages and durations the duration of the assurance has more effect than the age upon the rate of mortality.

In conclusion, I must thank you for the reception you have given to the paper. 